\title{
Technical Crisis Management and its Relationship to Developing Performance of the Palestinian Satellite Channels
}

Shehab Taha Mustafa Hammash*

Al-Aqsa Media Network Institution,

Gaza Strip, Palestine

Email: shehab.taha@ hotmail.com

Majed Terban

Al-Aqsa University,

Gaza Strip, Palestine

Received June, 2019; Accepted September, 2019

Abstract: This study aimed at identifying technical crisis management and its relationship to developing the performance of the Palestinian Satellite Channels and Local channels. The study used the descriptiveanalytical method, and the population of the study was selected from the TV channel employees that occupy the supervisory jobs and their number was (62). The study used a complete census style and handed out a (62) questionnaire, (62) of them were given back with a response rate of $100 \%$. The results showed that the relative mean of the whole technical crises management field is of .(57.07\%)This means that there is a relative agreement by the study sample individuals. In addition, the relative average of the whole performance development dimensions was (60.24\%) showing that there is a medium agreement on performance development dimensions. Furthermore, the study concluded that the dimensions of technical crisis management have a positive effect and statistically significant relationship at the level of $(\alpha \leq 0.05)$ on performance development.

Keywords: Technical Crisis Management; Palestinian Satellite Channels

Type: Research paper

This work is licensed under a Creative Commons Attribution 4.0 International License.

DOI: 10.51325/ijbeg.v2i3.45

إدارة الأزمات الفنية وعلاقتها بتطوير أداء القنوات الفضائية والأرضية الفلسطينية

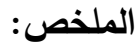

هدفت الدراسة التعرف إلى إدارة الأزمات الفنية وعلاقتها بتطوير أداء القنوات الفضائية والأرضية الفلسطينية بالمحافظات الجنوبية، ولتحقيق أهداف الدراسة الحالية استخدم الباحث المنهج الوصفي التحليلي، وتم اختيار مجتمع الدراسة من موظفي القنوات الذين يثغلون الوظائف الإشرافية والبالغ عددهم (62)، واستخدم الباحث أسلوب الحصر الثامل، وقام الباحث بتوزيع (62) استبانة تم استرداد (62)، منها؛ أي بمعدل استجابة (100\%) واستخدم برنامج الرزم الإحصائية للعلوم الاجتماعية هS وكS وتوصلت الدراسة إلى المتوسط الحسابي النسبي لمجالات إدارة الأزمات الفنية مجتمعة (57.07\%)، وهذا يعني أنَّ هنالك موافقة بدرجة متوسطة من قبل أفراد العينة. كما أن المتوسط الحسابي النسبي لأبعاد تطوير الأداء مجتمعة بلغت (60.24\%) وهذا يعني أنَّ هناك موافقة بدرجة متوسطة على أبعاد تطوير الأداء. كما توجد علاقة ذات دلالة إحصائية عند

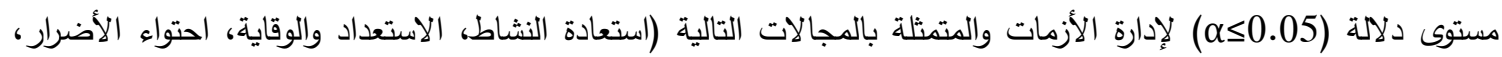
التعلم واكتشاف إشارات الإنذار) وتطوير الأداء حيث بلغ معامل ارتباطها (0.805)، وهي علاقة ارتباطية قوية طردية، وقد كان أقوى المجالات ارتباطًا مع تطوير الأداء مجال التعلم. كما خلصت الدراسة إلى أن لأبعاد إدارة الأزمات الفنية أثزر إيجابي وجوهري ذو دلالة إحصائية عند مستوى دلالة (1>05) في تطوير الأداء. الكلمات المفتاحية: إدارة الأزمات الفنية، القنوات الفضائية الفلسطينية 
ترتبط الإدارة بجميع الأنشطة الحياتية والمجتمعية، حيث إنها تعطينا أقصر الطرق للوصول إلى أهدافنا والحصول على أفضل النتائج، كمـا أنها سلم التطور والحضـارة، حيث أن الدول تعتمد عليها في تحقيق الرخاء لمواطنيها، ويعتبر فقدان الإدارة الجيدة من بين أهم الأسباب القائمة وراء نشوء الأزمات وتطورها.

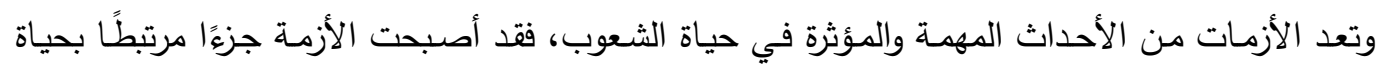
الناس، وتثكل مصدرَ قلق للجميع سواء الموظفين أو المسئولين؛ وذلك لصعوبة السيطرة عليها، ويعيش العالم في الصي

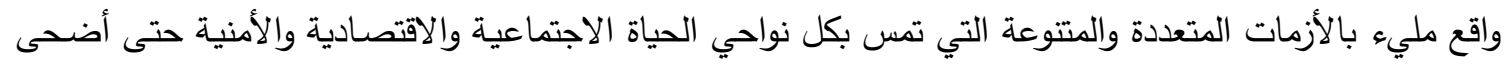

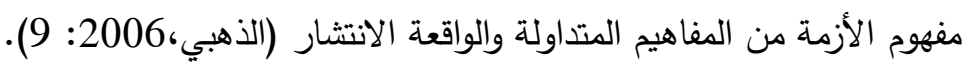

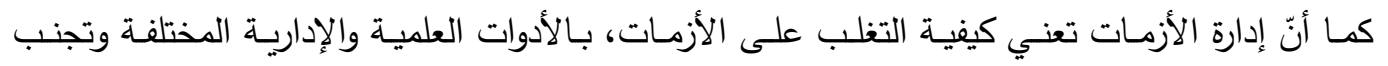

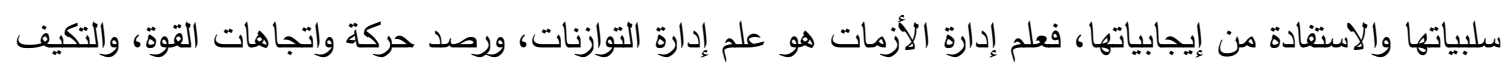

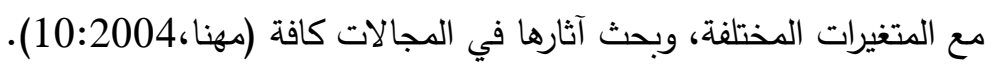

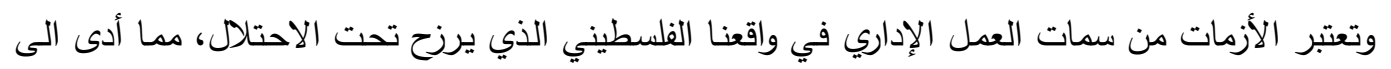
زيادة في حاجتنا لدراسة هذه الأوضاع، وعلاجها بطريقة مبتكرة وابداعية.

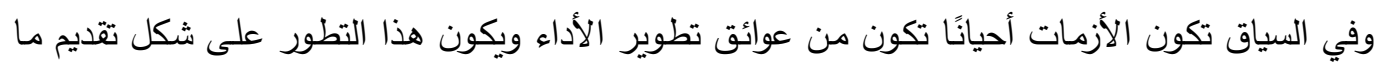
يكون فيه تقدم ورقي للبشرية والمجتمعات على حد سواء لذلك كان حري بنا أنْ نهتم بمفهوم التطوير ونكرس لـان لـانه

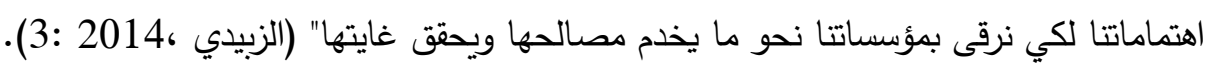

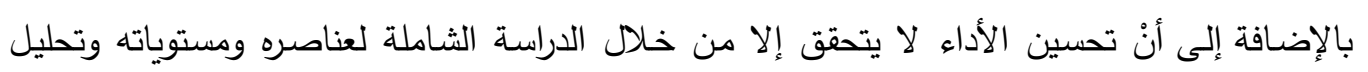
العوامل التنظيمية المؤثرة فيه، والبحث عن الأساليب الفعالة لتحسين وتطوير تلك العوامل، وفلسفة تحسين الأداء تمثل سياسة عامة تتتهجها المنظمات الحديثة (الفايدي، 123:2008) .

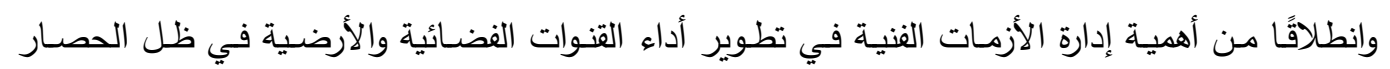

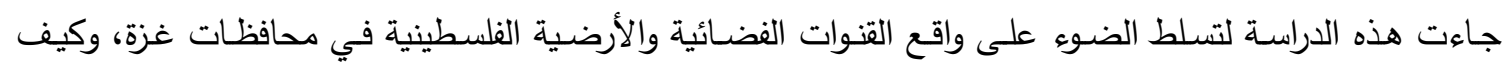

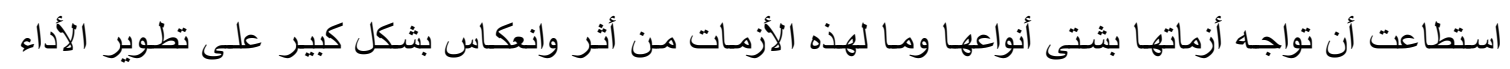
الإداري والتكنولوجي والمعرفي. مشكلة الاراسة ولإن

تقوم القنوات الفضائية والأرضية بدور مهم في عملية توعية المجتمع، مما يستوجب الاهتمام بها والعمل على تحسين أدائها لتتمكن من تحقيق الأهداف التي وجدت من أجلها؛ وذلك من خلال استخدام أسـاليب إداريـة حديثة من بينها إدارة الأزمات الفنية. والمتابع لواقع العمل الإعلامسي في فلسطين بشكل عام ومحافظات غزة بشكل خاص يمر بالعديد من

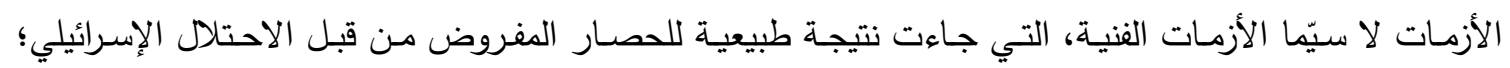

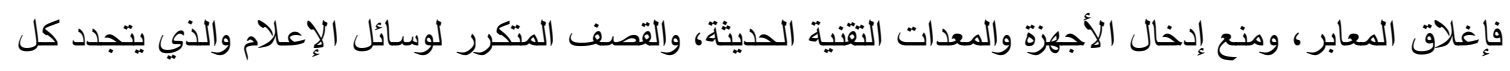

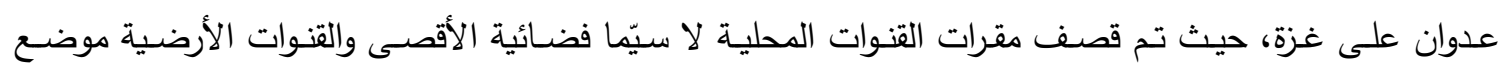
الدراسة، كل ذلك يؤثر بشكل مباشر على أدائها ويقلل من فعالية دورها.

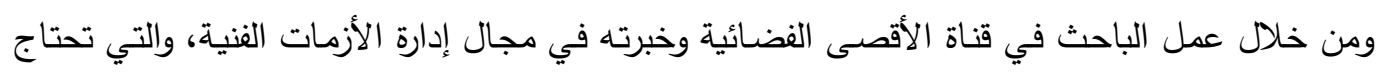
التجربـة والخطأ والتعلم من الأخطاء والتجارب التي خاضها أثناء وجوده على رأس عمله عند العدوان الاسرائيلي 
المتكرر على فضائية الأقصى وشبكة الأقصى الإعلامية استثعر الباحث أهمية القيام بهذه الدراسة بهدف التعرف

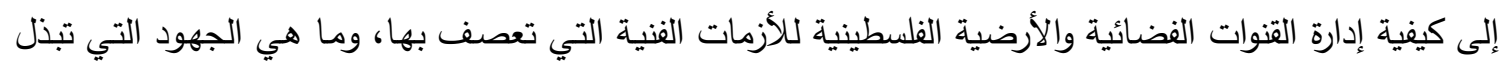

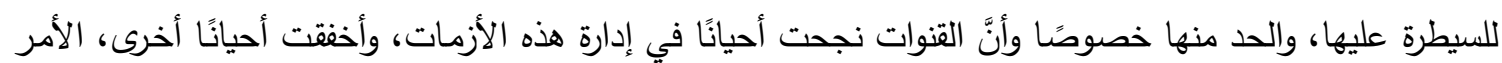
الذي أدى للحد من تطوير أدائها، وهو ما تسعى الدراسة التعرف وإن إليه. وتتلخص مشكلة الدراسة في محاولة الإجابة على السؤال الرئيس التالي: ما إدارة الأزمات الفنية وما علاقتها بتطوير أداء القنوات الفضائية والأرضية الفلسطينية الفئه ويتقرع عنه الأسئلة الفرعية التالية:

1. ما واقع إدارة الأزمات الفنية في القنوات الفضائية والأرضية الفلسطينية؟

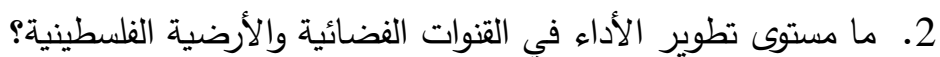

3. هل توجد علاقة بين إدارة الأزمات الفنية وتطوير الأداء في القنوات الفضائية والأرضية الفلسطينية؟ الفئي 4. ما أثر مراحل إدارة الأزمات على تطوير الأداء في القنوات الفضائية والأرضية الفلسطينية؟ الإدئ

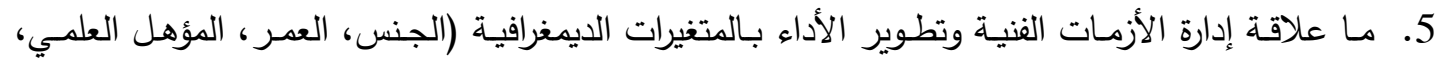

$$
\text { تهدف الدراسة الدراسة الىى ما يلي: }
$$

1. التعرف إلى واقع إدارة الأزمات الفنية في القنوات الفضائية والأرضية الفلسطينية.

2. الكثف عن مستوى تطوير الأداء في القنوات الفضائية والأرضية الفلسطينية.

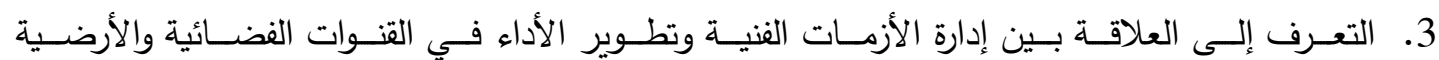

\section{الفلسطينية.}

4. توضيح أثر مراحل إدارة الأزمات على تطوير الأداء في القنوات الفضائية والأرضية الفلسطينية.

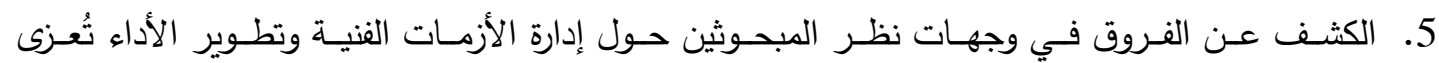

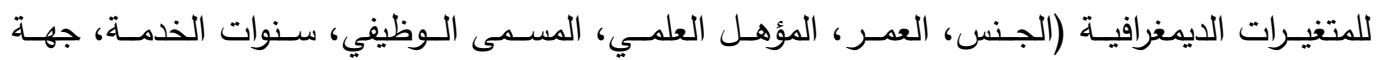

أ- يأمـل الباحثث أنْ تثري هذه الدراسـة المكتبـة العلميـة والبحـث العلمي في موضـوع إدارة الأزمـات الفنيـة

$$
\text { وعلاقتها بتطوير الأداء. }
$$

ب- تحاول الدراسـة الحالية الكثف عن العلاقة بين إدارة الأزمات الفنية ومتطلبات تطوير الأداء مما يمثل محاولـة لتحقيق الاستفادة في البيئة الفلسطينية وفي مجـال مـن مجـالات العمل المهمـة وهو المجـال

$$
\text { الإعلامي. }
$$

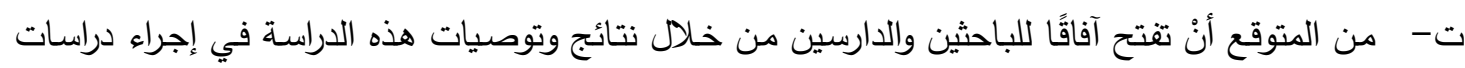
أعمق عن إدارة أزمات القنوات الفضائية والأرضية الفلسطينية وسبل تطوير أدين أدائها.

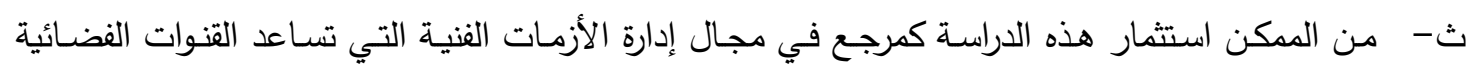
والأرضية الفلسطينية على الاستمرارية في التطور . 
2. 2 الأهمية العملية:

1- يمكن للدراسة أنْ تساهم في تتمية القدرات في الوظائف المهنية والهندسية والإشرافية في موضوع إدارة الأزمات الفنية ودورها بالتطوير •

2- تساعد الدراسـة القنوات الفضـائية والأرضية على تحقيق أهدافها في تطوير أدائها رغم وجود العديد من الأزمات المتوقع حدوثها، وتسليط الضوء على الطرق العلمية والمنهجية لإدارة هذه الأزمات الفنية.

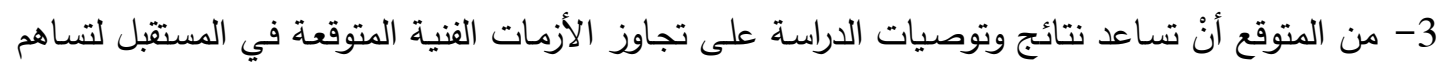
في تطوير أداء القنوات الفضائية والأرضية بمتطلباتها كافة.

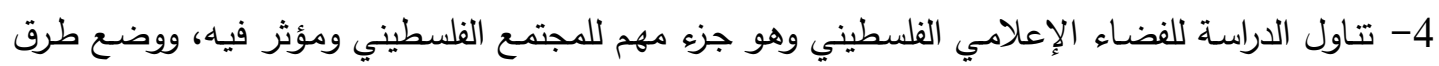
تجنبه أزماته الفنية من جهة إدارية وتقنية وعلاقة تطويرية في الأداء. متغيرات الاراسة 1. - المتفير المستقل: إدارة الأزمات الفنية. 2. - 2. المتغير التابع: تطوير الأداء.

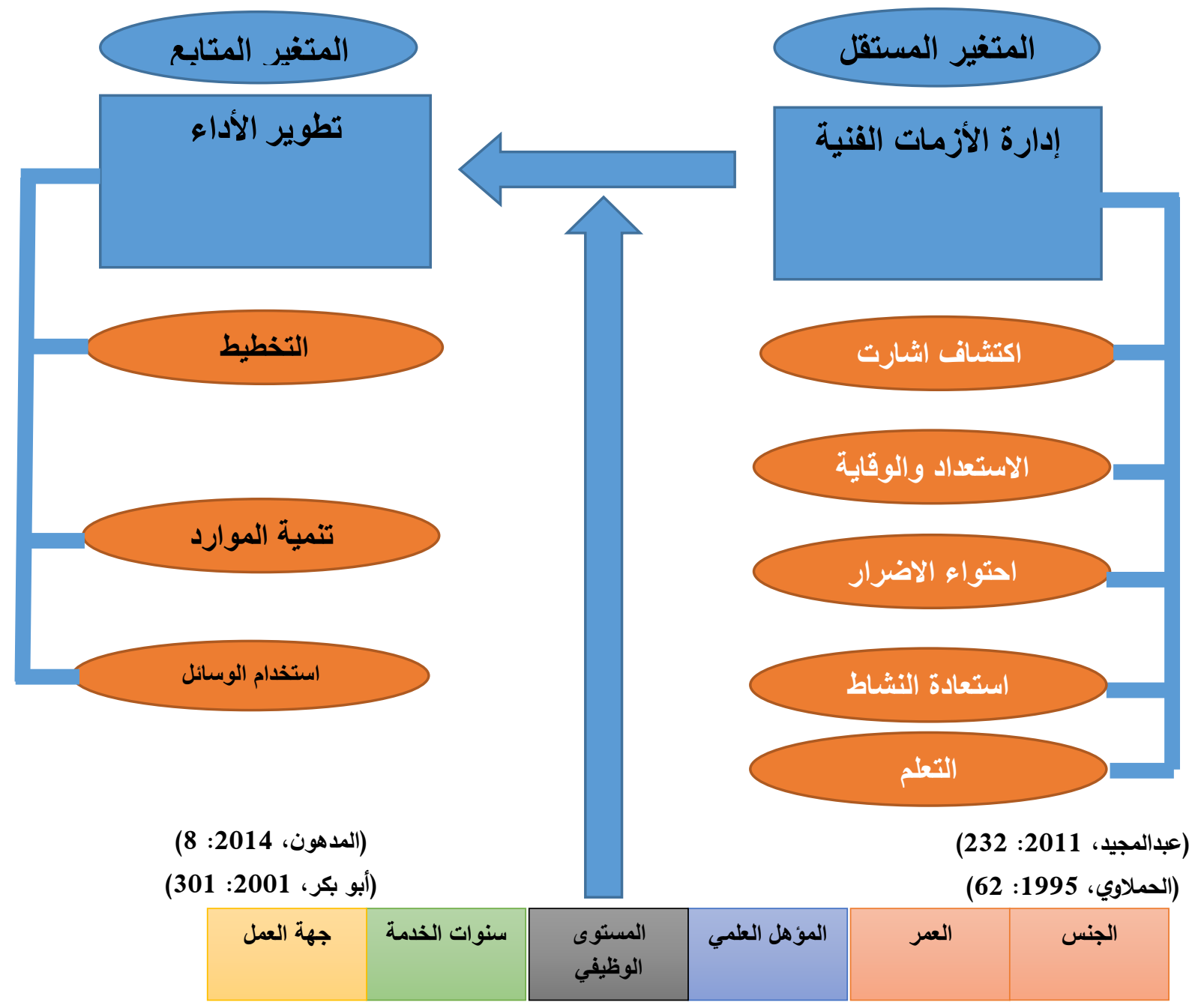

المتغيرات الايمغرافية

شكل (1) متغيرات الدراسة 
فرضيات الدراسة: 1

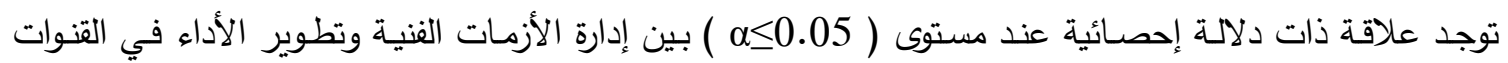
الفضائية والأرضية الفلسطينية. ويشتق من الفرضية الرئيسية الأولى الفروض التالية:

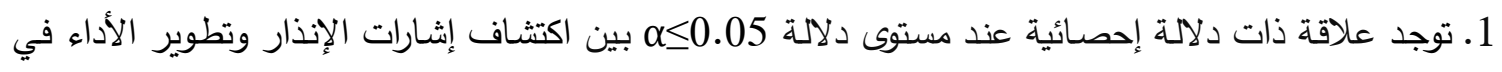
القنوات الفضائية والأرضية الفلسطينية.

2. توجد علاقة ذات دلالة إحصائية عند مستوى دلالة 0.05 بين الاستعداد والوقاية وتطوير الأداء في القنوات الفضائية والأرضية الفلسطينية. 3. توجد علاقة ذات دلالة إحصائية عند مستوى دلالة 0.05 بـ بين احتواء الاضرار وتطوير الأداء في القنوات الفضائية والأرضية الفلسطينية. 4. توجد علاقة ذات دلالة إحصائية عند مستوى دلالة 0.05 بين استعادة النشاط وتطوير الأداء في القنوات الفضائية والأرضية الفلسطينية. 5. توجد علاقة ذات دلالة إحصائية عند مستوى دلالة 0.05 بين التعلم وتطوير الأداء في القنوات الفضسائية والأرضية الفلسطينية. 2. 2 - 2 الفرضية الرئيسة الثانية: يوجد أثر ذو دلالة إحصائية عند مستوى ( $2 \leq 0.05$ ) لأبعاد إدارة الأزمات الفنية في تطوير الأداء في القنوات الفضائية والأرضية الفلسطينية. حدود الاراسة: 1. الحد الموضوعي: إدارة الأزمات الفنية وعلاقتها بتطوير الأداء. 2. الحد المكاني: أُجريت هذه الدراسة في أراضي السلطة الوطنية الفلسطينية - محافظات غزة - واقتصرت العرات

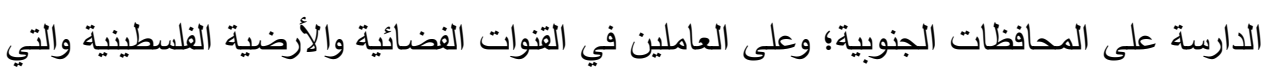
مركزيتها بالمحافظات الجنوبية لصعوبة التواصل مع الموظفين في المحافظات الثمالية بسبب الاحتلال الإسرائيلي والقيود التي يفرضها عليهم. بالتهات.

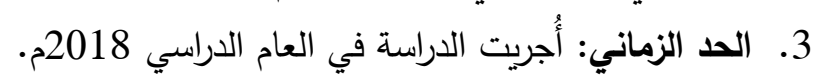
4. الصد البشري: أُجريت الدراسة على العاملين في المواقع القيادية والإثرافية في القنوات الفضائية والأرضية

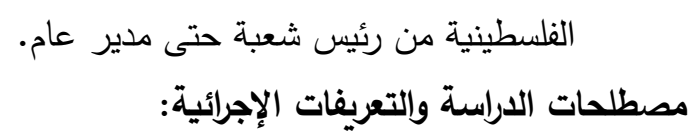
1. تعريف الأزمة لغة: مصنات

عرَّف لسان العرب الأزمة بأنَّها: " الثدة والقحط وجمعها أُزمه، بقال أزم الثـيء أمسك عنه، والمأزم: كل

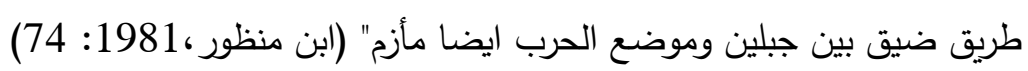

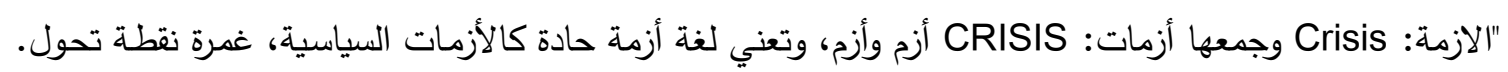
وأزمة العام: اشتد قحطه " (البزاز، 2001 : 11). 
تعريف الأزمة اصطلاحًا:

بأنها الحالـة الحرجـة والطارئـة الواقعـة أو المتوقعـة والتـي تواجـه المنظمـات الإداريـة أو أي هيئة أمنيـة أو

سياسية أو حتى مجموعة اجتماعية وأسرية. (الحريري، 2010: 129) تعريف الباحث للازمة إجرائياً:

هي موقف غير متوقع يؤثر في البيئة أو الأطراف ذات العلاقة مما يؤدي إلى حالة اضطراب، ولها مدى لهائ زمني تمر فيه بمراحلها من النمو حتى الثدة ثم الانحسار مما يعوق تحقيق الأهداف.

2. 2 - 2 تعريف إدارة الأزمة:

"إدارة الأزمة تعني كيفية التغلب على الأزمة بالأدوات العلمية والأدوات المختلفة وتجنب سلبياتها والاستفادة

$$
\text { من إيجابياتها" (الخضيري, 2003: 11: 11). }
$$
ويعرف الباحث إدارة الأزمة إجرائياً:

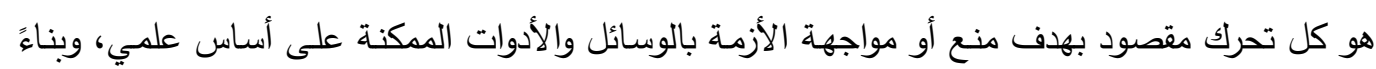

$$
\text { على المعرفة والخبرة المكتسبة من تجارب الآخرين. }
$$

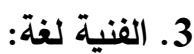

اسم مؤنَّث منسوب إلىى فَنّ، ومصدر صـناعيّ من فَنّ : تقنيَّة ، أسلوب فنسيّ في إنجاز عمل(عمر،

.(1747:2008

تعريف الفنية اصطلاحًا:

هي مهارةٌ يَحُمُهـا الذوقُ والمواهب ، والقدرة على إتقان فنّ من الفنون تبعًا لأصـوله وقواعده (عمر ،

.(1747:2008

$$
\text { ويعرف الباحث الفنية إجرائيًا: }
$$

الاستخدام الأمثل للمعرفة العلميّة والعملية والأسـاليب وتطبيقاتها وتطوير الوسـائل والأدوات التكنولوجيـة

لتحقيق التطور والتتمية للإنسان. ويعرف الباحث إدارة الأزمات الفنية إجرائيًا:

منهجيـة علميـة وإداريـة ومعرفيـة تحـول إلـى منهجيـة عمليـة لتسـخير جمـوع الجهـود البشـرية والوسـائل،

والأدوات، والمعدات، والتكنولوجيا، والتقنيات الحديثة، والخبرة، والتدريب، لمواجهات الأزمات والحد منها ومن اثارها.

4. التطوير:

هو التغيير أو التحويل من طور إلى طور، وتعني كلمة تطور "تحول من طوره"، وتعني كلمة "التطور"

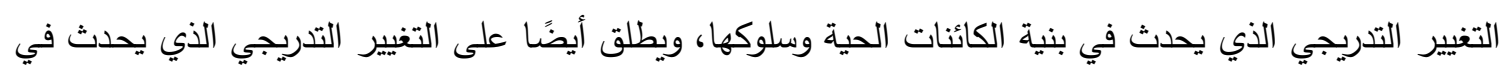

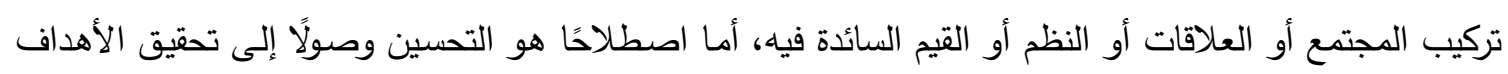

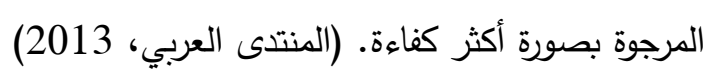

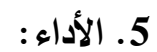

هو التفاعل بين السلوك والانجاز ، أو أنَّه مجموع السلوك والنتائج التي تحققت معا، مـع الميل إلى إبراز

الإنجاز أو النتائج، وذلك لصعوبة الفصل بين السلوك من ناحية، والإنجاز من ناحية أخرى. (نعيم، 2012 :40) 
6. الأداء المؤسسي: هو المنظومـة المتكاملة لنتاج أعمال المنظمة في ضوكية تفاعلها مـع عناصر بيئتها الداخلية والخارجية. (الدوري، (67 : 2007 7. تطوير الأداء:

هو استخدام جميع الموارد المتاحة لتحسين المخرجات وإنتاجية العمليات، وتحقيق التكامل بين التكنولوجيا

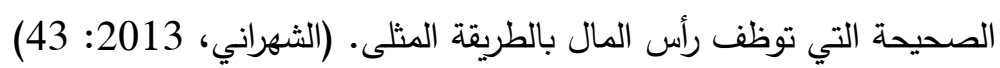
يعرف الباحث تطوير الأداء اجرائياً:

هو توفير وتحقيق المعرفة بين الموارد البشرية والتكنولوجيا والتقنيات الحديثة لتحسين العمليات للوصول

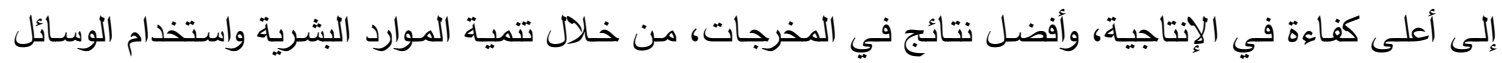
التكنولوجية والتخطيط، ويقصد بمصطلح (تطوير الأداء) في متن الدراسة (تطوير الأداء المؤسبي).

تتجه جميع المنظمات نحو وضع طرق وأساليب لمواجهة أي ظرف طارئ، ومن هنا اتجه علماء الإدارة إلى وضع منهجية علمية للتعامل مع مثل هذه الظروف تحت مسمى إدارة الأزمات، كأسلوب جديد تبنته المنظمات الحكومية والغير حكومية، لإيجاد حلول ومخارج لأي مأزق طارئ. والمنهج المتكامل لإدارة الأزمات يركز على وصفئ عال عام وشامل للأزمة، يتتاولها من كل متغيراتها جميًًا

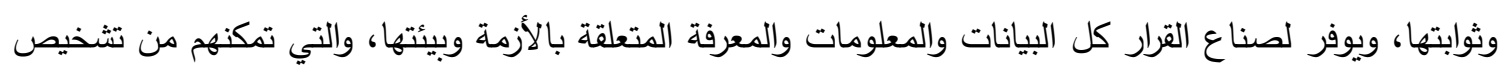
الأزمة تثخيصًا سليمًا ودقيقًا وصحيحًا، وتمكنهم من تحديد القرارات المناسبة للتعامل مع هذه الأزمة، بكات ولكفاءة وفاعلية

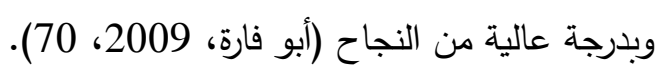
كما أنَّ هذه الأزمات تتطلب ضرورة الاستعداد والإعداد الجيد والتخطيط العلمي والتدريب المستمر لتحقيق

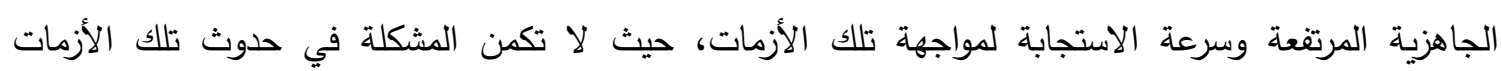
والضغوط، بل تكمن في ردود أفعالنا تجاهها وكيفية تعاملنا وإدارتتا لهذه الطوارئ (أبو ركبة، 2013: 22: 22). ولهذا أكَّد العلماء والباحثون على ضرورة تفصيل الكيفية والمنهجية التي يمكن من خلالها تدارك الكثير من

تأثيرات الأزمة والحد منها. الاطار النظري للدراسة مفهوم إدارة الأزمات:

يقصد بإدارة الأزمات بأنها عملية إدارية تقوم على التخطيط والتدريب بهدف التتبؤ بالأزمات والتعرف على

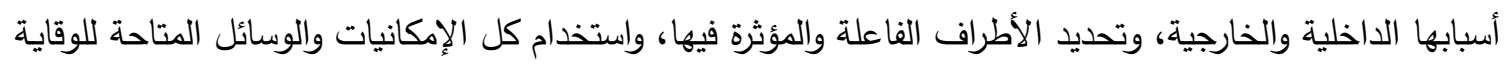

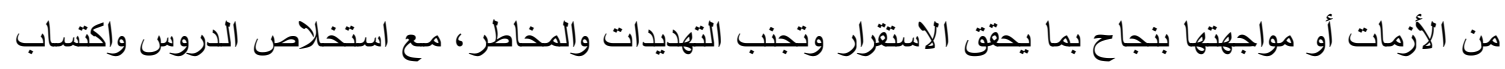

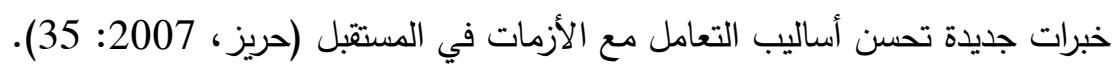
كما تعرف بأنَّا: القدرة على إزالة الكثير من المخاطر وعدم التأكد لتحقيق أكبر قدر من التحكم في في في مصنير

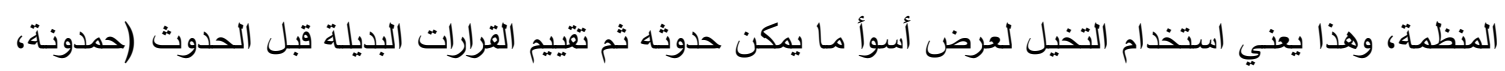
$(27: 2006$

وتعـرف أيضًا بأنَّها: كيفيـة التغلب علـى الأزمـة بـالأدوات العلميـة الإداريـة المختلفـة وتجنب سـلبياتها والاستفادة من إيجابياتها، وهي إدارة للأزمـة ذاتها للتحكم في ضغنطها وفي مسارها واتجاهها، وتقوم على البحث 
والحصـول على المعرفـة واستخدام البيانـات والمعلومـات المناسبة كأسـاس للقرار المناسب، وتقوم على التخطيط والتتظيم والتوجيه والرقابة والبعد عن العشوائية، وتعمل من خلال هدف تلقائي، وهو التعامل الفوري مع الاحداث

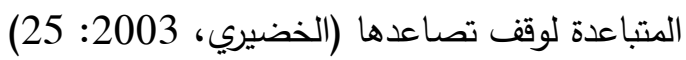

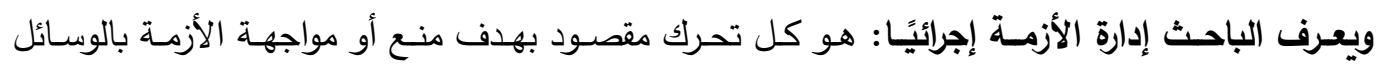
والأدوات المكنة على أساس علمي وبناءً على المعرفة والخبرة المكتسبة من تجارب الآخرين. الفرق بين إدارة الأزمات والإدارة بالأزمات:

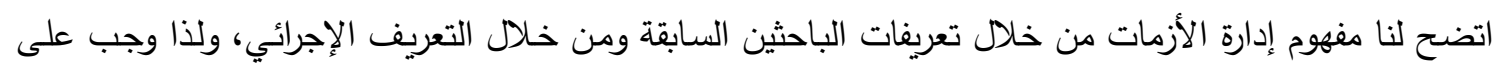
الباحث إيضاح مفهوم الإدارة بالأزمات حتى يتبين الفرق بين المفهومين.

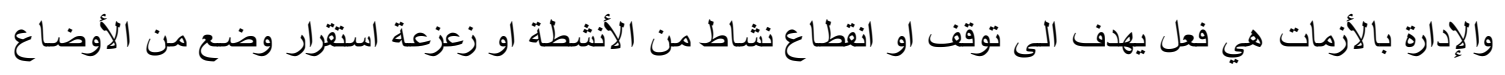

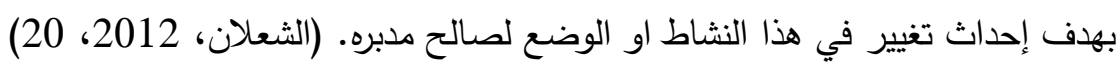

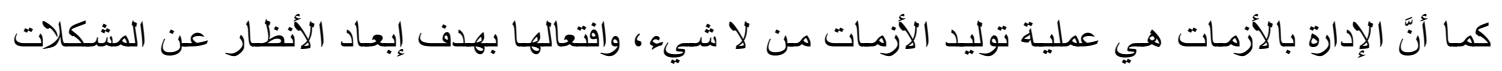

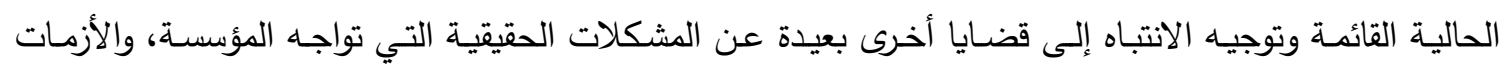

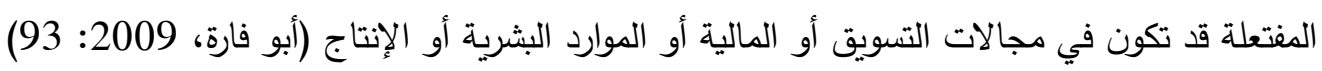

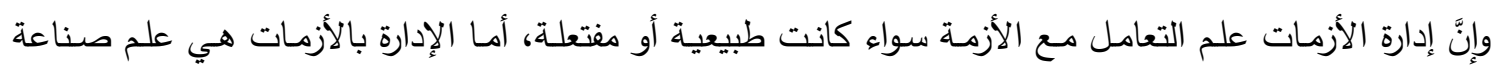
الأزمة.

مهام إدارة الأزمات وعوامل نجاحها: إنَّ لإدارة الأزمات مهام وعوامل عدة تحقق نجاحها نذأدر أولًَا مهامها، ثم نتطرق إلى عوامل نجاح إدارة الأزمات ثانيًا، ومنها نتعرف على ركنين أساسيين تتميز بهم إدارة الأزمات.

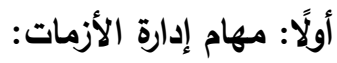
وتتلخص مهام إدارة الأزمات في الآتي: (سرور ، 2013:

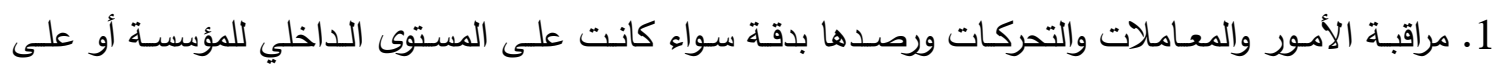
المستوى الخارجي. 2. التركيز التام على الجهات المنافسة للمؤسسة ومعرفة أهدافها ومخططاتها. 3. التخطيط السابق، والتوقع المسبق، والتتبؤ، والاستعداد التام لمواجهة كل الأزمات الدحتملة الحدوث في المستقبل.

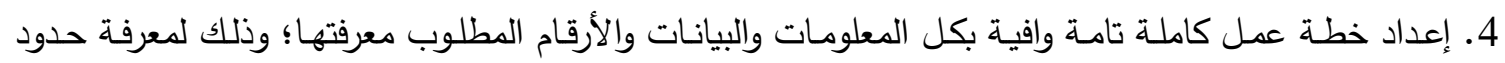
الإمكانيات المتاحة للمؤسسة. 5. تتظيم للعمليات المالية في المؤسسة وتتظيم الإدارات والعمل على تتسيق الأمور والقرارات الإدارية وتحديد طريقة التواصل مع الإداريين والموظفين. 6. إصدار الأوامر والتوجيه وتقديم الآراء في الوقت المناسب قلوطين قبل فوات الأوان لكل الموظفين في الإدارات المختلفة. 7. الرقابة والإثراف على الموظفين وكذلك للعملاء والزبائن.

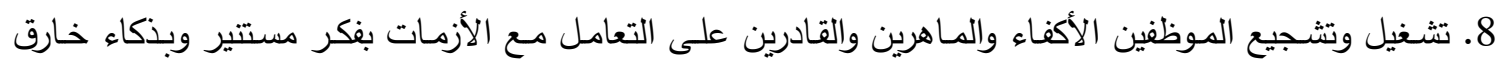
وبدهاء شديد وبشجاعة وحكمة وصبر •

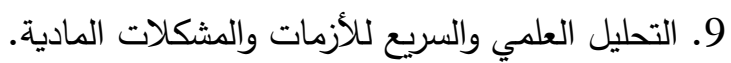
10. المواجهة الثجاعة دون تردد للجهات المسببة للأزمات. 
11. تدريب الموظفين على كيفية مواجهة الأزمات وحل المشكلات الإدارية.

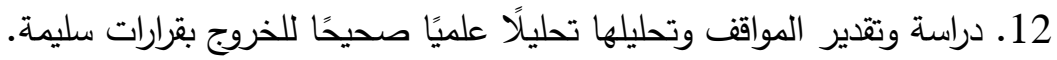
13. معرفة وتحديد القوى صانعة الأزمة، وتحديد نقاط قواها وضعفها. 14. وضع خطة لامتصاص الأزمات وحل المشكلات والآثار الناتجة عنها، والاستفادة من الأخطاء السابقة. 15. تثكيل لجنة عمل خاصة لتبحث كل مقومات الأزمة ومكوناتها من أفضل الموظفين. 16. تكوين فرق عمل دائمة للتصدي للأزمات، والقيام بمهام استطلاعية لمد الإدارة بالمعلومات الصحيحة عبر نظم معلومات متكاملة.

17. إصدار قرارات معينة وقوانين واضحة ومحددة والتحذير من مخالفتها في كل إدارات المؤسسة.

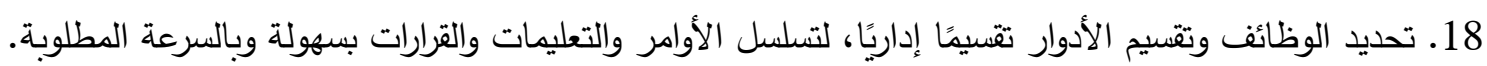
19. تطوير الموارد البشرية والمادية المتوفرة للمؤسسة للمساهمة في إدارة الأزمات. الدراسات السابقة الداسات السابقة التي تناولت موضوع إدارة الأزمات الفنية: أولاً: الدراسات المحلية 1. دراســة (اسـليم، 2017) بعنـوان: دور القيـادة الاسـتراتيجية فـي إدارة الأزمــات الأمنيـة بـوزارة الاخليـة والأمن الوطني الفلسطيني. هدفت الدراسـة التعـرف إلى دور القيادة الاستراتيجية بجهاز الأمسن الـاخلي، وقياس قدراتها في إدارة

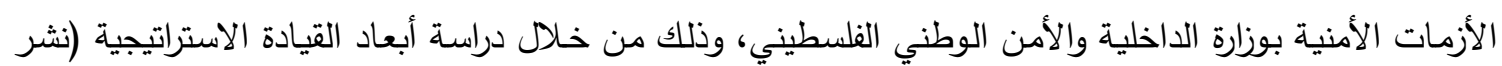

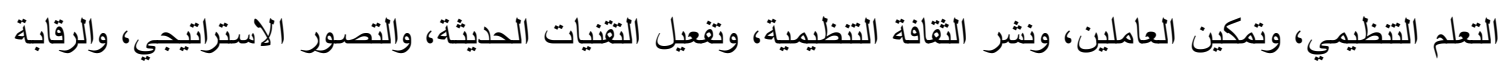

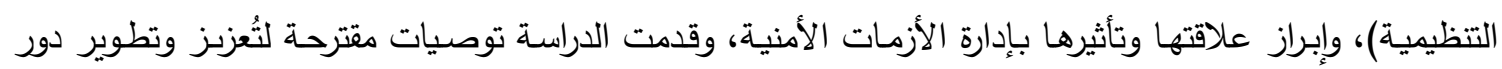
القيادة الاستراتيجية في إدارة الأزمات الأمنية.

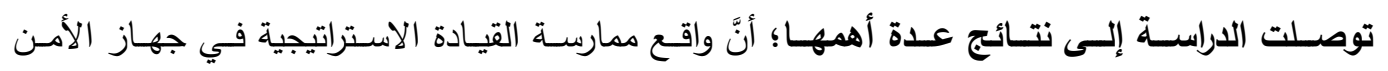

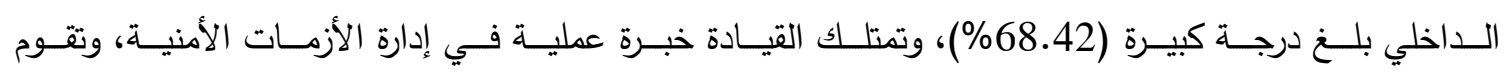

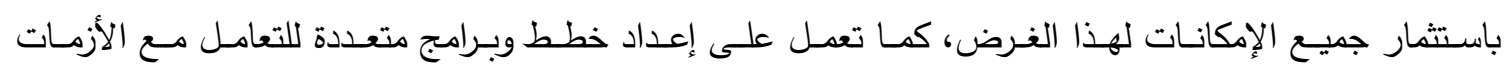

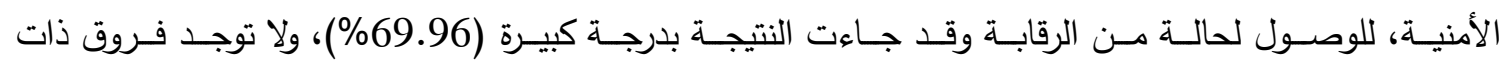

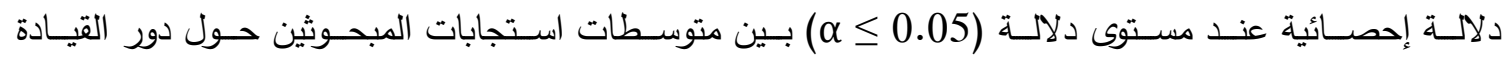

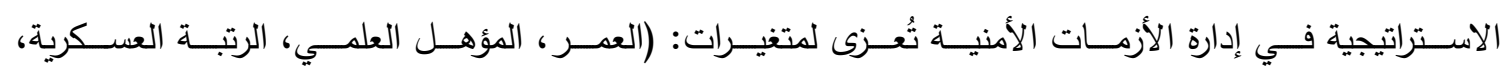
المسمى الإداري، عدد سنوات الخدمة، الدحافظة التي يعمل بها).

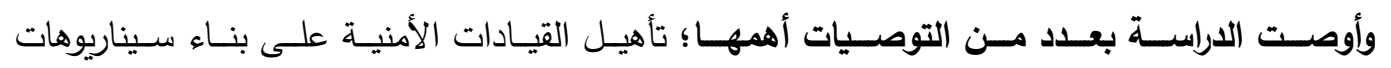

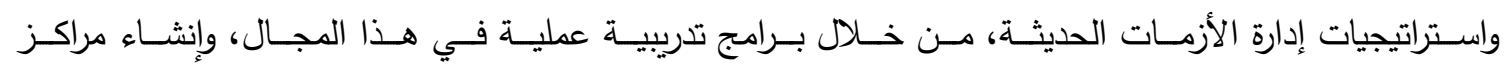

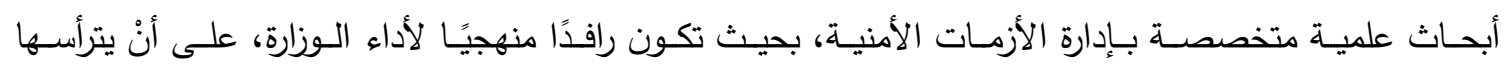

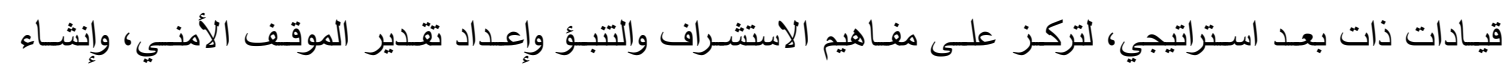

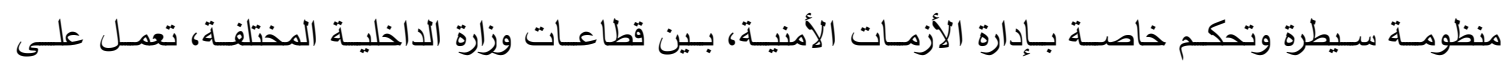
تحديد الصلاحيات والمهام الوظيفية لكل جهاز أمني. 
2. دراســة (عبـدالعال، 2017)، إدارة الأزمــات وأثرهـا علـى جـودة القـرارات الإداريـة بـوزارتي العمـل والتنميـة الاجتماعية بالمحافظات الجنوبية.

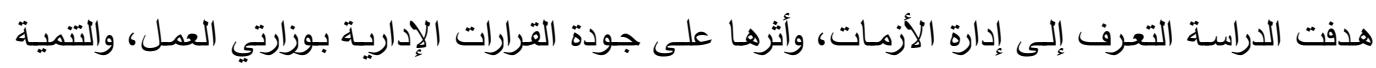
الاجتماعية بالمحافظات الجنوبية، تبعاً لمراحلها الخمسة (مرحلة اكتثاف الإنذار المبكر ، مرحلة الاستعداد الوقاية،

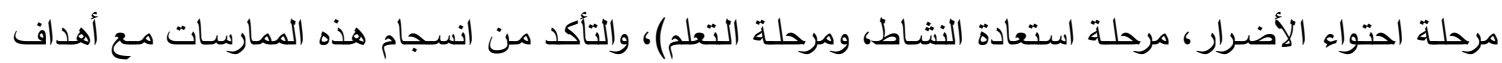

توصـلت الدراســة إلـى نتـائج عـدة أهمهــا؛ أنَّ هنـالك موافقـة بدرجـة متوسـة مـن قبـل المبحـوثين

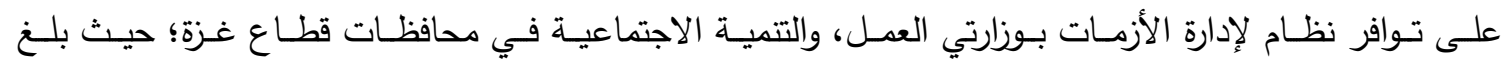
المتوســـ الحســي العـام (3.18)، وبـوزن نسـبي مقـــاره (63.58\%)، وهنــاك موافقــة مـن قبـل المبحــوثين

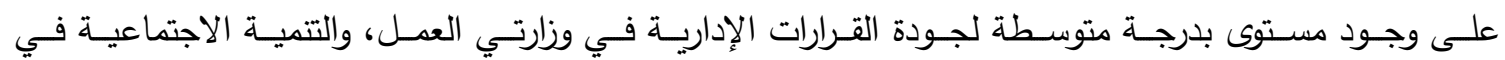

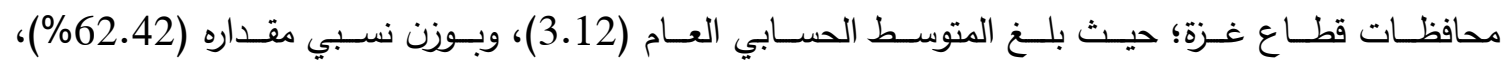

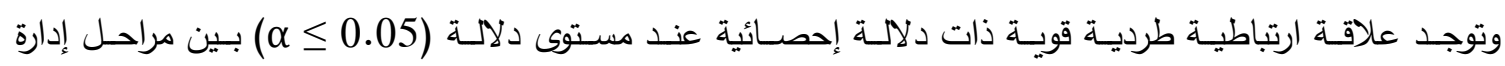

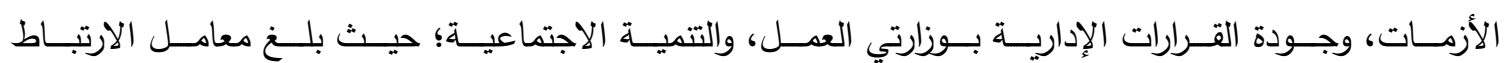

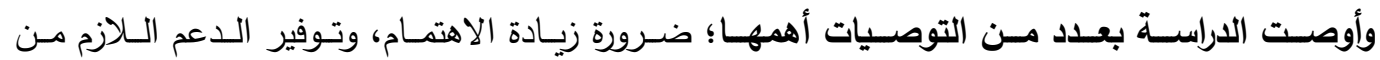

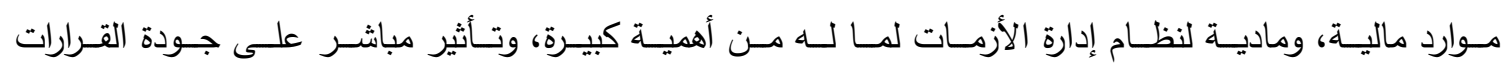

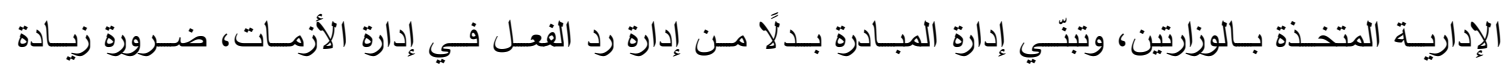

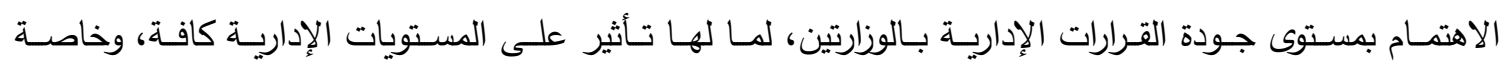
في ظل الأزمات بالوزارتين، يُلقى على عاتقها إدارة الأزمات، واتخاذ القرارات الرشيدة المناسبة.

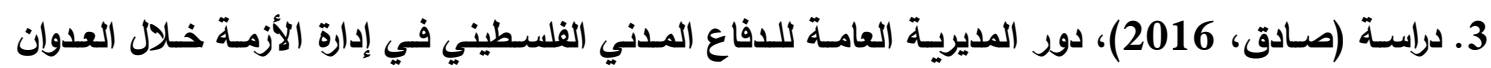

\section{الإسرائيلي على غزة عام 2014م}

هدفت الدراسة التعرف إلى الدور الذي قام به جهاز الدفاع المدني في إدارة أزمة العدوان الاسرائيلي على الدي

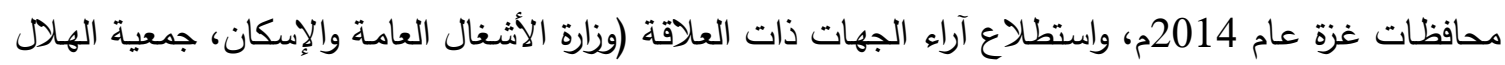
الأحمر الفلسطيني، دائرة الإسعاف والطوارئ التابع لوزارة الصحة الفلسطينية) حول أداء جهاز الدفاع المدني أثناء وقوع الأزمة.

توصلت الدراسة إلى نتائج عدة أهمها؛ أنَّ نسبة مجال التخطيط للأزمات من وجهة نظر العاملين بجهاز الدفاع المدني بلغت (71\%) أما من وجهة نظر الجهات ذات العلاقة بلغت (61.4\%)، أما مجال اتصالات الأزمة بلغت نسبتها (67.5\%) من وجهة نظر العاملين بجهاز الدفاع المدني، أما من وجهة نظر الجهات ذات العلاقة

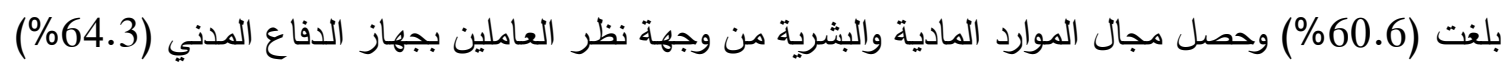
أما من وجهة نظر العاملين بالجهات ذات العلاقة فحصل على (60.9\%)، أما نسبة مجال القرارات في أثناء وقوع الأزمة فبلغت (72\%)، أما مجال المعلومات فحصل على (68.8\%)، أما مجال المعوقات التي تؤثر على إدارة الأزمات فحصل على (62.9\%) وهذه النسبتين من وجهة نظر العاملين بالجهات ذات العلاقة. وأوصت الاراسـة بعدد من التوصيات أهمها ضرورة استحداث إدارة متخصصـة تقوم بمهام إدارة الأزمة كافة، وتفعيل المجلس الأعلى للدفاع المدني، والمجلس الأعلى للإِسعاف والطوارئ، وإنشاء قاعدة بيانات مشتركة التهات بين الجهاز والجهات التي يتعامل معها في الميدان، وتكون مبرمجة بطريقة سهلة وسلسة وتستطيع أنْ تقدم الحلول بلول 
لفرق إدارة الأزمة في الميدان، وضرورة تنفيذ مناورات مشتركة بين الجهاز والجهات التي يتعامل معها في الميدان للتدرب على إدارة الأزمات.

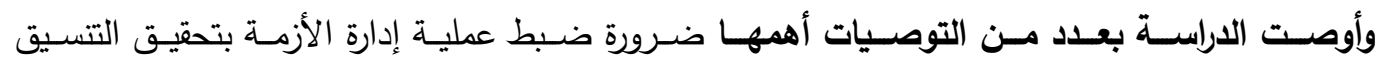

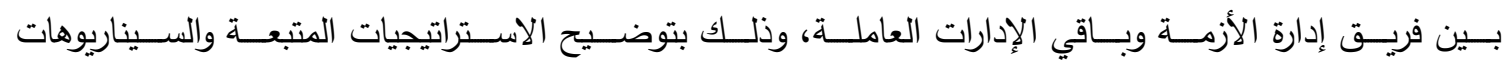

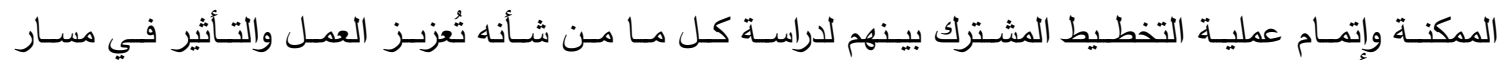
القرار المتخذ لإدارة الأزمة.

4. دراســة (منــاع، 2015) بعنـوان: واقـع إدارة الأزمــات فـي وزارة النقـل والمواصـلات فـي قطـاع غـزة (مسن وجهة نظر العاملين).

جاءت هذه الدراسة للتعرف إلى واقع إدارة الأزمات في وزارة النقل والمواصـلات في قطاع غزة من خلال معرفة مدى توفر المتطلبات الأساسية لدى الوزارة، والمتمثلة في (التخطيط الفعال، مرونـة الهيكل التنظيمي، القدرة

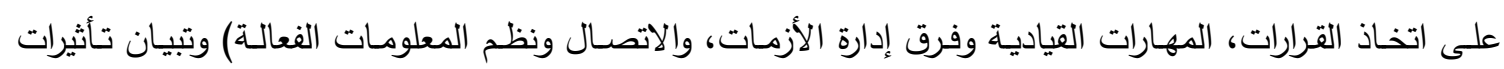

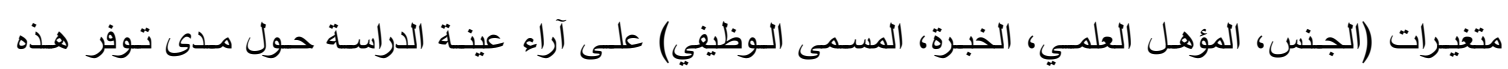
المتطلبات.

توصلت الدراسـة إلى نتائج عدة أهمها؛ أنَّ هناك ضعف في توفر المتطلبات الأساسية لاى وزارة النقل

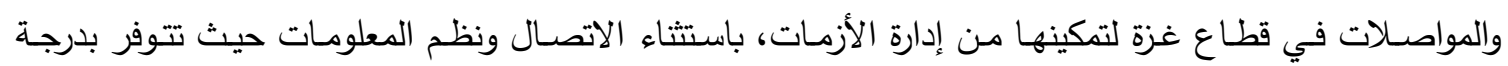

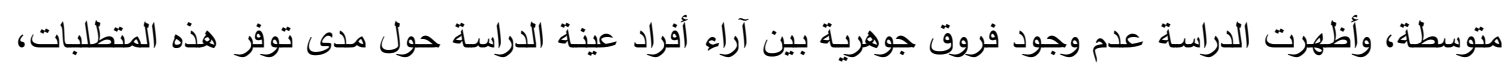
تُعزى إلى المتغيرات الديمغرافية الواردة في الدراسة. وأوصت الاراسة بعدد من التوصيات أهمها ضرورة تبني التخطيط لإدارة الأزمات وجعله ضمن التهني التخطيط

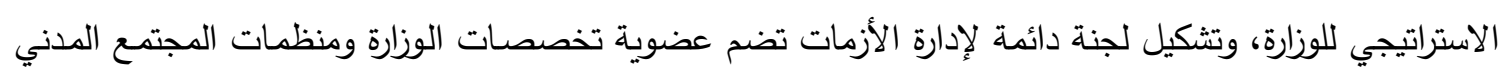

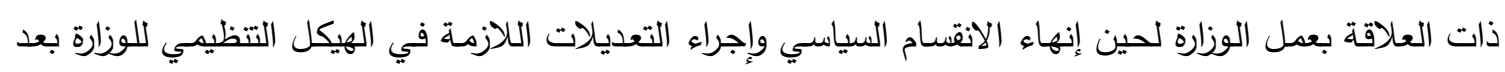

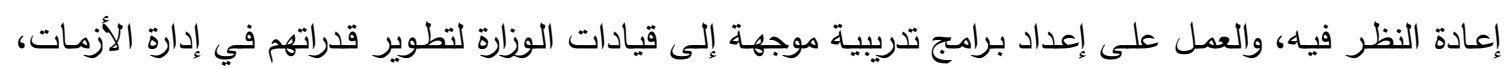

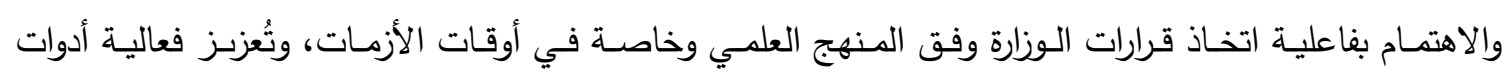
الاتصال المتوفرة في الوزارة بشكل مستمر ، وتوفير المتطلبات الإدارية اللازمة لإدارة الأزمات.

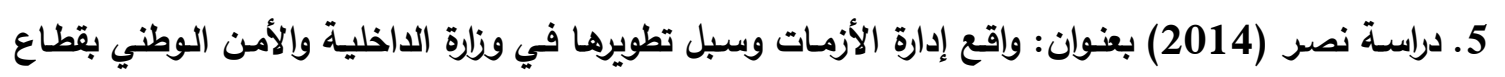

هدفت الدراسة إلى التعرف إلى واقع إدارة الأزمات وسبل تطويرها في الثقق المدني من وزارة الداخلية

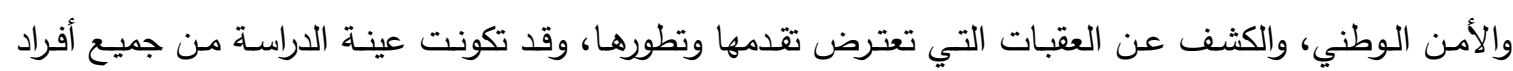
المجتمع الأصلي والبالغ عددهم (206) "موظف، وكيل، مساعد، مدير دائرة، رئيس قسم" وقد استخدمت الدراسـة المنهج الوصفي التحليلي، وطبقت الاستبانة كأداة للبحث.

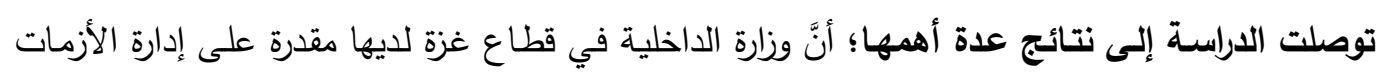

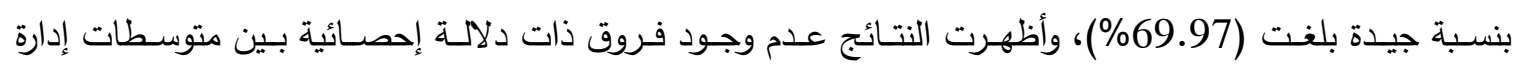
المبحوثين حول واقع إدارة الأزمات.

وأوصت الاراسـة بعدد من التوصيات أهمها؛ إنشاء إدارة مستقلة لإدارة الأزمات في وزارة الداخلية تتبع

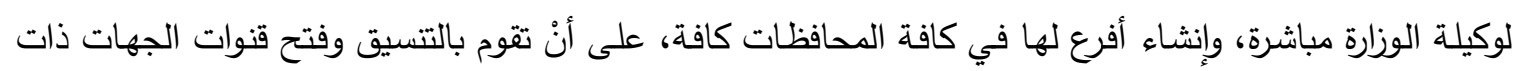


6. دراســة عـودة (2008) بعنــوان: واقــع إدارة الأزمــات فـي مؤسســات التعـيم العـالي (دراســة تطبيقيـة على الجامعة الإسلامية).

هدفت الدراسة التعرف إلى أنواع الأزمات والمخاطر الإدارية التي يمكن أنْ تتعرض لها مؤسسات التعليم

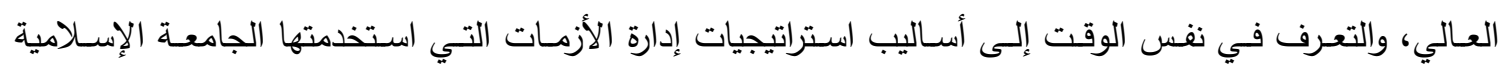

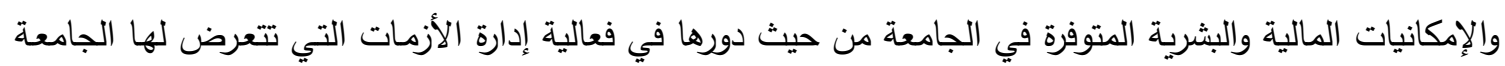

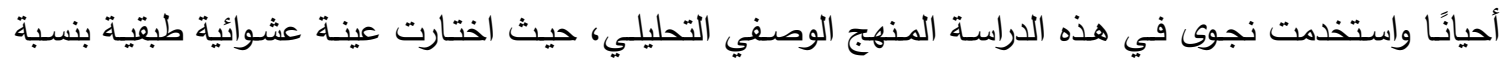
(25\%) من العاملين في الجامعة من الأكاديميين والموظفين والإداريين في جميع المستويات الإدارية.

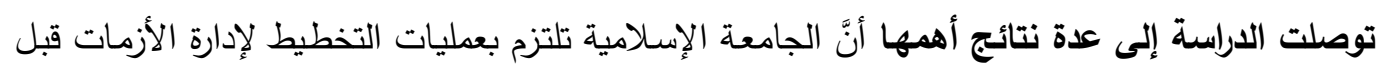

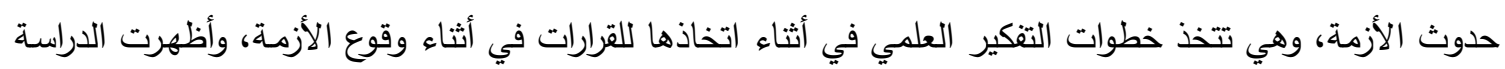
أيضًا أنَّ الجامعة تلتزم بعملية المراجعة وتقييم النتائج بعد انتهاء الأزمة.

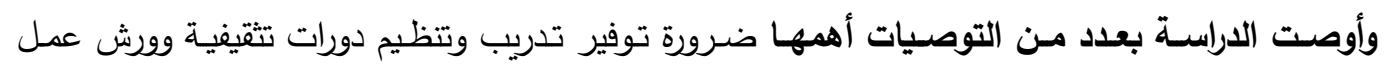

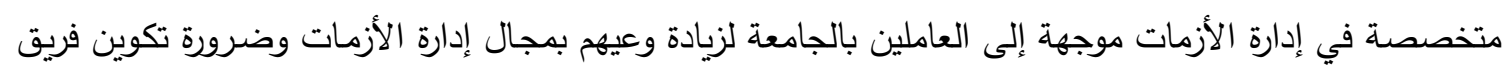

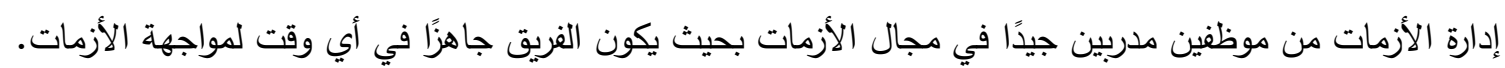
ثانيًا: الاراسات العربية

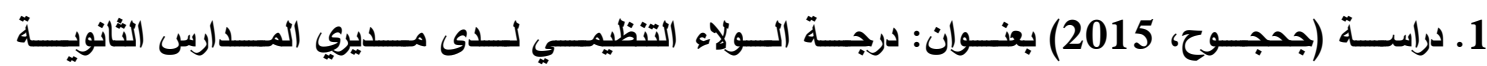

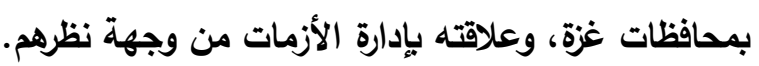

هدفت الدراسة التعرف إلى درجة الولاء التظظيمي لدى مديري المدارس الثانويـة بمحافظـات غزة، وعلاقهـ بإدارة الأزمات من وجهة نظرهم، ولتحقيق أهداف الدراسة قام الباحث باستخدام استبانتين: الأولى لقياس درجة الولاء

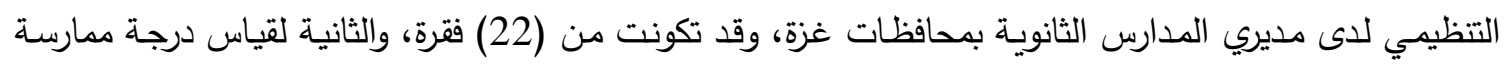

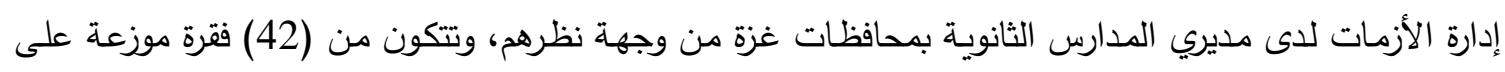

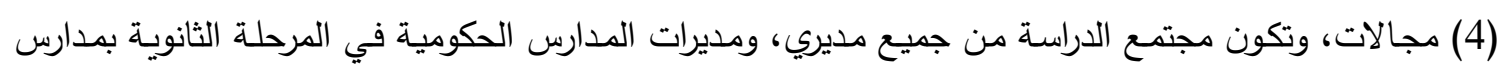

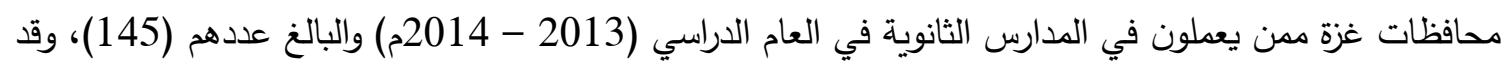

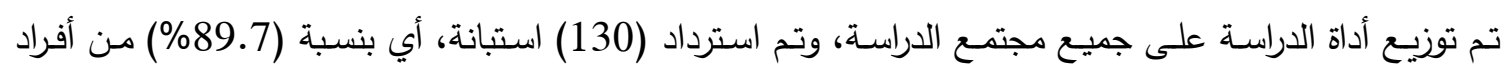
مجتمع الدراسة، وقد استخدم الباحث برنامج الرزم الإحصائية للعلوم الاجتماعية (SPSS).

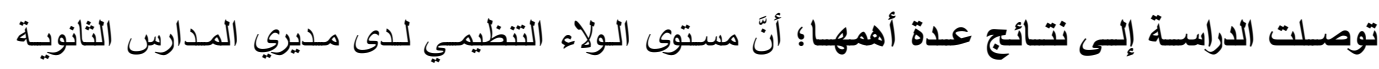

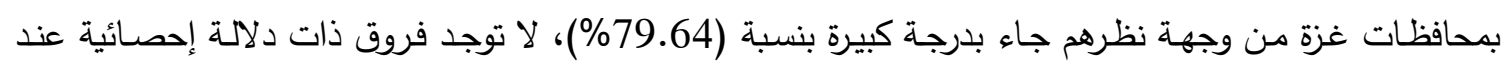

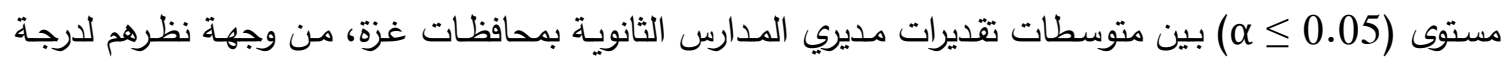

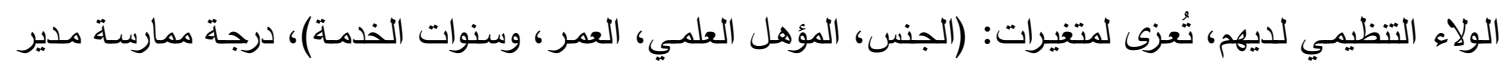

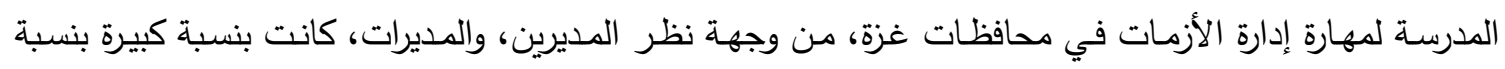

وأوصت الاراسة بعدد من التوصيات أهمها؛ تُعزبز مقومات ظاهرة الولاء التظظيمي، اختيار أعضاء فريق مدرب لإدارة الأزمة، وتطوير أدائه من خلال (عقد ورش عمل لمناقثة الأزمة بعد الانتهاء منها، عقد دورات تدريبية

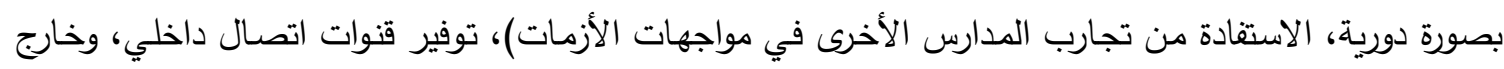

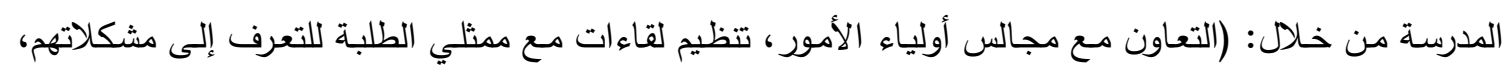

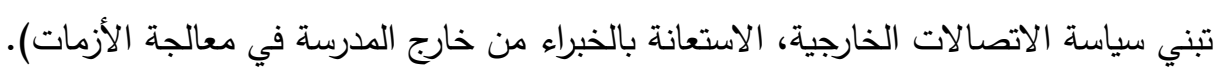


2. دراسة (زويلف، 2015) بعنوان : نجاح نظم المعلومات المحاسبية وأثره في مراحل إدارة الأزمات.

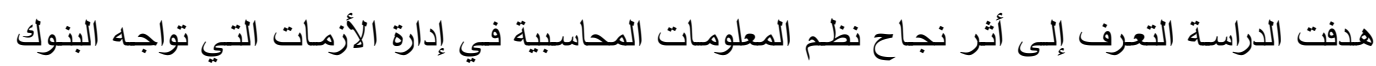

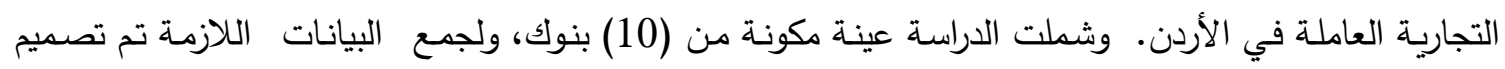
استبانه وزعت على أفراد عينة الدراسة في الادارات العامة لهذه البنوك. وقد تم توزيع (120) استبانة، اعتمد منها

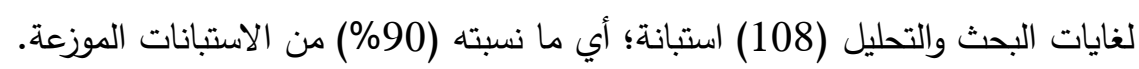

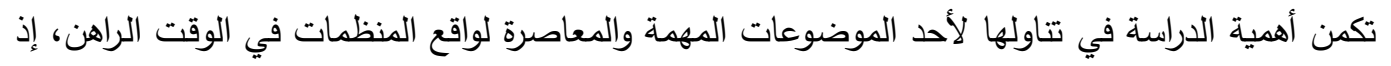

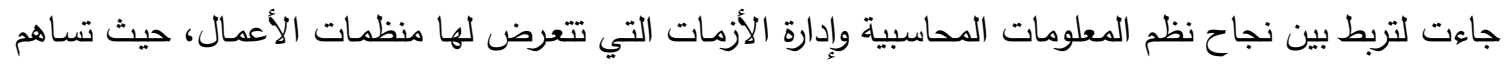
نظم المعلومات المحاسبية الناجحة في ترشيد إدارة الأزمات لما تقدمه من معلومات تساعد الإدارة في مواجهة وإيجاد الحلول الناجعة للأزمات من أجل الحفاظ على منجزات هذه المنظمات وضمان بقائها واستمراريتها. كما تتبع أهمية

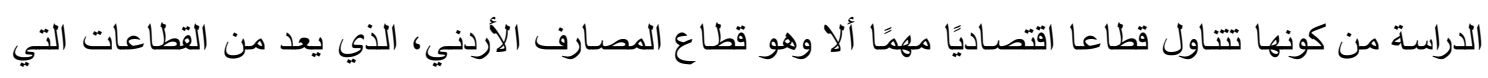

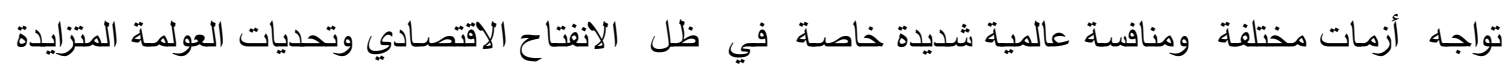

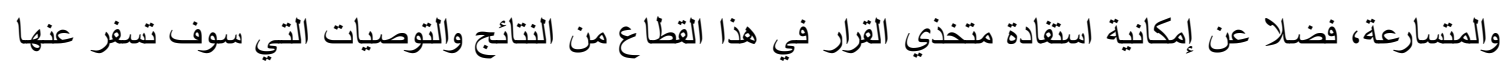

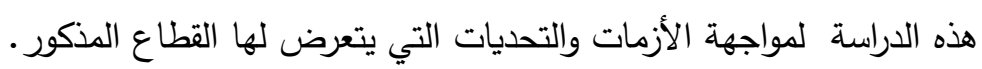

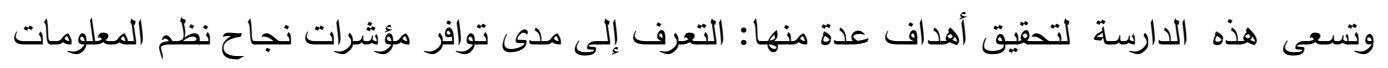
المحاسبية في البنوك التجارية العاملة في الأردن، والتعرف إلى مدى توافر نظام لإدارة الأزمات بجميع مراحلها في

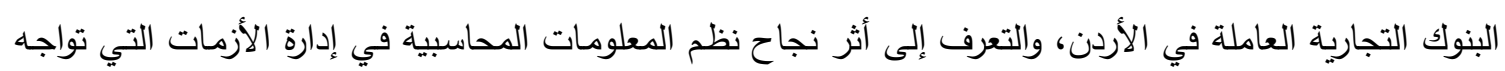
البنوك التجارية العاملة في الأردن وبكل مراحلها. 3. دراسـة (آل سـالم، 2008) بعنوان: مدى الجاهزيـة لإدارة الأزمات والكوارث "دراسـة مسحية على ضباط

\section{الأجهزة الأمنية بمنطقة نجران ".}

هدفت الدراسـة التعرف إلى مدى الجاهزيـة لإدارة الأزمات والكوارث في الأجهزة الأمنية بمنطقة نجران،

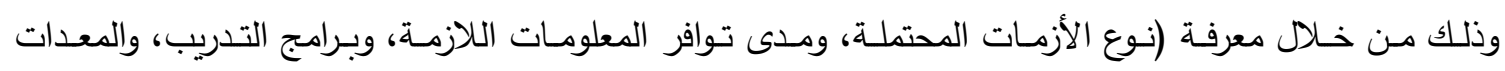

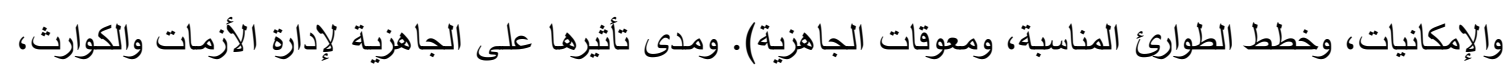

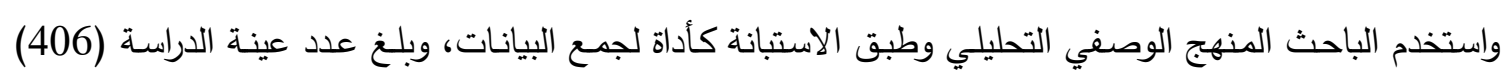

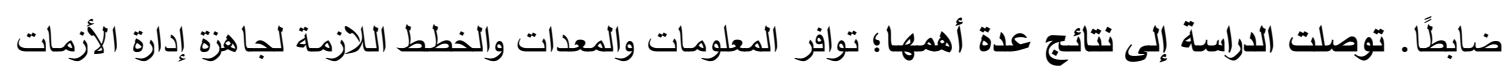
والكوارث، وضعف برامج التدريب، وكذلك ضعف التتسيق بين الجهات المعنية.

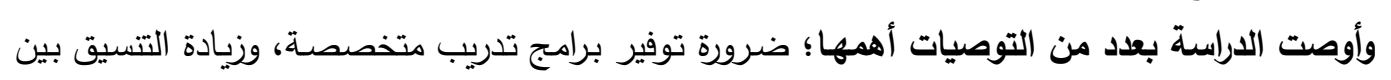

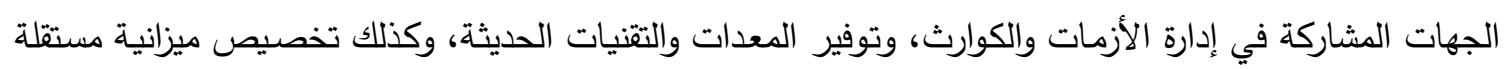
للأجزة المختصة بإدارة الأزمات والكوارث. 4. دراسـة (بيومي، 2008) بعنوان: تحسين قدرة المدارس الثانويـة العامـة والفنيـة الصناعية على إدارة أزمـات الطوارئ، دراسة ميدانية

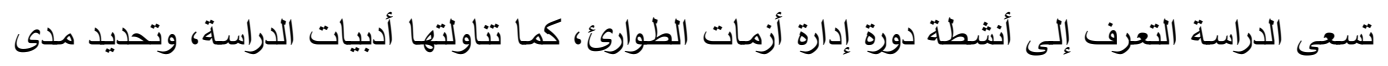

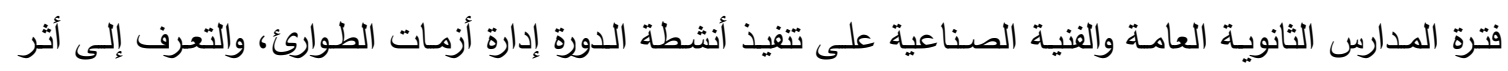
متغيري نوع التعليم الثانوي والخبرة السابقة في إدارة الأزمات على درجة تتفيذ أنثطة دورة إدارة أزمات الطوارئ. 
توصلت الدراسة إلى نتائج عدة أهمها؛ أنَّ القدرة الضعيفة جدًا للمدارس الثانوية العامة والفنية على إدارة

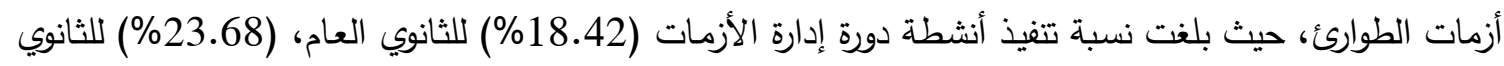
الفني الصناعي، تدني نسب تتفيذ مجالات أنشطة دورة أزمات الطوارئ في المدارس الثانويـة بنوعيها (مجال أنشطة

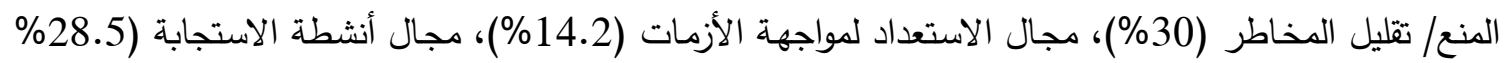

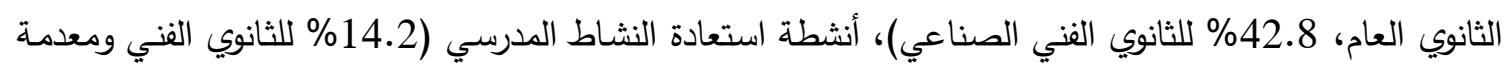

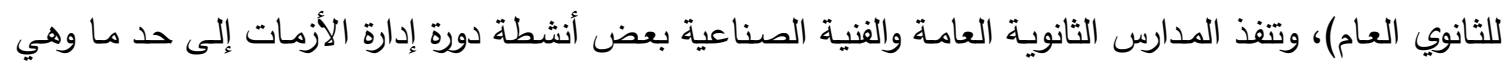

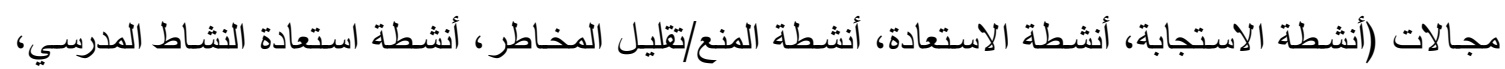
أنشطة الاستعداد). ثالثًا: الدراسات الأجنبية 1- دراسـة (Mwaiwa\&Odiyo, 2015) بعنـوان: التأثثر الاستراتيجي لإدارة الأزمـات على إدارة استمرارية الأعمال في المؤسسات المؤسسية: حالة من بنك إكيتول كينيا The Strategic Effect of Crisis Management on Business Continuity Management in Corporate Organizations: A Case of Equitol Bank Kenya هدفت الدراسة التعرف إلى استراتيجيات إدارة الأزمات في المنظمات التجارية، والكثف عن أثر استراتيجية إدارة الأزمات على إدارة استمرارية العمل والأداء في المنظمة.

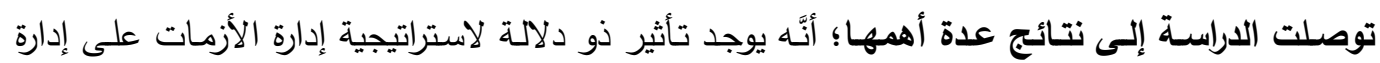

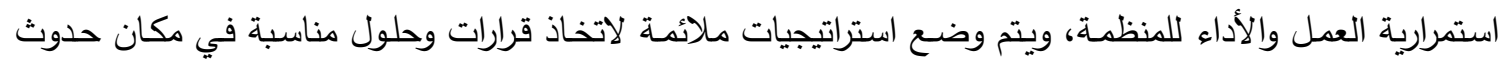

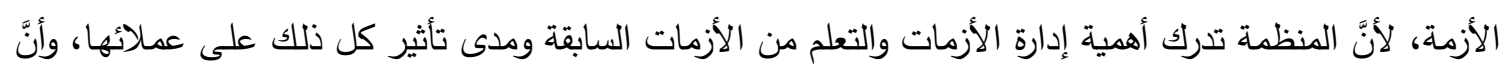

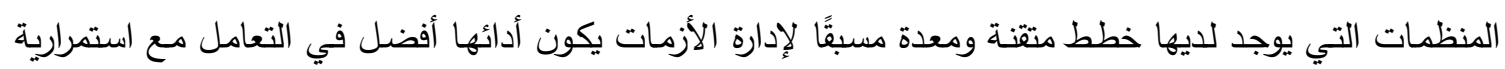

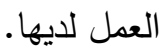

وأوصت الاراسة بعدد من التوصيات أهمها؛ ضرورة معرفة سابقة لدى الموظفين بخطط استمرارية العمل

$$
\text { وهياكل وبرامج الاتصالات المناسبة عند حدوث الأزمة. }
$$

2-دراسة Sara Campo (2014) بعنوان: أثر الابتكار على أداء الفنادق السياحية في أوقات الأزمات

Hotel innovation and performance in times of crisis.

هدفت الدراسـة إلى تحليل تأثير التوجـه القائم على الابتكار على أداء الفنادق السياحية، وكيفية إدراك إدارتها لذلك وتأثير جو الأزمات عليها، وقام الباحث بجمع بيانات الدراسة من خلال استطلاع للرأي على الإنترنت بين مديري الفنادق السياحية ذات درجة (أربعة نجوم) في (52) مدينة إسبانية.

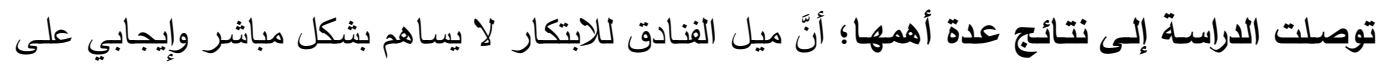

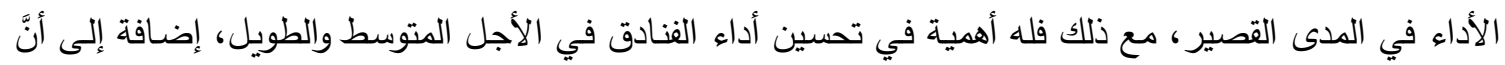
الأزمات وعدم الاستقرار يؤثر على الرغبة في الابتكار .

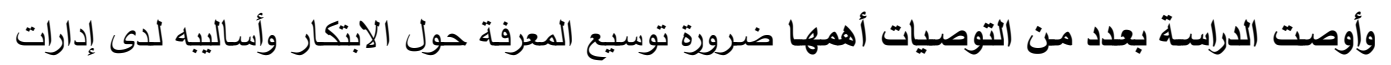

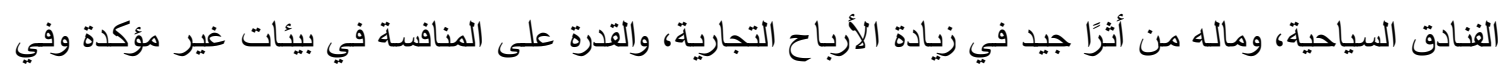
أوقات الأزمات. 3-دراسة (Taneja,2014) بعنوان: إدارة الأزمات الاستراتيجية: أساس لمنع الأزمات Strategic Crisis Management: A Basis for Renewal and Crisis Prevention 
هدفت الدراسـة التعرف إلى الاستراتيجيات التظظيميـة لمنـع الأزمـات وإدارة الأزمـات التي تحدث بكفاءة

وفاعلية، إضافة للتعرف إلى الطرق والأساليب التي يمكن اتباعها لتوقع الأزمات التي قد تواجها هذه المنظمات.

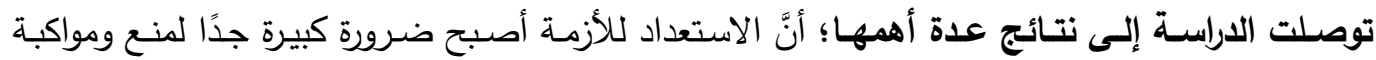
الأزمات المتوقعة بصورة فاعلة ومتميزة، وتوافر استراتيجيات وخطط تتفيذية لإدارة الأزمات.

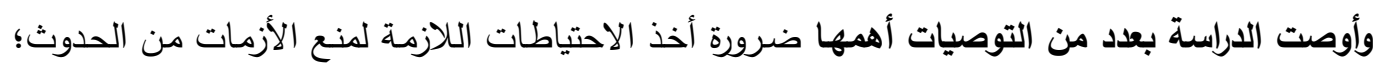
لأن ذلك يؤدي إلى حماية المنظمة من الأزمات أو على الأقل التخفيف من حدتها حال وقوعها. 4- دراسة Anna Bengtson (2013) بعنوان: إدارة الاستقرار والأزمـات في العلاقات التجاريـة (حالة شركة اريكسون في الأسواق الناشئة)

Managing stability and crises in business relationships: The case of Ericsson in an emerging market.

هدفت الدراسـة إلى تطوير نظريـة التغيرات على نحو سلس في تتمية العلاقات التجاريـة للاستفادة منها في

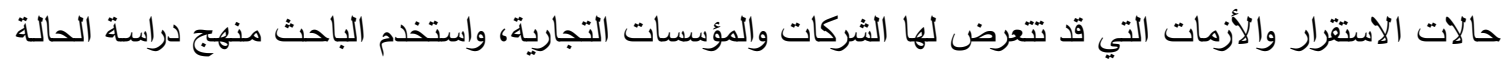
على الثركة في الأسواق الناشئة في الأرجنتين خلال الفترة (1998م -2004 م) من أرشيف الثركة والصحف والانترنت.

توصلت الاراسة إلى نتائج عدة أهمها؛ أنَّ هناك ضعف حقيقي في العلاقات التجارية للشركة بسبب سلوكها

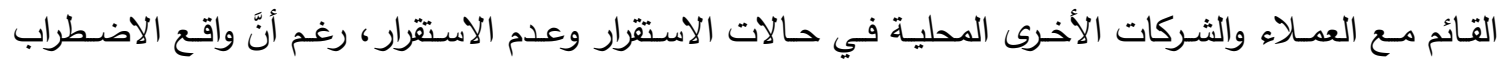
والأزمات أصبح أكثر شيوعًا في العلاقات التجارية بسبب دخول الثركات الكبرى إلى أسواق غير مستقرة.

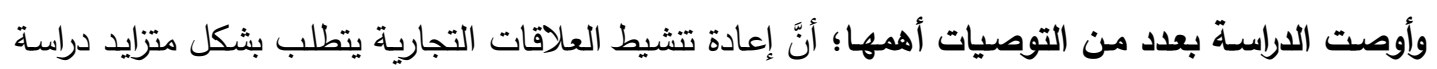
السلوك المتبادل بين الشركات والعملاء والثركات الأخرى في الأسواق، وضرورة إيجاد نموذج موحد للشركة يضمن التهن تحديد أساليب تتبعها الشركة في حالات الاستقرار وعدم الاستقرار في العلاقات التجارية. 5ahim, et al, 2012) بعنوان : دور البلديات في إدارة الأزمات

The Role of Municipality in Crisis Management.

هدفت الدراسـة التعرف إلى دور البلدية في إدارة الأزمات (قبل وأثناء وبعد) من أجل التخطيط لتحسين

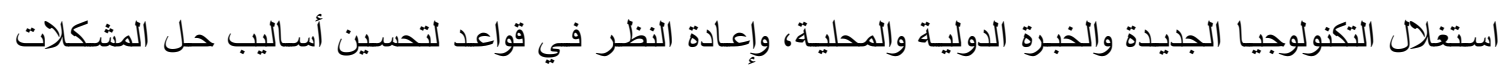

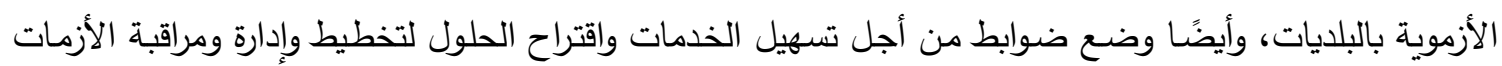

من قبل المديرين والخبراء، واستخدمت الدراسة المنهج التحليلي، والاستبانة والمقابلة أدوات للدراسة. توصلت الاراسـة إلى نتائج عدة أهمها؛ أنَّ بلدية مشهد محل الدراسة تقوم ببعض الأنشطة قبل حدوث الأزمات للحد من حدوثها، وتقوم ببعض الأثشطة لتحسين إدارتها للأزمات، وكذلك تقوم ببعض الأنثطة أثناء

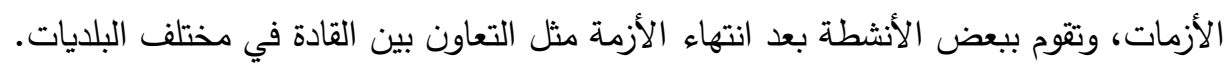

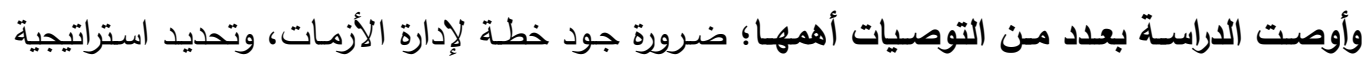

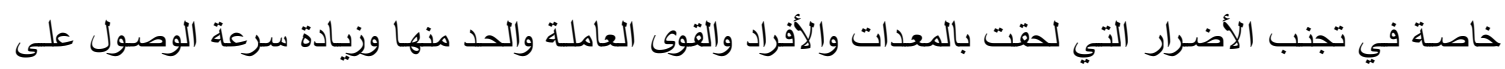
المعلومات وتحليلها في حالة الأزمة.

6-دراسة Unlu (2010) بعنوان: إدارة الأزمات والكوارث في تركيا: "مدى الحاجة لنظام إدارة أزمات موحد". Disaster and crisis management in Turkey: A need for a unified crisis management system. 
هدفت هذه الدراسة لتوضيح مدى تطور وقدرة أنظمة إدارة الأزمات والكوارث لاى الحكومة والنظام التركي،

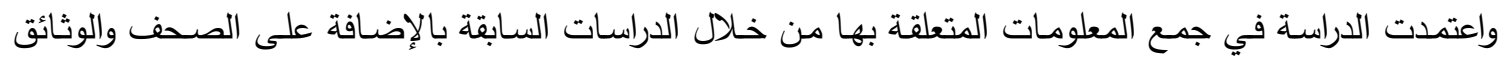
الرسمية والقوانين.

توصلت الدراسـة إلى نتائج عدة أهمها؛ أنَّ هناك مشكلة كبيرة في تتسيق حيث لا توجد آلية واضحة

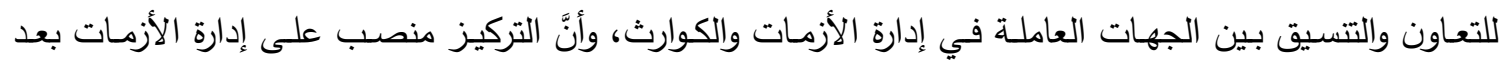
وقوعها، ولا يوجد استفادة من التجارب السابقة للأزمات والكوارث.

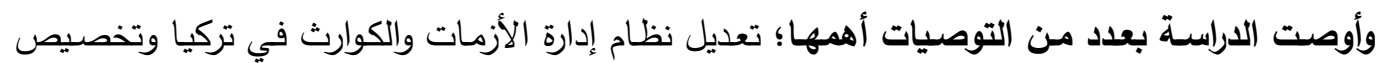
المزيد من الإمكانات الماديـة والبشرية، وزيـادة التسـيق بين جميع الجهات المعنية، وتوفير الصـلاحيات والوسـائل المساندة الإدارة الأزمات والكوارث، والعمل على إدارة الأزمة في مراحلها كافة.

7-دراسة wang (2009) بعنوان غياب اتصالات الأزمة: دور المحتوى في التخفيف من حدة القضايا.

.Examining a crisis communication void: The role of context tomitigate issues هدفت الدراسة التعرف إلى دور المعلومات في إدارة الأزمة، حيث أظهرت الدراسات السابقة فعالية أنواع

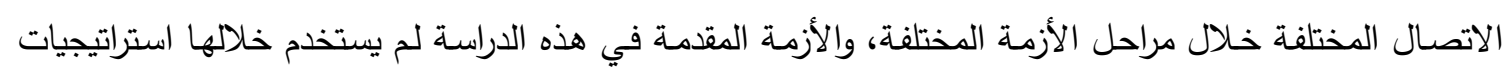
لاتصالات الأزمة للتخفيف من حدتها، وهذا شكل قصور حيث كان يجب استخدام استراتيجية لاتصالات الأزمة، فلم يكن هناك اتصالات أزمة وقائية أو استراتيجية. توصلت الاراسة إلى نتائج عدة أهمها؛ أنَّ القضايا التي يتم تتاولها من خلال وسائل الإعلام لا يمكن التخفيف من حدتها بالتوضيح من قبل المنظمـة، كما يؤدي إلى زيـادة النتائج السلبية، كذلك تزداد حدة وخطورة

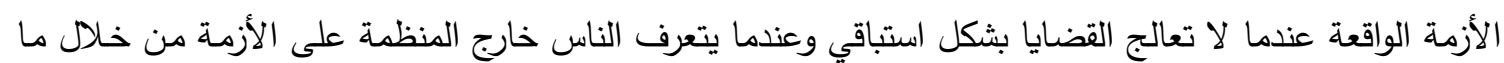
يطرحه الإعلام.

وأوصت الاراسة بعدد من التوصيات أهمها ضرورة استخدام وتفعيل الاتصالات الوقائية قبل الأزمة لإدارة الاتصالات خلال الأزمة ودراسة أهمية الاتصالات الوقائية على الرأي العام. 8-دراسة wing (2009)، بعنوان: " اعتماد إدارة المعرفة في أوقات الأزمات".

Knowledge management adoption in times of crisis

هدفت الدراسة إلى تحسين الفهم للدور الذي تتبعه إدارة المعرفة في رفع الأداء التتظيمي خلال الأزمات،

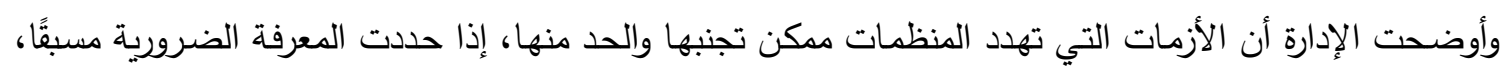

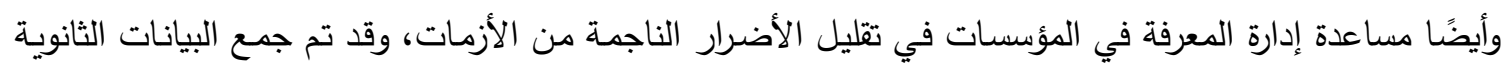
من الوثائق التنظيمية، وبيانات الأرشيف. توصلت الدراسة إلى نتائج عدة أهمها؛ أنَّها أبرزت أهمية استخدام استراتيجيات إدارة المعرفة، التي تمكن

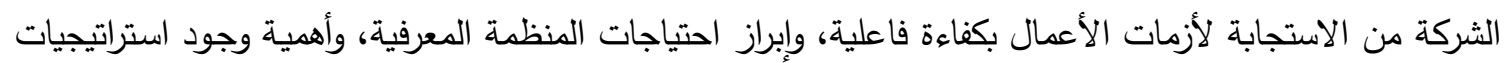
إدارة المعرفة، وتوجيه إدارة الأزمات في كل مرحلة من مراحل تطورها.

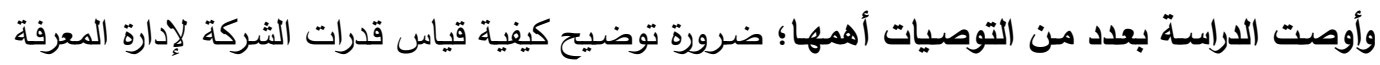

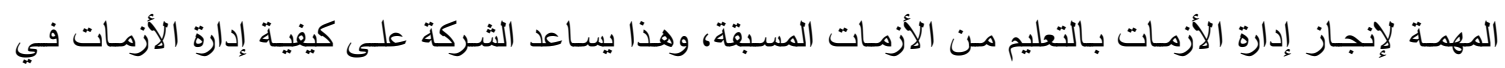

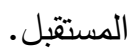

9-دراسة white (2009) بعنوان: "إدارة الإعلام للأزمة: دور المحتوى في التخفيف من حدة القضايا". 
هدفت الدراسـة التعرف إلى دور الإعلام في اتصـالات الأزمـة، وكانت عينـة الدراسـة تضم (250) من الإعلاميين في وسائل الإعلام، واستخدم الباحث المنهج الوصفي التحليلي.

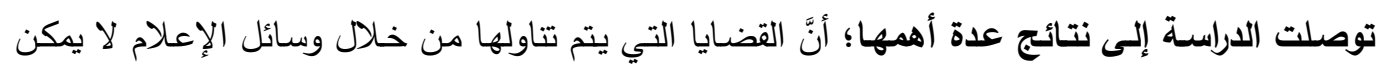

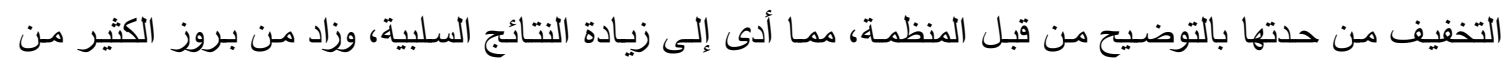

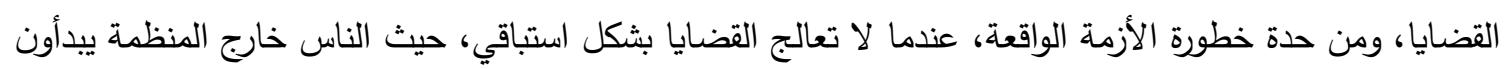

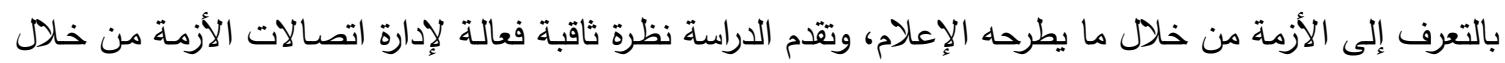

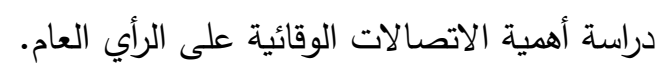

وأوصت الاراسـة بعدد من التوصيات أهمها ضرورة الاعتماد على استراتيجية معينة لاتصـالات الأزمة

للتخفيف من حدتها.

10-دراسـة Esbensen and krisciunas a تطبيقية على الثركات الصناعية.

هدفت الدراسـة التعرف إلى كيفية تحضير المنظمـات أنفسها للأزمات التي تؤثر على نظم المعلومـات

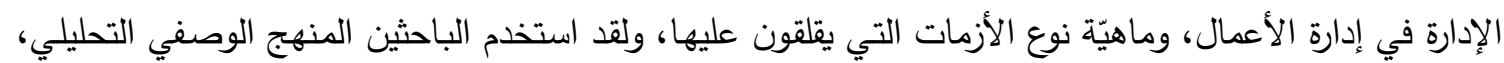

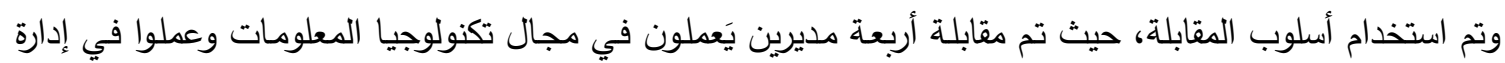

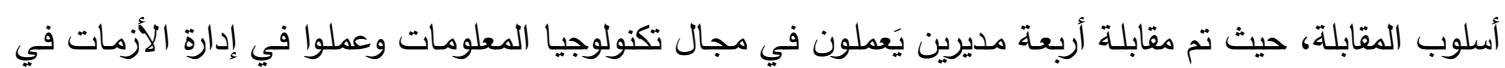
ثلاثة مشاريع عالمية.

توصلت الاراسـة إلى نتائج عدة أهمها؛ أنَّ جلب خبراء ومتخذي قرار في إدارة الأزمات (فريق أزمات)

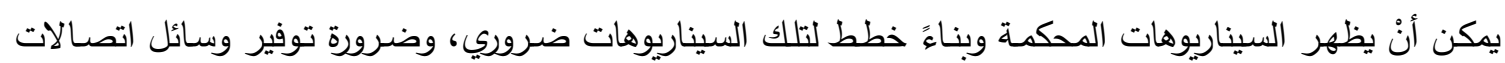
بديلة وتدريب المستخدمين عليه مما يجعلهم يشعرون بالأمان ويعرفهم كيف يعملون في المواقف الحرجة.

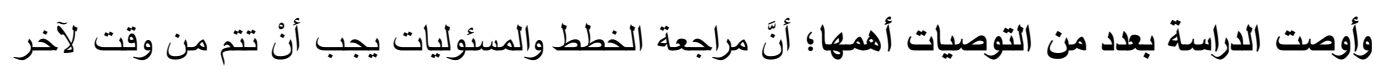

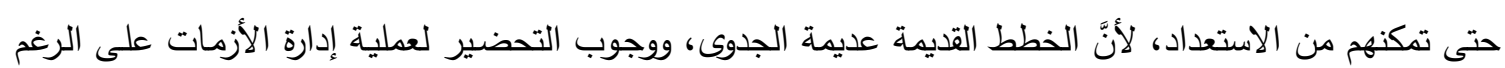
من أنَها مكلفة وتأخذ وقت من الأتون. ثالثًا: الاراسات الأجنبية 1-دراسة (Amin, et al, 2013) بعنوان: "أثر تدريب الموظفين على أداء المهام الوظيفية في قطاع التعليم في باكستان". "the impact of employees training on the job performance in education sector of

Pakistan".

هدفت الدراسة لتحديد العلاقة بين التدريب والأداء الوظيفي في قطاع التعليم في باكستان، ومعرفة علاقة التتمية مع الأداء الوظيفي في قطاع التعليم في باكستان، وفهم ضرورة الربط بين السياسات والممارسات التظظيمية

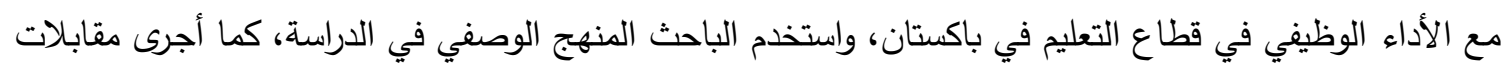

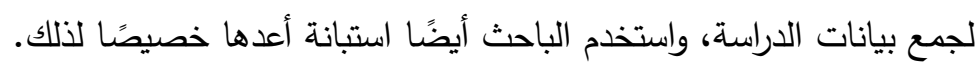

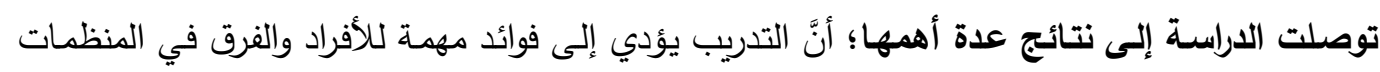

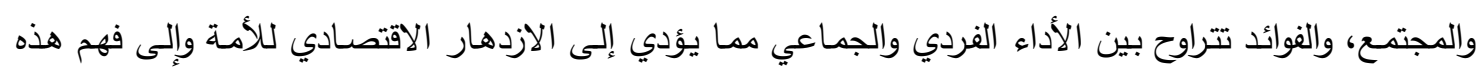
الفوائد من التدريب. 
وأوصت الاراسة بعدد من التوصيات أهمها؛ أنَّ محاولة فهم العوامل التي تسهل انتقال سلس على مستوى

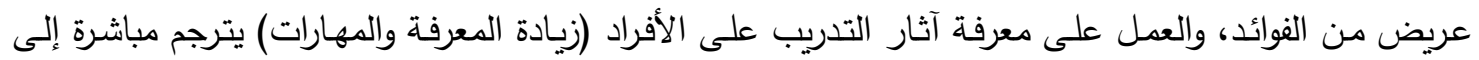
أفضل أداء في الفريق والمستوى التتظيمي.

1- دراسة Kasim (2010) بعنوان : العلاقة بين ممارسات إدارة المعرفة والأداء الوظيفي في دوائر الحكومـة الماليزيـة.

The Relationship of Knowledge Management Practices, Competencies and the Organizational Performance of Government Departments in Malaysia. هدفت الدراسة إلى بيان الدور المهح لممارسات إدارة المعرفة في تحسين الأداء وكفاءة مؤسسات القطاع

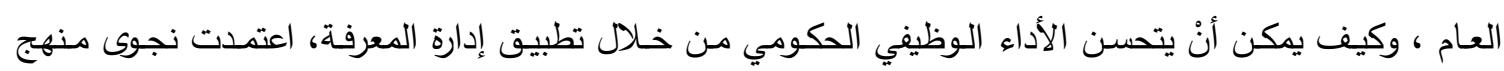

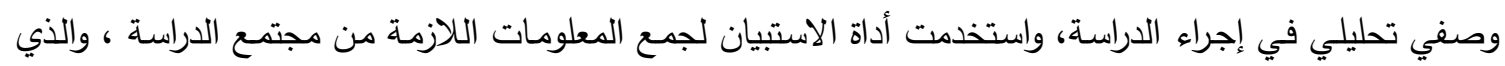
يمثل جميع المديرين العاملين في الوزارات الماليزية والبالغ عددها (28) وزارة، وحيث تم أخذ عينة عشوائية منتظمة الأنة

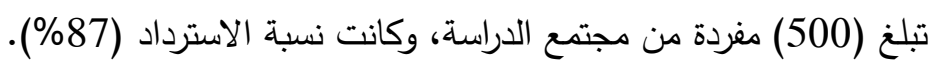
توصلت الاراسـة إلى نتائج عدة أهمها؛ وجود علاقة إيجابية بين ممارسات إدارة المعرفة وكفاءة الأداء الوظيفي في مؤسسات القطاع العام الماليزي.

وأوصت الاراسة بعدد من التوصيات أهمها؛ ضرورة فهم الإدارة العليا للعوامل والعناصر التي تساهم في التي فعالية الأداء الوظيفي، وعلى الإدارة تُعزبز هذه العوامل وخلق التميز التنظيمي، حيث يتطور الأفراد شخصيًا ومهنيًا.

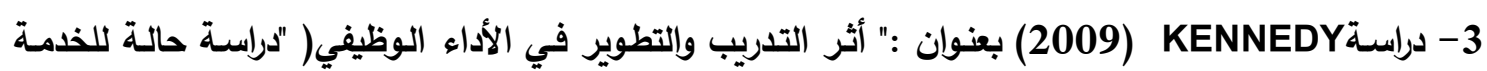
القضائية من غانا). The Impact Of Training And Development On Job Performance" (A Case Study Of The Judicial Service Of Ghana).

هدفت الدراسة إلى تقييم أثر التدريب والتطوير في الأداء الوظيفي لموظفي الخدمة القضائية في غانا، بلغ

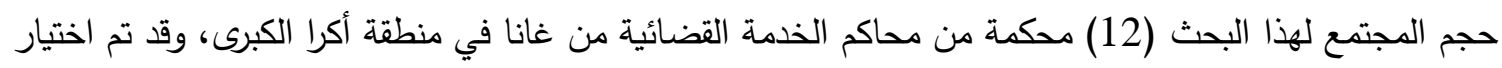

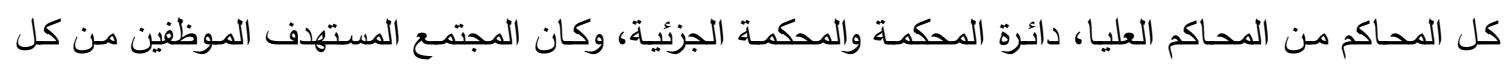
المحاكم من مسجل المحكمة ومترجم ومأمور المحكمة.

توصلت الدراسة إلى نتائج عدة أهمها؛ أنَّ التدريب الذي أجراه الجهاز القضائي لموظفيه لا يذكر ، وكان يجب أنْ يكون هنالك تدريب مناسب وتطوير للموظفين لرفع كفاءة الأداء.

وأوصت الدراسة بعدد من التوصيات أهمها؛ زيادة وتيرة التدريب لموظفي الخدمة القضائية لتطوير الخدمة لتفادئ التي يقدموها، وتثجيع المنظمات على تدريب وتطوير موظفيها لتحقيق أقصى كفاءة وفعالية.

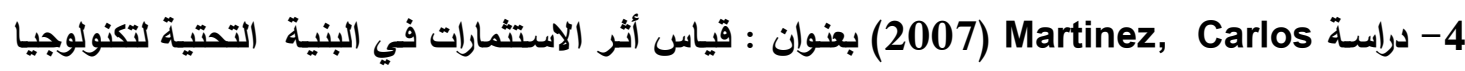
المعلومات والعمليات لتوليد ما يزيد على أداء الثركات العاملة.

Analysis and Measurement of the Impact of information Technology Investment on Performance in Mexican companies.

هدفت الدراسة لقياس أثر الاستثمارات في البنية التحتية لتكنولوجيا المعلومات والعمليات لتوليد ما يزيد

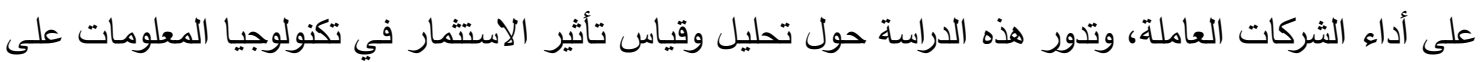


أداء الشركات المكسيكية، وتكونت عينة الدراسة من(40) شركة من الشركات المكسيكية، واستخدم الباحثان المنهج الوصفي التحليل، وتكونت أدوات الدارسة من استبانة.

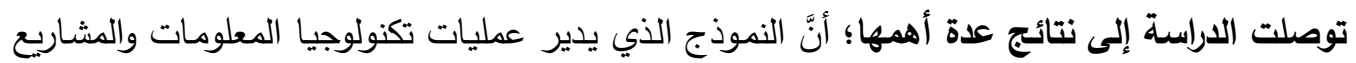

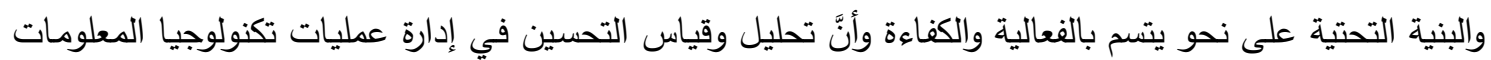
والمشاريع ظهرت في اثنتين فقط من الشركات.

وأوصت الاراسة بعدد من التوصيات أهمها؛ ضرورة الاهتمام باستخدام التكنولوجيا في الأعمال الإدارية،

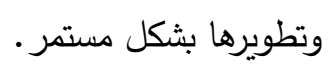

$$
\text { منهجية وأسلوب البحث: }
$$

بناءً على طبيعة الدراسة والأهداف التي تسعى لتحقيقها، فقد استخدم الباحث المنهج الوصفي التحليلي، والذي يعتمد على دراسة الظاهرة كما توجد في الواقع، ويهتم بوصفها وصفًا دقيقًا، ويعبر عنها تعبيرًا كيفيًا وكميًا،

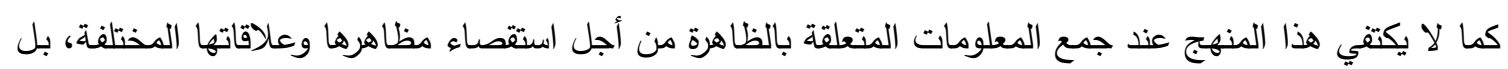

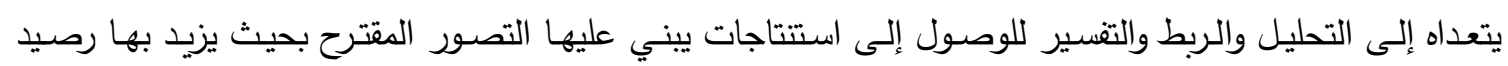
المعرفة عن الموضوع. وقد استخلم الباحث مصدرين أساسين للمعلومات: (1) المصادر الثانوية: حيث اتجه الباحث إلى الكتب والمراجع العربية والأجنبية ذات العلاقة، والدوريات والمقالات

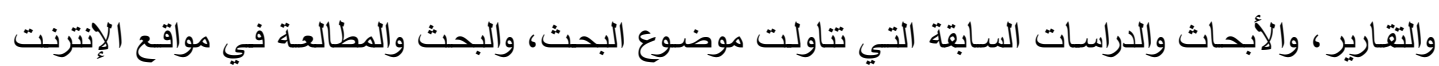

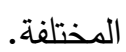

(2) المصادر الأولية: لمعالجة الجوانب التحليلية لموضوع البحث لجأ الباحث إلي جمع البيانات الأولية من خلال

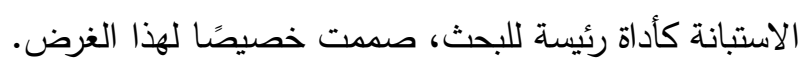

\section{مجتمع وعينة الدارسة:}

مجتمع الدراسة يعرف بأنَّه: جميع مفردات الظاهرة التي يدرسها الباحث, وبناءً على مشكلة الدراسة وأهدافها فإنَّ المجتمع المستهدف يتكون مدَنْ يشغلون الوظائف الإثرافية من مديرين عامين ومديري دوائر ورؤساء أقسام

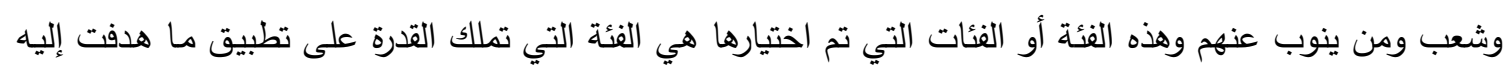

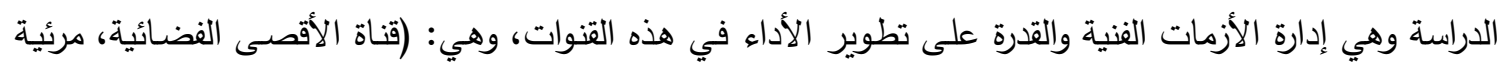

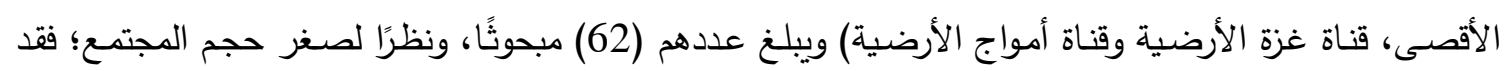

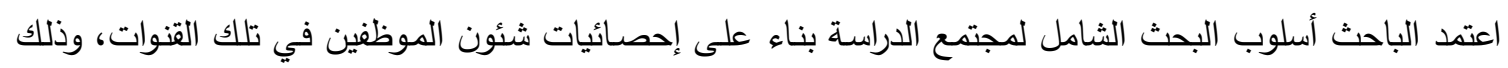

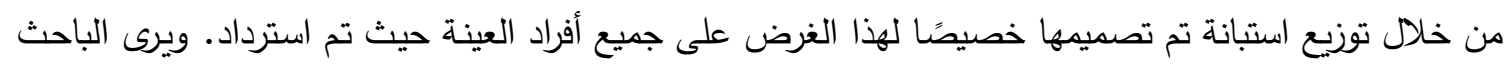
أنَّ أفراد المجتمع المستهدفون في هذه الدراسة ملائمون للموضوع الذي سيتعرف تلى إدئ إدارة الأزمات الفنية وعلاقتها

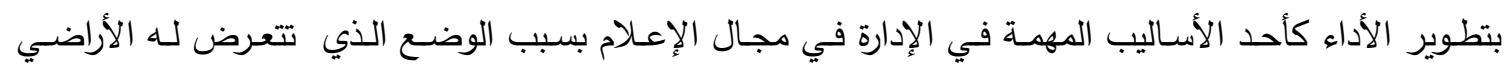

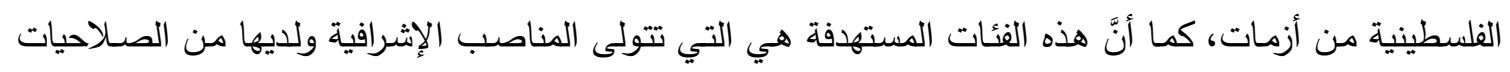

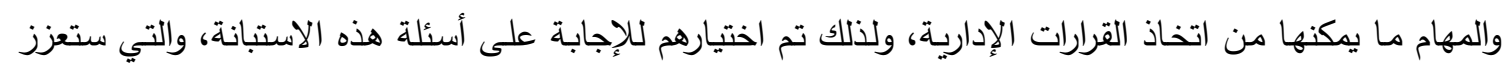

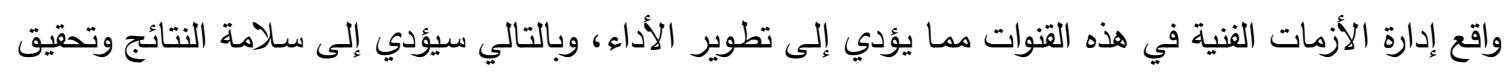
أهداف هذه الدراسة. 
قام الباحث باستخدام الاستبانة كأداة لجمع البيانات وذلك لاعتبارات عدة منها: إمكانية الحصول على عدد كبير من الاستجابات في وقت قصير ، إعطاء فرصة للمبحوث للإجابة بشكل أكثر دقة على أسئلة الاستبانة، قليلة

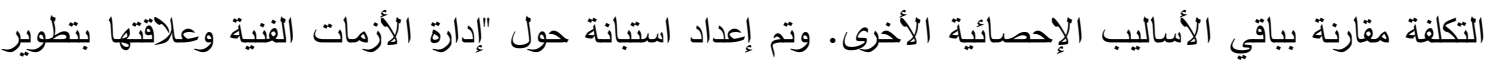

أداء القنوات الفضائية والأرضية الفلسطينية". تم تقريغ وتحليل الاستبانة من خلال برنامج التحليل الإحصائي Statistical Package for the Social

.Sciences (SPSS)

اختبار التوزيع الطبيعي Normality Distribution Test:

تم استخدام اختبار كولمجوروف - سمرنوف Kolmogorov-Smirnov Test (K-S لاختبار ما إذا كانت البيانات تتبع التوزيع الطبيعي من عدمه، وكانت النتائج كما هي مبينة في جدول رقم (17). جلول (1) يوضح نتائج اختبار التوزيع الطبيعي

\begin{tabular}{|c|c|c|c|c|}
\hline $\begin{array}{l}\text { المعنويـة } \\
\text { Sig. }\end{array}$ & سمرنوف(K-S) سلموروف- & الفقرات & \multicolumn{2}{|l|}{ محاور الدراسة } \\
\hline 0.873 & 0.594 & 7 & أولًا: (اكتشاف إثارات الإنذار) & \multirow{5}{*}{ الألأول: إدارة المجال } \\
\hline 0.508 & 0.823 & 6 & ثانيًا: الاستعداد واللوقاية & \\
\hline 0.755 & 0.673 & 6 & ثالثًا: (احتواء الأضرار) & \\
\hline 0.922 & 0.550 & 6 & رابعًا: (استعادة النشاط) & \\
\hline 0.935 & 0.537 & 6 & خامسًا: (التعلم) & \\
\hline 0.877 & 0.590 & 31 & \multicolumn{2}{|c|}{ المجال الأول: إدارة الأزمات الفنية } \\
\hline 0.873 & 0.593 & 6 & أولاً: التخطيط & \multirow{3}{*}{ الثاني: تطاور المجال } \\
\hline 0.335 & 0.944 & 6 & ثانيًا: تنمية الموارد البشرية & \\
\hline 0.490 & 0.834 & 6 & ثالثًا: استخدام الوسائل التكنولوجية & \\
\hline 0.422 & 0.879 & 18 & \multicolumn{2}{|c|}{ المجال الثاني: تطوير الأداء } \\
\hline 0.835 & 0.625 & 49 & \multicolumn{2}{|c|}{ إجمالي محاور الاستبانة } \\
\hline
\end{tabular}

واضتح من النتائج الموضحة في جدول رقم (17) أن القيمة الاحتمالية (Sig) لجميع مجالات الدراسة كانت أكبر من مستوى الدلالة 0.05؛ وبذلك فإنَّ توزيع البيانات لهذه المجالات يتبع التوزيع الطبيعي وحيث سيتم استخدام الاختبارات المعلمية للإجابة على فرضيات الدراسة. الوصف الإحصائي لعينة الاراسة وفق البيانات الثخصية: وفيما يلي عرض لخصائص عينة الدراسة وفق البيانات الثخصية، يتضـح من خلال الجدول (18) أنَّ (100\%) من الاستمارات تم استكمالها بالتعبئة من المبحوثين؛ وذلك بسبب متابعة الباحث الحثيثة للحصول على لئح جميع البيانات الموزعة وفق عينة الدراسة. 
جدول (18) عدد الاستبانات المكتملة

\begin{tabular}{|c|c|c|}
\hline النسبة & الت التكرار & الاستبانات \\
\hline$\% 100$ & 62 & استبانة كاملة \\
\hline$\% 0$ & 0 & استبانة مفقود (لم يتم الإجابة عنها) \\
\hline$\% 100$ & 62 & المجموع \\
\hline
\end{tabular}

يوضـح الجدول رقم (19) أن توزيع أفراد مجتمع الدراسـة حسب متغير الجنس، حيث يبين الجدول بأنَّ

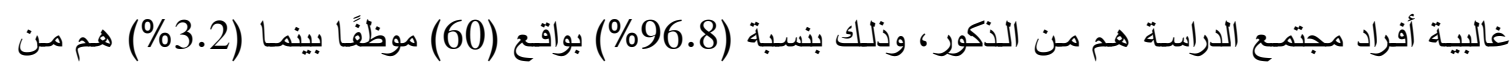
الإناث بواقع (2) موظفين.

جدول (19) الجنس

\begin{tabular}{|c|c|c|}
\hline النسبة & التكرار & \\
\hline 96.8 & 60 & ذكر \\
\hline 3.2 & 2 & أنثى \\
\hline 100.0 & 62 & لمجموع \\
\hline
\end{tabular}

ويعزو الباحث تفوق نسبة الذكور على نسبة الإناث إلى طبيعة العوامل الثقافية والاجتماعية والعادات والتقاليد السائدة في المحافظات الجنوبية من فلسطين، والتي تفضل العمل مع الذكور أكثر من العمل مع الإناث، كما أنَّ

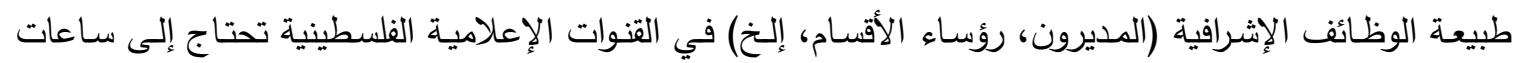

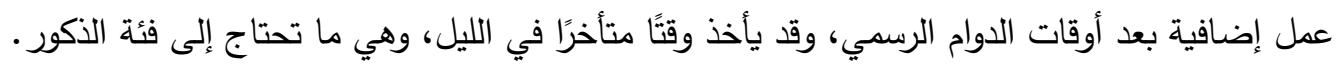

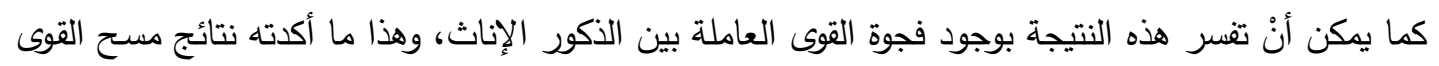

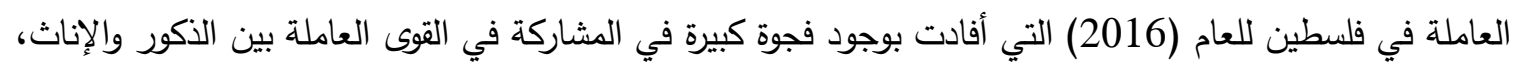
حيث بلغت (71.6\%) للذكور مقابل(19.3\%) للإناث. (الجهاز المركزي للإحصاء الفلسطيني 2016). توزيع عينة الدراسة حسب الفئة العمرية: يوضح الجدول رقم (20) توزيع أفراد مجتمع الدراسة حسب متغير العمر ، حيث يتضح من خلال النتائج بأن

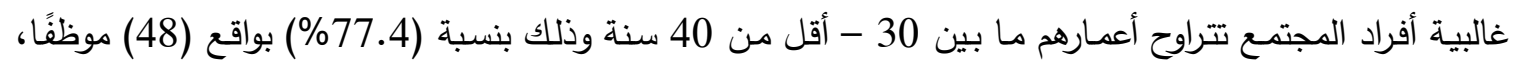
بينما بلغت نسبة (16.1\%) في الفئة العمرية من 40 - أقل من 50 سنة بواقع (10) موظفين، في حين بلغت نسبة (4.8\%) أعمارهم أقل من 30 سنة بواقع (3) من الموظفين، بينما بلغت نسبة (1.6\%) من من الموظفين الذين تزيد أعمارهم عن (50) عامًا بواقع موظف واحد فقط. جدول (2) الفئة العمرية

\begin{tabular}{|c|c|c|}
\hline النسبة & التكرار & \\
\hline 4.8 & 3 & أقل من 30 سنة \\
\hline 77.4 & 48 & من 30- أقل من 40 سنة \\
\hline 16.1 & 10 & من 40- أقل من 50 سنة \\
\hline 1.7 & 1 & من 50 سنة فأكثر \\
\hline 100.0 & 62 & الإجمالي \\
\hline
\end{tabular}


ويعزو الباحث أنَّ نتيجة النسبة الأكبر من عينة الدراسة هي من 30 سنة إلى أقل من 40 سنة والتي كانت بنسبة (77.4\%) تعود إلى أنَّ هذه القنوات ركزت على عنصر الثباب الحيوي، وهذا يعتبر مؤشرًا جيدًا؛ لأنَّ هذه

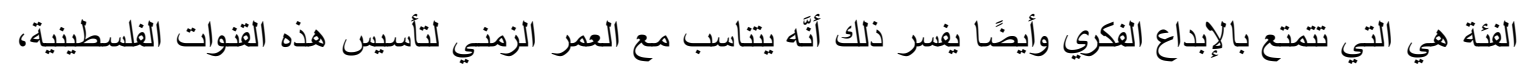

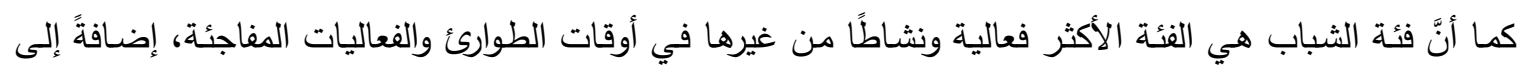

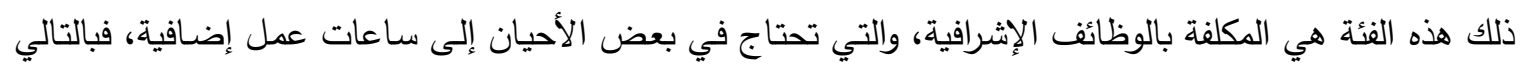

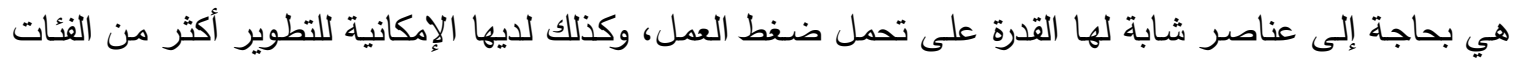
الأخرى.

توزيع عينة الاراسة حسب متغير المؤهل العلمي:

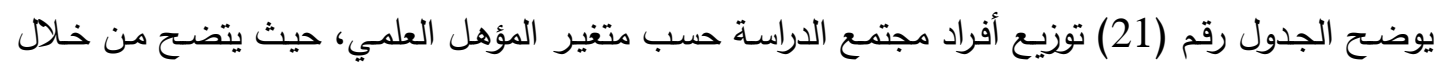

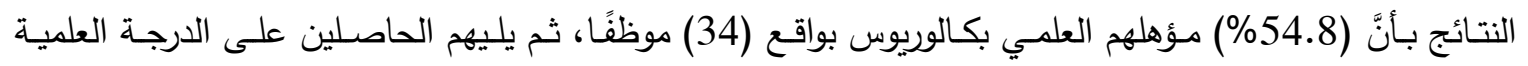

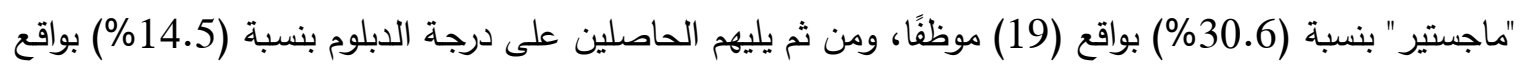
(9) موظفين.

\begin{tabular}{|c|c|c|}
\hline النسبة & التكرار & \\
\hline 30.6 & 19 & ماجستير \\
\hline 54.9 & 34 & بكالوريوس \\
\hline 14.5 & 9 & دبلوم \\
\hline 100.0 & 62 & الإجمالي \\
\hline
\end{tabular}

ويعزو الباحث ارتفاع نسبة الموظفين والذين يحملون المؤهل العلمي البكالوريوس (54.8\%) بسبب أنَّ الوصف الوظيفي للوظائف الإشرافية تحتاج إلى هذا المؤهل العلمي كحد أدنى في أغلب هذه الوظائف الموجودة في القنوات، كما أنها تعتبر أحد الشروط الأساسية في نظام الاختيار والتعيين، والذي يتفق مع وظائف الموارد البشرية في

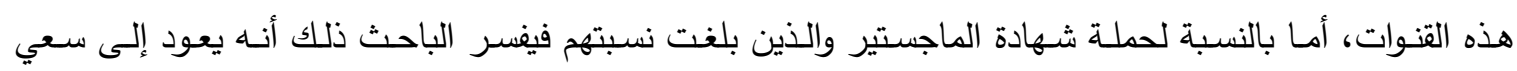
الموظفين لتحسين مستواهم التعليمي وتطوير أنفسهم علميًا مما يؤدي إلى تحسين مستوى العمل ورفع كفاءته. وهذه النسب تعطي مؤشرات إيجابية لاى الباحث في أنَّ هذه الفئة المستهدفة تمتلك القدرة على فئن فهم أسئلة

الاستبانة والإجابة عليها، وبالتالي سيكون لديها القدرة على المشاركة في تطبيق نتائج وتوصيات هذه الدراسة. توزيع عينة الدراسة حسب متغير سنوات الخدمة:

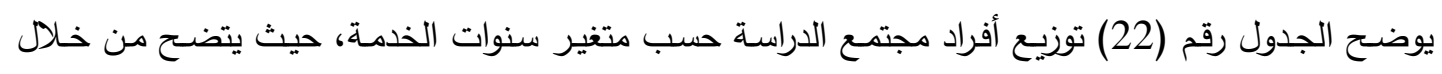

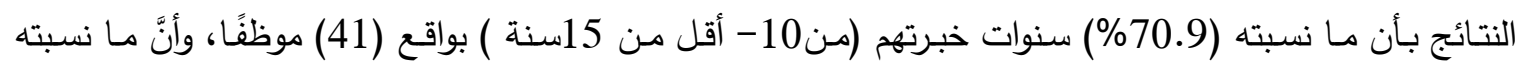

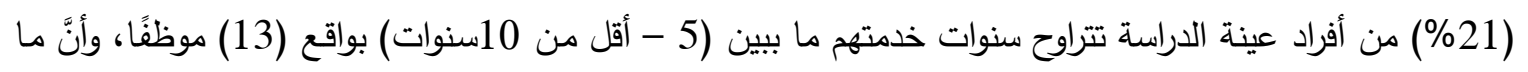
نسبته (8.1\%) من أفراد عينة الدراسة خدمتهم أقل من (5) سنوات بواقع (5) موظف فيما لم تظهر النتائج أيَا من أفراد العينة أنَّ سنوات خدمتهم تزيد عن 15 عاثمًا.

جدول (4) عدد سنوات الخدمة

\begin{tabular}{|c|c|c|}
\hline أقل من 5 & \\
\hline 8.1 & 5 & $(4)$ \\
\hline
\end{tabular}




\begin{tabular}{|c|c|c|}
\hline 21 & 13 & من 5 - أقل من 10 سنوات \\
\hline 70.9 & 44 & من 10- أقل من 15 سنة \\
\hline 100.0 & 62 & الإجمالي \\
\hline
\end{tabular}

ويعزو الباحث هذه النتيجة إلى أنَّ غالبية العاملين في هذه القنوات قد بدأوا منذ تأسيس أقدم قناة في هذه

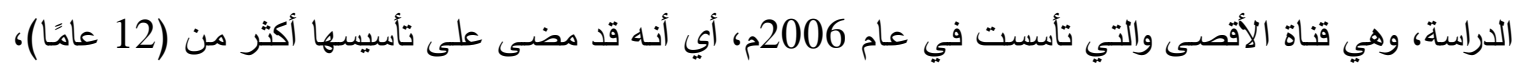

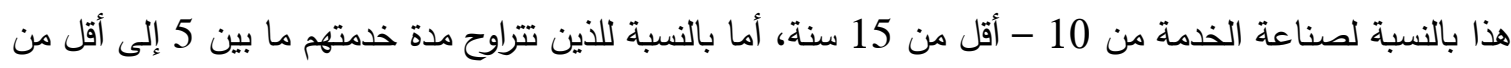
10 سنوات، حيث إنَّ هذه الفئة العمرية قد استحقت الحصول على هذه الوظائف الإشرافية بعد الحصول على سنوات

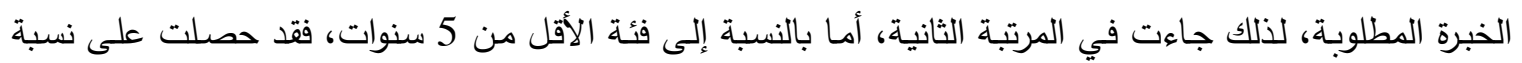
(8.1\%) وذلك بسبب وجود قنوات حديثة العهد وبها وظائف إشرافية جديدة. أيضًا هذه النسب تؤكد على النسب الخاصـة بالمؤهلات العلمية وتضيف مدلولات إيجابية لدى الباحث بأنَّ عينة الدراسة لايها الخبرة والكفاءة والممارسة الكافية بإدارة الأزمات، كما أنَّها تتمتع بالقدرة على تطوير التصات الأداء. توزيع عينة الدراسة حسب متغير المسمى الوظيفي: يوضح الجدول رقم (23) توزيع أفراد مجتمع الدراسة حسب متغير المسمى الوظيفي، حيث يتضـح من خلال

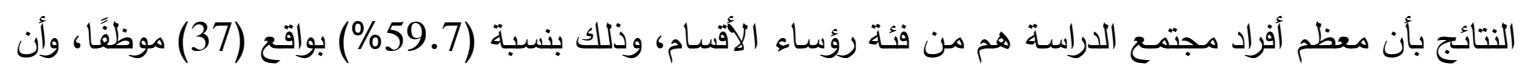

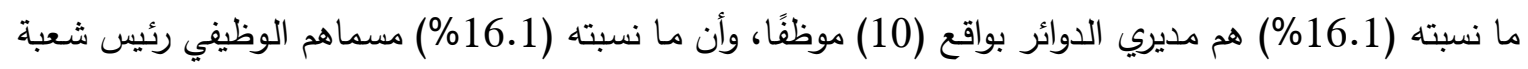
بواقع (10) موظفين، بذلك يكون عدد رؤساء الأقسام والثعب هو (47) موظفًا أي ما نسبته (75.8\%) من من عينة

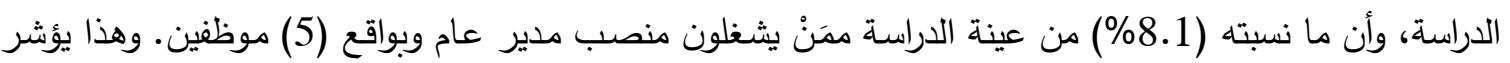

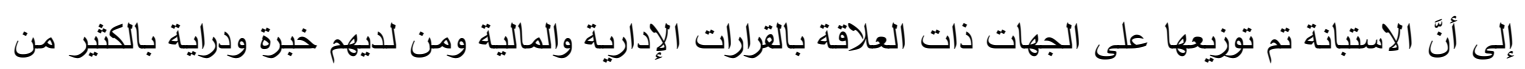
الجوانب المتعلقة بموضوع الدراسة وأبعادها.

\begin{tabular}{|c|c|c|}
\hline \multicolumn{3}{|c|}{ جدول (2) المسمى الوظيفي } \\
\hline النسبة & التكرار & \\
\hline 8.1 & 5 & مدير عام \\
\hline 16.1 & 10 & مدير دائرة \\
\hline 59.7 & 37 & رئيس قسم \\
\hline 16.1 & 10 & رئيس شعبة \\
\hline 100.0 & 62 & الإجمالي \\
\hline
\end{tabular}

ويعزو الباحث هذه النتيجة التي حصل عليها المسمى الوظيفي للمناصب الإدارية رئيس قسم وشعبة ما

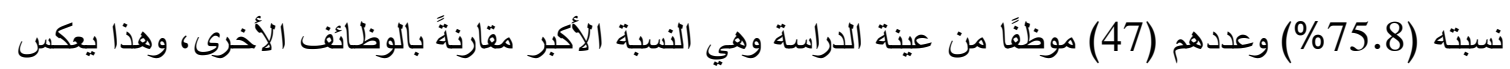

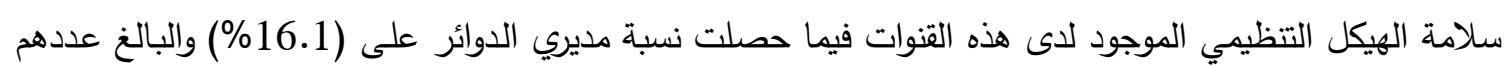
(10) موظفين وذلك نسبةً طبيعية مـع عدد رؤسـاء الأقسام والثـعب في هذه القنوات، أمسا بالنسبة لفئسة المديرين العامين فقد حصلت على نسبة (8.1\%) والبالغ عددهم (5) مديرين عامين ويعود ذلك إلى عدد القنوات التي ودئ

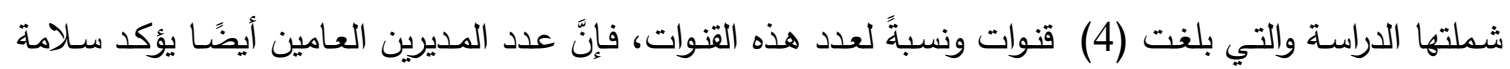
الهيكل التظظيمي داخل هذه القنوات، كما أنَّ هذه النسب توضـح مدى صحة التسلسل التخصصي في في الوظائف الإثرافية داخل الهياكل التتظيمية في القنوات. 
توزيع عينة الاراسة حسب متغير جهة العمل: يوضتح الجدول رقم (22) توزيع أفراد مجتمع الدراسة حسب متغير جهة العمل، حيث يتضح من خلال النتائج

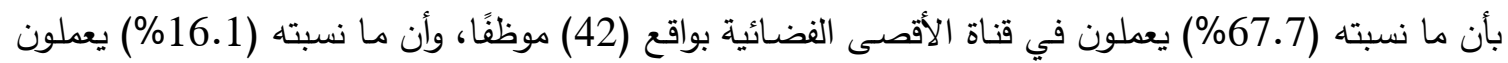

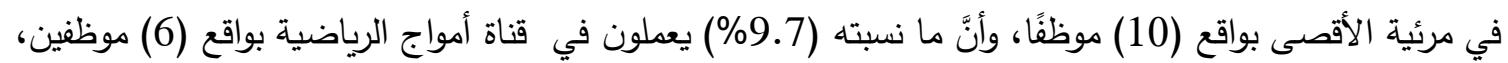
وأنَّ ما نسبته (6.5\%) بواقع (4) موظفين يعملون في قناة غزة الأرضية. وهذا يؤشر إلى أنَّ قناة الأقصى الفضائية هي الأكثر عددًا في الموظفين، وكذلك من ناحية عدد متخذي القرارات مقارنة بالقنوات الأخرى. جدول (3) جهة العمل

\begin{tabular}{|c|c|c|}
\hline النسبة & التكرار & \\
\hline 74.1 & 46 & قناة الأقصى الفضائية \\
\hline 9.7 & 6 & مرئية الأقصى \\
\hline 6.5 & 4 & قناة غزة الأرضية \\
\hline 9.7 & 6 & قناة أمواج الأرضية \\
\hline 100.0 & 62 & الإجمالي \\
\hline
\end{tabular}

ويعزو الباحث ارتفاع نسبة العاملين في قناة الأقصى الفضائية بنسبة (74.1\%) والبالغ عددهم (46) موظفًا، حيث إنَّ طبيعة عمل القناة مختلف عن باقي القنوات، بالإضافة إلى نطاق التغطية التي تعمل القناة ضمنهاه،

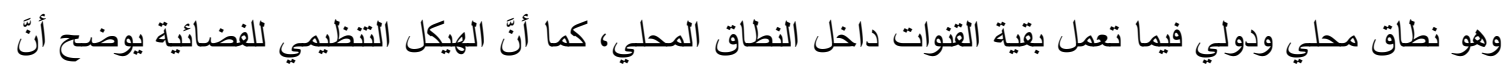

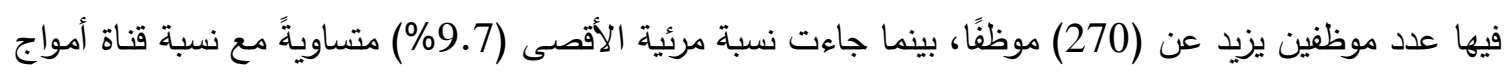
من حيث عدد الوظائف الإشرافية؛ وذلك بسبب طبيعة عمل هذه القنوات، حيث تبث إرسالها بنظام البث الأرضي

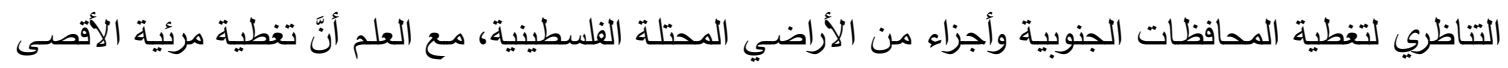

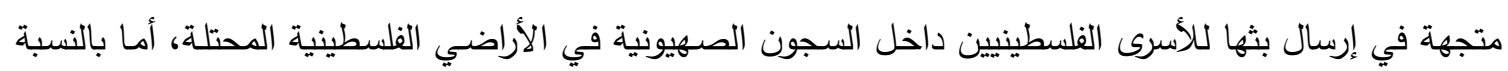
لقناة أمواج فجاءت بنسبة (9.7\%) لوجود مديري دوائر تتفيذيين داخل القناة والتي تبث الأحداث الرياضية داخل

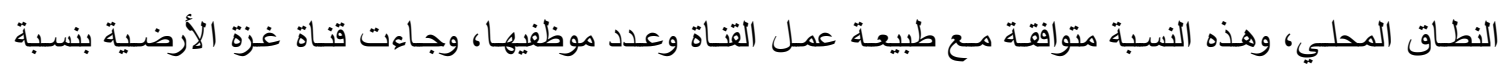

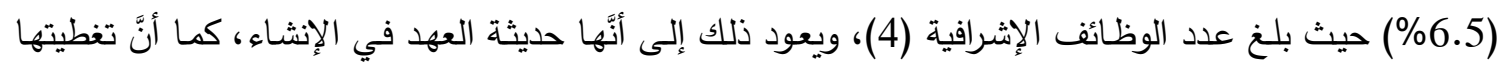
محلية وكذلك يوجد تتاسب بين عدد الوظائف الإشرافية فيها وعدد الموظفين وفق الهيكل التظظيمي الخاص بهاص الها. اختبار الفرضيات : اختبار الفرضيات حول العلاقة بين متغيرين من متغيرات الدراسة (الفرضية الرئيسية الأولى)؛ فرضيات الدراسة :

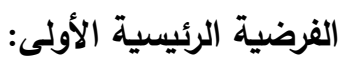
توجد علاقة ذات دلالة إحصائية عند مستوى ( القنوات الفضائية والأرضية الفلسطينية. 
جدول (7) معامل الارتباط بين إدارة الأزمات الفنية وتطوير الأداء في القنوات الفضائية والأرضية الفلسطينية

\begin{tabular}{|c|c|c|c|}
\hline نتيجة الحكم الفرضية & $\begin{array}{l}\text { الاحتمالية } \\
\text { (Sig.) }\end{array}$ & لبرسون & الفرضية \\
\hline مقبولة & 0.000 & $* 0.805$ & 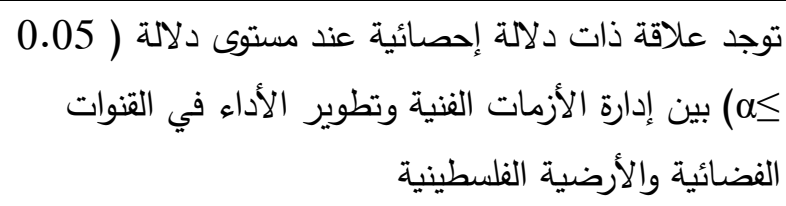 \\
\hline
\end{tabular}

* الارتباط دال إحصائيًا عند مستوى دلالة 0.05.

يبين جدول رقم (36) أنَّ معامل الارتباط يساوي 0.805، وأن القيمة الاحتمالية (.019)

وهي أقل من مستوى الدلالمة 0.05 م وهذا يدل على وجود علاقة ذات دلالة إحصائية قوية طردية بين إدارة

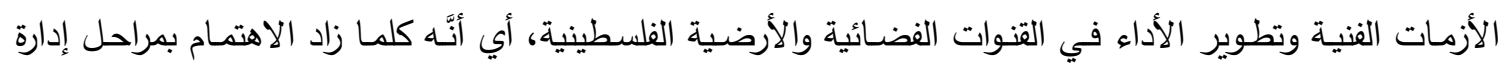

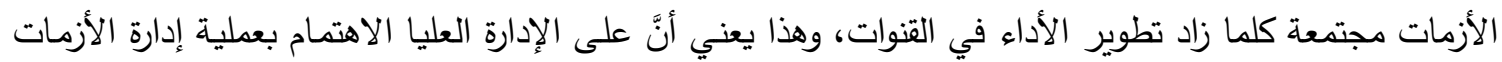

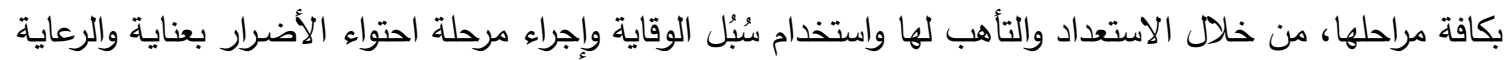

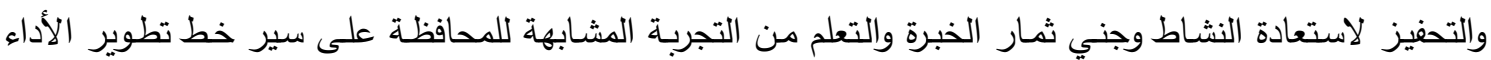
وتحقيقه بالتخطيط لكل الأعمال، وحصر نقاط الغاية المراد الوصول إليها، من خلال تدريب وتجهيز وتتمية الموارد البشرية وتحديث كافة الوسائل الإعلامية والتكنولوجية والترتيب لذلك كله بمنهجية علمية.

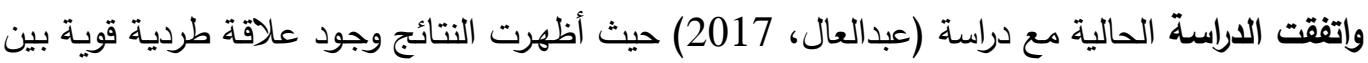
إدارة الأزمات والجودة، وكذلك مع دراسـة (صـادق، 2016) و (نصر ، 2014) حيث أظهرت النتائج وجود علاقة

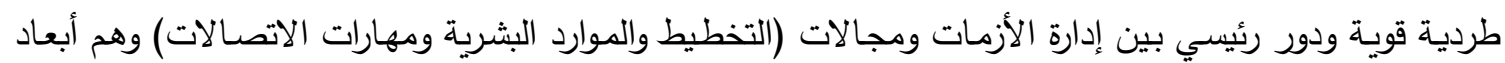
تطوير الأداء. واختلفت هذه الدراسـة مع دراسة (مناع، 2015)، (أبو ركبة، 2013)، (عزيز، 2010) حيث أظهرت

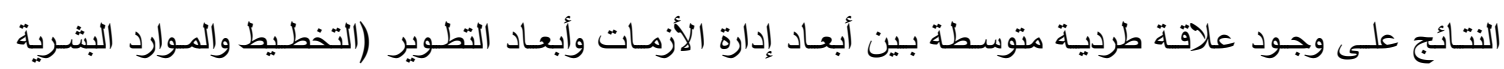
والتكنولوجيا).

ويتفرع منها الفرضيات الفرعية التالية: 1. توجد علاقة ذات دلالة إحصـائية عند مستوى دلالـة 0.05 بئة بين اكتثاف إثـارات الإنذار وتطوير الأداء في القنوات الفضائية والأرضية الفلسطينية. جدول (8) معامل الارتباط بين اكتثاف إثارات الإنذار وتظوير الأداء في القنوات الفضائية والأرضية الفلسطينية

\begin{tabular}{|c|c|c|c|}
\hline عليجة المكم الفرضية & $\begin{array}{c}\text { الاحتمالية } \\
\text { (Sig.) }\end{array}$ & لبرنبون & الفرضية \\
\hline مقبولة & 0.000 & $* 0.637$ & 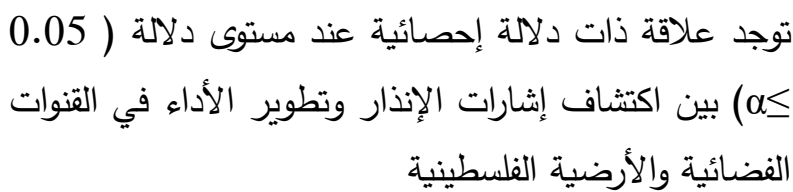 \\
\hline
\end{tabular}

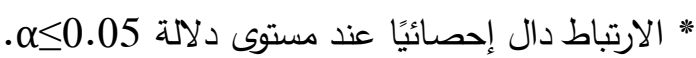


يبين جدول رقم (37) أنَّ معامل الارتباط يساوي 0.637، وأنَّ القيمة الاحتمالية (.Sig) تسـاوي 0.00

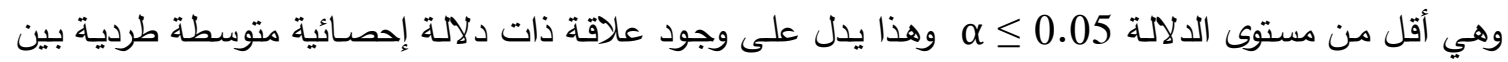
اكتشاف إثارات الإنذار وتطوير الأداء في القنوات الفضائية والأرضية الفلسطينية، أي أنَّه كلما زاد الاهتمام بمرحلة

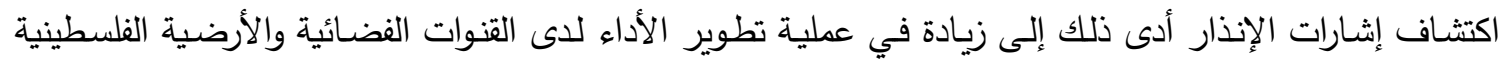
والعكس صحيح.

ويعزو الباحث أن النتيجة صحيحة، لأنَّ مرحلة اكتشاف إثـارات الانذار مرتبطة بشكل أساسي بتحقيق

التطوير حيث إنَّ التوقع السليم واستثعار المسؤولون للأزمة وعمل اختبارات وإجراءات وتدريب على استثعار وجود الأزمة يساعد بشكل ملحوظ في عملية تطوير الأداء ورفع الكفاءة والإنتاجية، وتجنب المشاكل العرضية التي تطرأ لاى هذه القنوات مما يشكل عائقًا في عملية التطوير. ويتضح مما سبق أنه وبالرغم من وجود علاقة طردية بين مرحلة اكتثاف إشارات الإنذار وتطوير الأداء إلى أنَّ الاهتمام والاستعداد لدى هذه القنوات على اكتثاف إثشارات الإنذار وبدرجة متوسطة فيها، وهذا يعني أنَّها بحاجة إلى اهتمام أكبر وتركيز أكثر من الإدارة العليا بخصوص هذه هذه المرحلة لاى هذه القنوات.

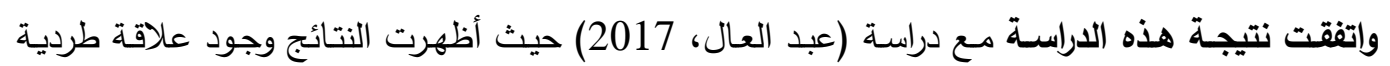
متوسطة بين مرحلة اكتثاف إثارات الإنذار والجودة حيث بلغ معامل الارتباط 0.599 كما اتفقت مع دراسة (مناع،

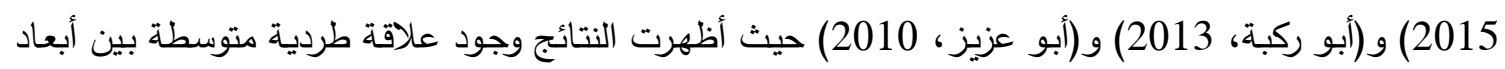
إدارة الأزمات وأبعاد التطوير (التخطيط والموارد البشرية والتكنولوجيا). 2. توجد علاقة ذات دلالة إحصائية عند مستوى دلالة 0.05 مبئ بين الاستعداد والوقاية وتطوير الأداء في القنوات الفضائية والأرضية الفلسطينية.

جدول (9) معامل الارتباط بين الاستعداد والوقاية وتطوير الأداء في القنوات الفضائية والأرضية الفلسطينية

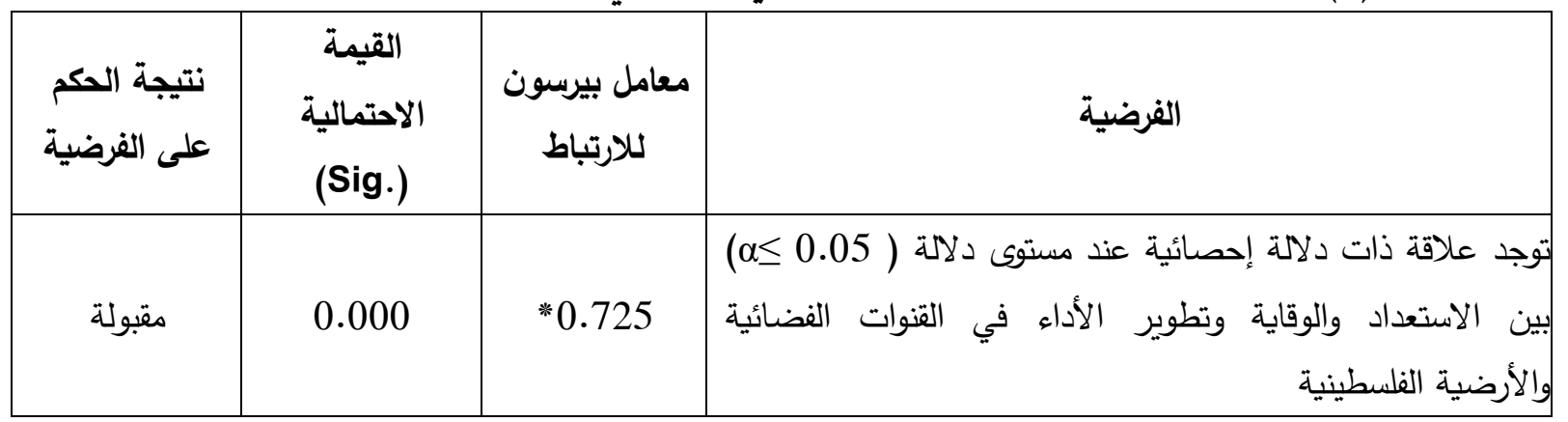

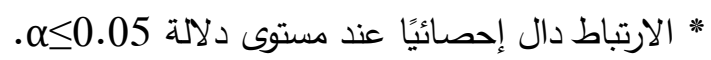

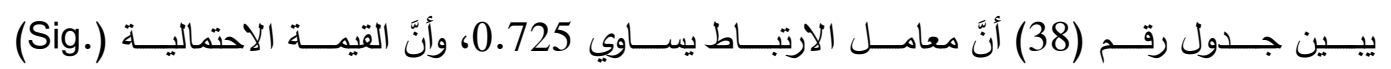

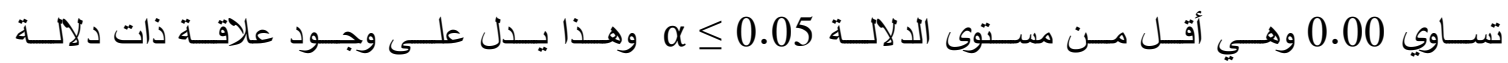

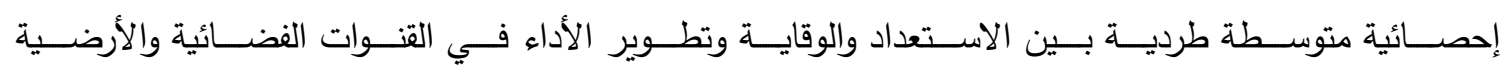

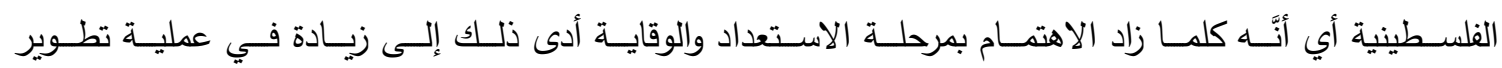

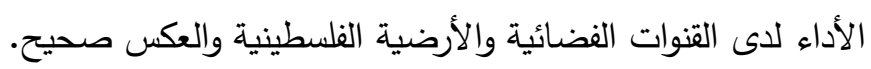
ويعزو الباحث أنَّ النتيجة صحيحة، حيث إنَّ الاستعداد والوقاية لمواجهة الأزمة والعمل وفق نظام حماية

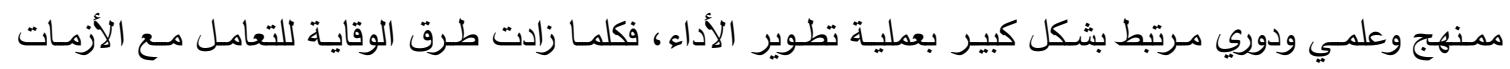


المحتملة من خـلال وضـع الخطط واتباع منهجية واضحة والمتابعة الدوريـة لعمل اختبارات تجريبية، وعمل دورات

تدريبية واجتماعات وورش عمل كلما زادت عملية تطوير الأداء لاى القنوات الفضائية والأرضية الفلسطينية.

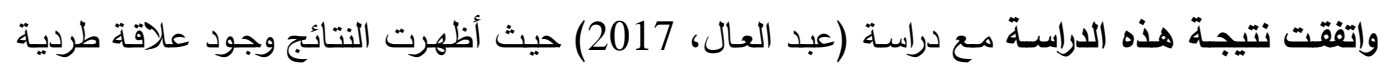
متوسطة بين مرحلة الاستعداد والوقاية والجودة، حيث بلغ معامل الارتباط (0.573) كما اتفقت مع دراسة (مناع، 2015) و (أبو ركبة، 2013) حيث أظهرت النتائج وجود علاقة طردية متوسطة بين أبعاد إدارة الأزمات وأبعاد التطوير (التخطيط والموارد البشرية والتكنولوجيا). ويتضـح مما سبق أنَّهـ يوجد قدرة لدى القنوات في مرحلة الاستعداد والوقاية للأزمة بدرجة متوسطة ويتم التأكيد عليها من خلال نتائج جدول (38) أنَّه كلما زاد الاهتمام بمرحلة الاستعداد والوقاية زاد تحقيق تطوير الأداء في هذه القنوات؛ نظرًا لوجود علاقة طردية بين المتغيرين. 3. توجد علاقة ذات دلالة إحصائية عند مستوى دلالة الفضائية والأرضية الفلسطينية.

جدول (10) معامل الارتباط بين احتواء الأضرار وتطوير الأداء في القنوات الفضائية والأرضية الفلسطينية

\begin{tabular}{|c|c|c|c|}
\hline على الفيجة الحكم & $\begin{array}{c}\text { الاحتمالية } \\
\text { (Sig.) }\end{array}$ & بيرسون & الفرضية \\
\hline مقبولة & 0.000 & $* 0.611$ & 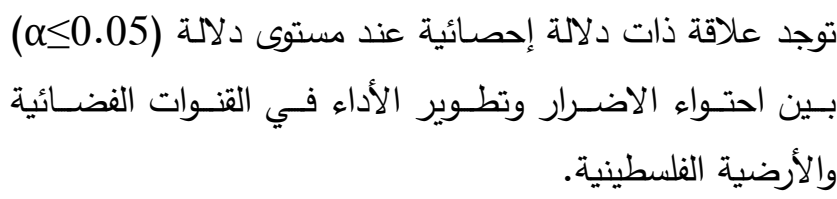 \\
\hline
\end{tabular}

* الارتباط دال إحصائيًا عند مستوى دلالة 0.05 *

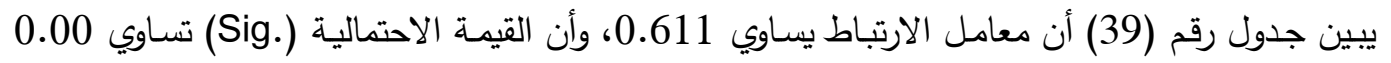

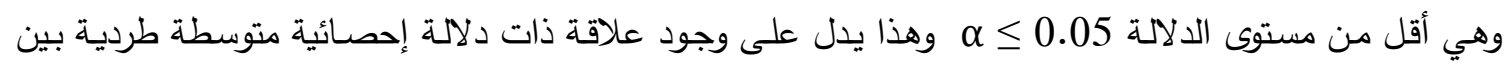

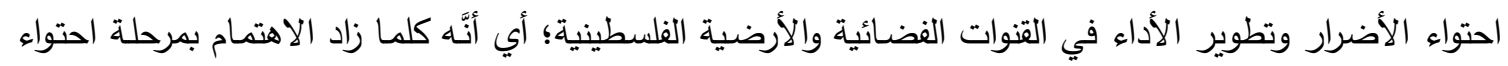
الأضرار زاد تحقيق تطوير الأداء لاى القوات الفضائية والأرضية الفلسطينية والعكس صحيح.

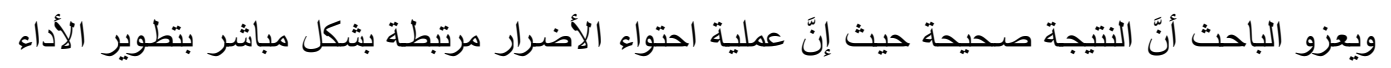

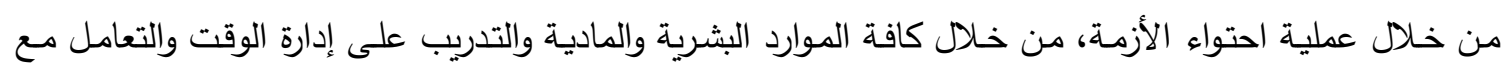

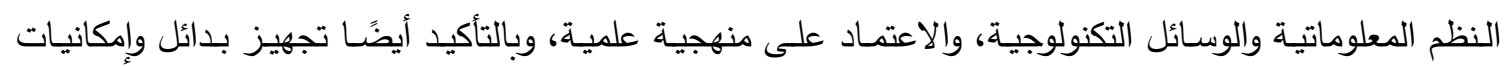

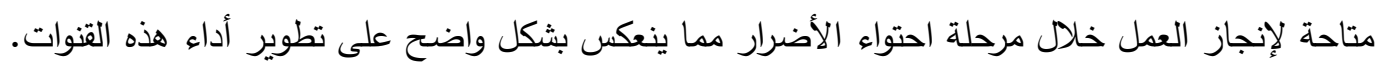

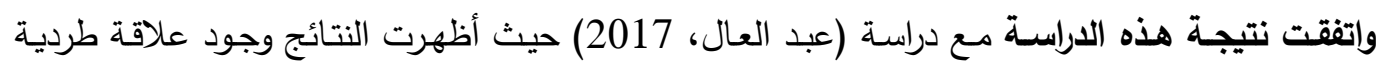

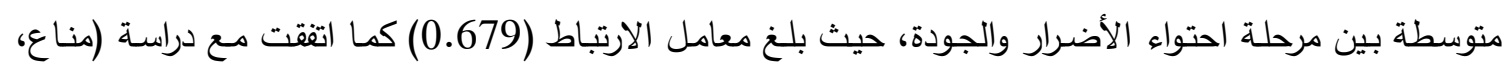
2015) و(أبو ركبة، 2013) حيث أظهرت النتائج وجود علاقة طرديـة متوسطة بين أبعاد إدارة الأزمات وأبعاد

التطوير (التخطيط والموارد البشرية والتكنولوجيا).

ويتضح مما سبق أنَّها يوجد قدرة لاى القنوات في مرحلة احتواء أضرار الأزمات بدرجة متوسطة ويتم التأكيد

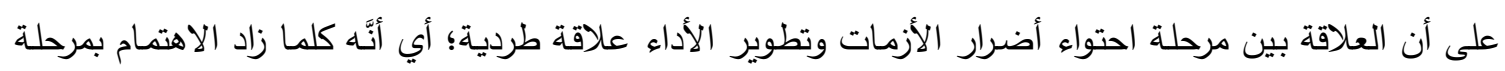
احتواء الأضرار زاد تحقيق تطوير الأداء في القنوات الفضائية والأرضية الفلسطينية والعكس صلاء صحيح. 
4. توجد علاقة ذات دلالة إحصائية عند مستوى دلالة 0.05 بين استعادة النشاط وتطوير الأداء في القنوات الفضائية والأرضية الفلسطينية.

جدول (11) معامل الارتباط بين تعديل استعادة النشاط وتطوير الأداء في القنوات الفضائية والأرضية الفلسطينية

\begin{tabular}{|c|c|c|c|}
\hline على الفرضة الحكم & $\begin{array}{l}\text { الاحتمالية } \\
\text { (Sig.) }\end{array}$ & بيرسون & الفرضية \\
\hline مقبولة & 0.000 & $* 0.731$ & 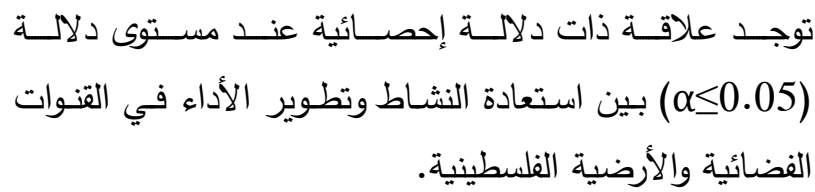 \\
\hline
\end{tabular}

* الارتباط دال إحصائيًا عند مستوى دلالة 0.05.

يبين جدول رقم (40) أنَّ معامل الارتباط يسـاوي 0.7310، وأن القيمـة الاحتماليـة (.Sig) تساوي 0.00

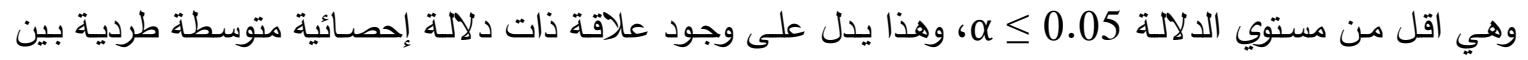

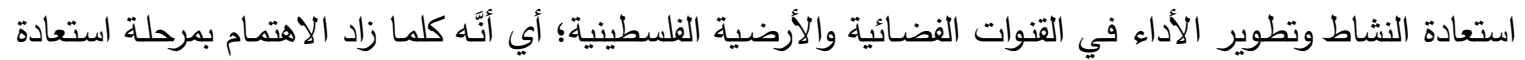

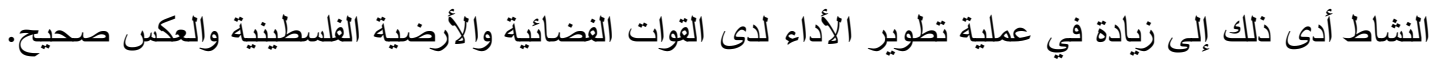
ويعزو الباحث أنَّ النتيجة صحيحة، حيث إنَّ مرحلة استعادة النشاط مرتبطة بشكل مباشر بتطوير الأداء كون أنَّ الكيفية التي يتم التعامل بها بعد الأزمة، من تحديد المهام المطلوب إنجازها بالإضافة لاحتياجات العمل سواء كانت الداخلية أو الخارجية وتتفيذ الخطط الموضوعة لاستعادة النشاط، وملائمة الإجراءات المنفذة في القناة لاستعادة الوضع الاعتيادي والطبيعي للعمل وتقييم سرعة معالجة الآثار من خلال الأداء المنفذ من الكوادر البشرية أو بواسطة الإداء

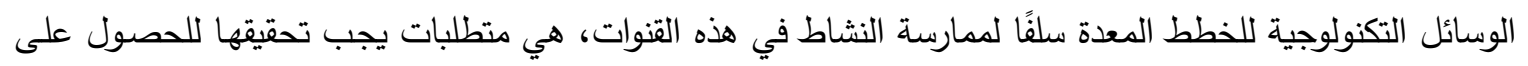
أداء متوازن ونوعي ومواكبة لعملية التطوير • اتفقت هذه الدراسـة مع دراسة (مناع، 2015) حيث أظهرت النتائج علاقة طردية قوية بين مراحل إدارة

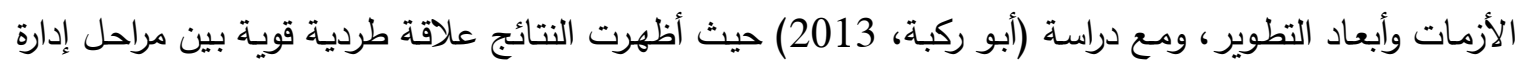
الأزمات وأبعاد التطوير، ومع رسالة (عبدالعال، 2017) حيث أظهرت النتائج علاقة طردية متوسطة بين التين استعادة النشاط والجودة، حيث بلغ معامل الارتباط (0.716).

ويتضح مما سبق أنَّهَ يوجد قدرة لدى القنوات في مرحلة استعادة النشاط بدرجة، ويتم التأكيد على أنَّ العلاقة

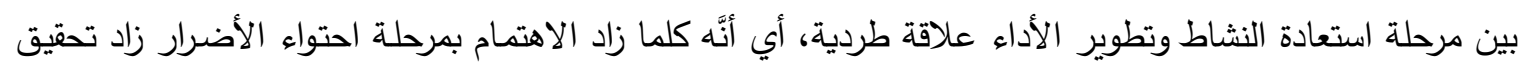
تطوير الأداء في القنوات الفضائية والأرضية الفلسطينية والعكس صحئح.

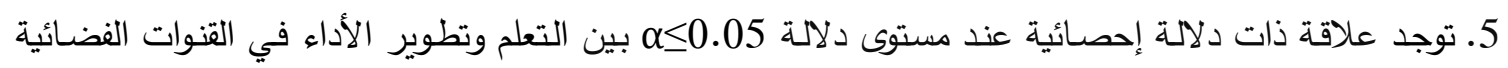
والأرضية الفلسطينية.

جدول (12) معامل الارتباط بين التعلم وتطوير الأداء في القنوات الفضائية والأرضية الفلسطينية

\begin{tabular}{|c|c|c|c|}
\hline علىيجة الحكم & $\begin{array}{c}\text { القيمة الاحتمالية } \\
\text { (Sig.) }\end{array}$ & لمعامل بيرسون & 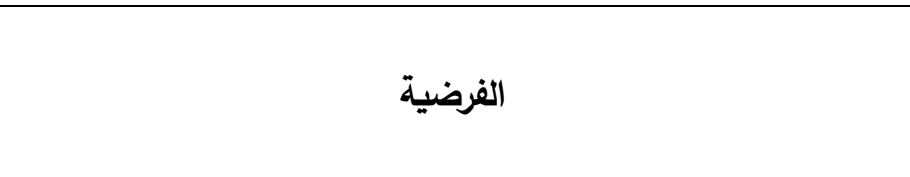 \\
\hline 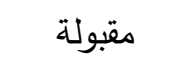 & 0.000 & *0.771 & توجد علاقة ذات دلالة إحصائية عند مستوى دلالة (0.05 $\alpha$ بين \\
\hline
\end{tabular}




\begin{tabular}{|l|l|l|l|}
\hline & & & \\
\hline
\end{tabular}

$$
\text { * الارتباط دال إحصائيًا عند مستوي دلالة 0.05. }
$$

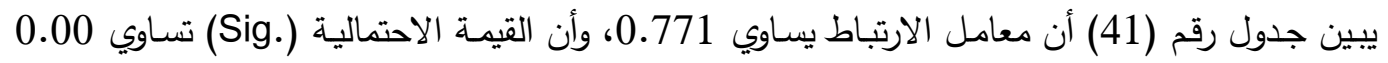

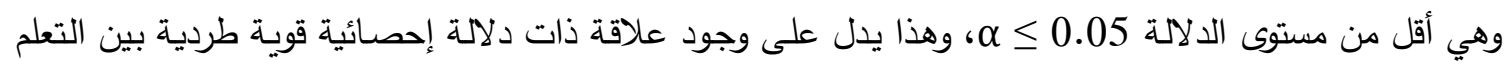

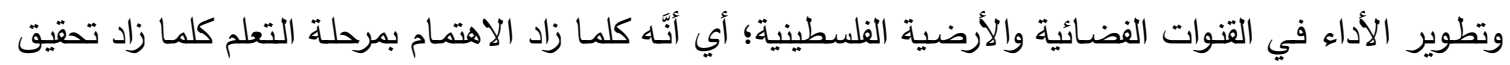
تطوير الأداء لدى القنوات الفضائية والأرضية الفلسطينية والعكس صحيح.

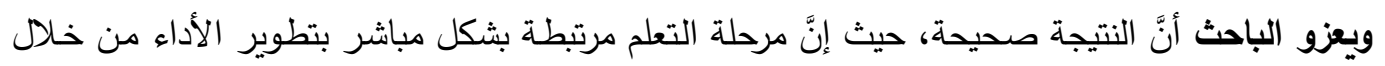

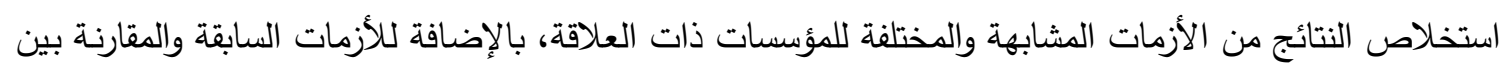

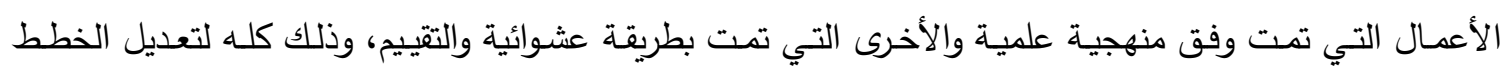

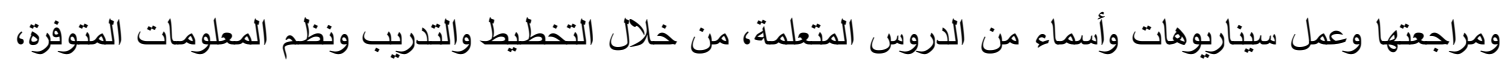
لتحقيق المعرفة المطلوبة لهذه القنوات في مجال إدارة الأزمات والمحافظة على تطوير أدائها. اختلفت نتيجة هذه الدراسة مع دراسة (مناع، 2015) حيث أظهرت النتائج علاقة طردية قوية بين مراحل إدارة الأزمات وأبعاد التطوير ، ومع دراسة (أبو ركبة، 2013) حيث أظهرت النتائج علاقة طردية قويـة بين مراحل

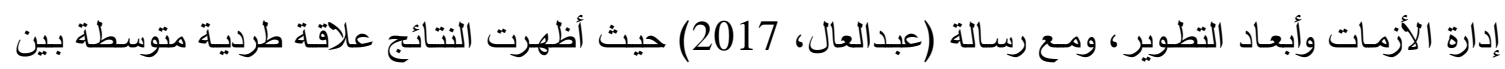
استعادة النشاط والجودة، حيث بلغ معامل الارتباط (0.718).

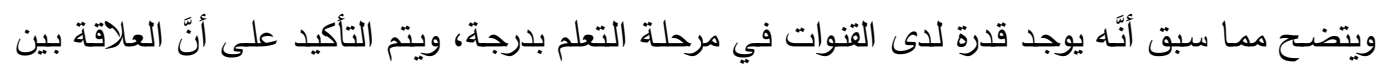
مرحلة استعادة النثاط وتطوير الأداء علاقة طردية، أي أنَّه كلما زاد الاهتمام بمرحلة التعلم زاد تحقيق تطوير الأداء في القنوات الفضائية والأرضية الفلسطينية والعكس صحئح.

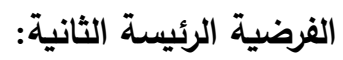
يوجد أثر ذو دلالة إحصائية عند مستوى ( 0.05 م ) لأبعاد إدارة الأزمات الفنية في تطوير الأداء في القنوات الفضائية والأرضية الفلسطينية. جدول (13) نتائج اختبار تحليل الانحدار المتعدد لتأثير ابعاد إدارة الأزمات الفنية في تظوير الأداء

\begin{tabular}{|c|c|c|c|c|c|c|c|c|c|c|}
\hline $\begin{array}{l}\text { Sig. } \\
\text { الدلالةت }\end{array}$ & $\begin{array}{c}\text { T } \\
\text { المحسوبة }\end{array}$ & بحدار & B معام B & $\begin{array}{l}\text { Sig. } \\
\text { مستوى لالاكة }\end{array}$ & & ل & $\begin{array}{c}\text { F } \\
\text { المحسوبة }\end{array}$ & $\begin{array}{c}\left(\mathbf{R}^{2}\right) \\
\text { معامل } \\
\text { التحديد }\end{array}$ & $\begin{array}{c}\text { الارتباط } \\
\text { ال }\end{array}$ & التابع \\
\hline 0.000 & 4.115 & 1.7562 & الثابت & \multirow{3}{*}{0.000} & 2 & الانحدار & \multirow{3}{*}{56.38} & \multirow{3}{*}{0.660} & \multirow{3}{*}{0.813} & \multirow{3}{*}{ تطوير } \\
\hline 0.000 & 4.475 & 0.408 & التعلم & & & & & & & \\
\hline 0.001 & 3.365 & 0.335 & الإلوقاية & & 58 & البواقي & & & & \\
\hline
\end{tabular}

للوقوف على مستوى تأثير أبعاد إدارة الأزمات الفنية (اكتثـاف إثــارات الإنـار، الاستعداد والوقايـة،

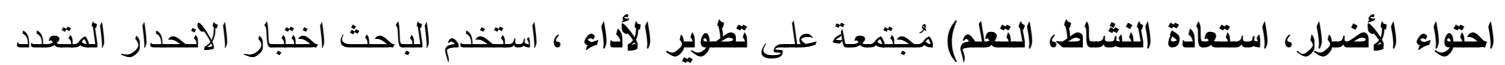
باستخدام طريقة Stepwise ويمكن استتناج ما يلي: الاصني 
أ- يبين نموذج الانحدار النهائي باستخدام طريقة Stepwise أن تطوير الأداء، وهو يمثل المتغير التابع يتأثر بصورة جوهرية وذات دلالة إحصائية بكل من المتغيرات (التعلم، الاستعداد والوقاية).

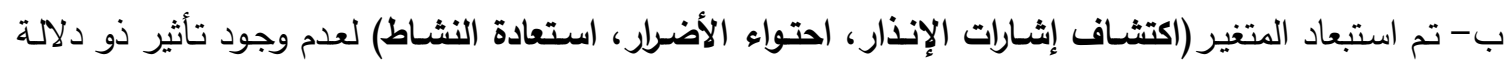

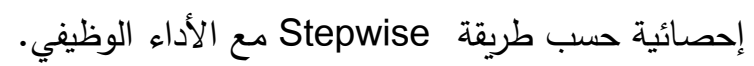

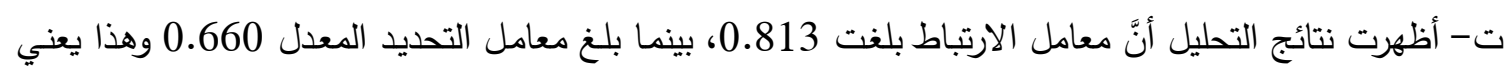
أنَّ (66.0\%) من التغير في تطوير الأداء يعود إلى تأثير المتغيرات المستقلة التالية (التعلم، الاستعداد والوقاية) والباقي (34\%) يعود لعوامل أخرى تؤثر على المتغير التابع في تطوير الأداء. ويعزو الباحث ذلك لوجود اهتمام بدرجة متوسطة في المراحل الثلاثة (اكتشاف إثـارات الإنذار ، احتواء

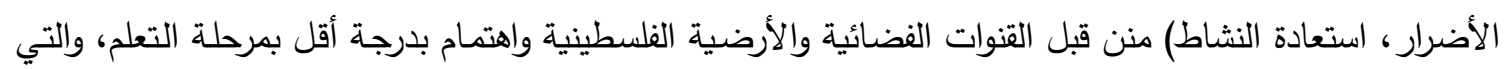
تؤثر على مرحلة الاستعداد والوقاية بشكل مباشر ، حيث إنَّه كلما زادت المعرفة وتينفيذ السيناريوهات المحتملة، كلما

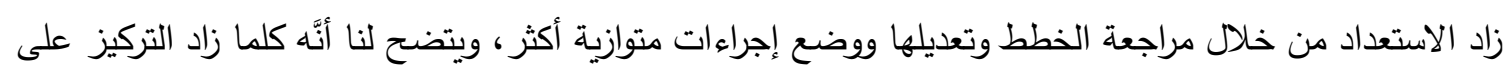

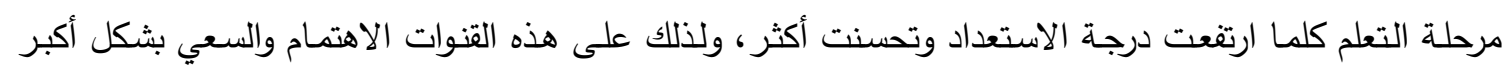

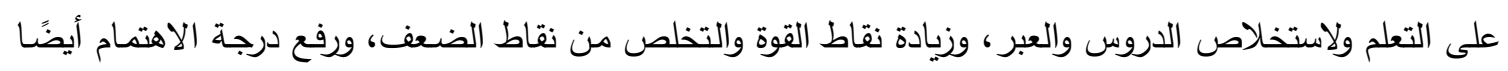

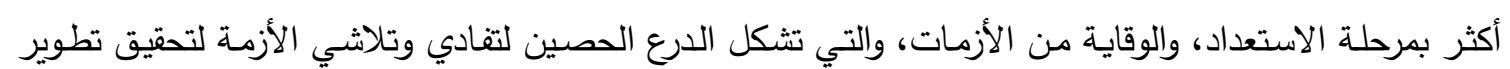
الأداء.

اتفقت نتيجة هذه الاراسة مع دراسة (عبد العال، 2017) حيث أظهرت النتائج أنَّ مرحلة التعلم من أهم المراحل التي تؤثر على الجودة بثكل كبير، ومع دراسة (اسليم، 2016) حيث أظهرت النتائج أنَّ إدارة الأزمات تتأثر بتطوير التقنيات الحديثة بشكل كبير • اختلفت نتيجة هذه الاراسـة مع دراسة (زويلف، 2015) حيث تبين وجود أثر بين مراحل إدارة الأزمات

$$
\text { معادلة التأثير: والثعومات والأداء. }
$$

$$
\text { تطوير الأداء =1.75 + } 0.408 \text { (التعلم) + } 0.335 \text { (الاستعداد والوقاية) }
$$

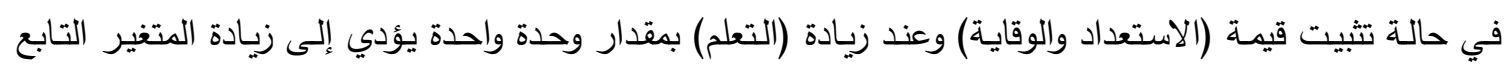
(تطوير الأداء) بمقدار (0.408). في حالة تثبيت قيمة (التعلم) وعند زيادة (الاستعداد والوقايـة) بمقدار وحدة واحدة يؤدي إلى زيادة المتغير التابع تطوير الأداء بمقدار (0.335). وهذا ما يدعو المعنيين إلى الاهتمام وزيادة التركيز على المحاور (التعلم ، الاستعداد والوقاية).

$$
\text { نتائج الار اسة }
$$

1- خلصت الدراسة إلى وجود علاقة ذات دلالة إحصائية عند مستوى (0.05 (1) لإدارة الأزمات

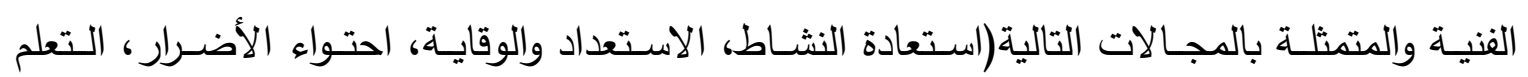
واكتشـاف إشـارات الإنـار) في تطـوير الأداء حيـث بلـخ معامـل ارتباطهـا(0.805)، وهـي علاقـة

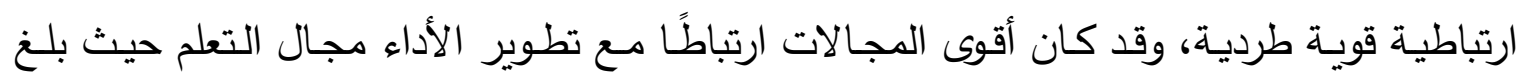
معامل الارتباط (0.771) ومن ثم يليه مجال استعادة النشاط وقد بلـغ معامل ارتباطها (0.731) 
بينما ثم يليه مجال النشاط الاستعداد والوقاية ثم يليه مجال اكتشاف إشـارات الإنذار، وقد بلغن معامل ارتباطها (0.637) بينما اقلها ارتباطًا مجال احتواء الأضرار حيث بلغ معامل ارتباطها (0.611) حيث بلغ معامل ارتباطها (0.721). 2- خلصت الدراسة إلى أنَّ لأبعاد إدارة الأزمات الفنية أثرًا إيجابيًا وجوهريًا ذو دلالة إحصائية عند

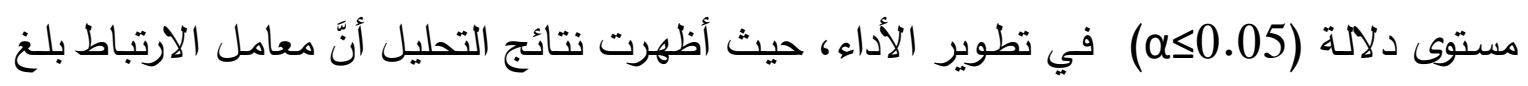
(0.813)، بينما بلغ معامل التحديد المعدل (0.660) وهذا يعني أن (66\%) من التغير في تطوير الأداء يتأثر بالمتغيرات المستقلة التالية: (التعلم، والاستعداد، والوقاية) والباقي(34\%) تعود لعوامل أخرى تُؤثر على المتغير التابع في تطوير الأداء. توصيات الدراسة

1) ضرورة الاهتمام بالنظام الإداري للأزمات، وإنشاء قسم إدراي متخصص في إدارة الأزمات الفنية ضمن الهيكل التظيمي. 2) ضرورة الاهتمام بتطوير الأداء من خـلا الاستمرار في توفير الاحتياجات التطويريـة للقناة من تقنيات حديثة 3) التركيز على تنفيذ برامج تدريبية للموظفين على التعامل مع التطور التكنولوجي.

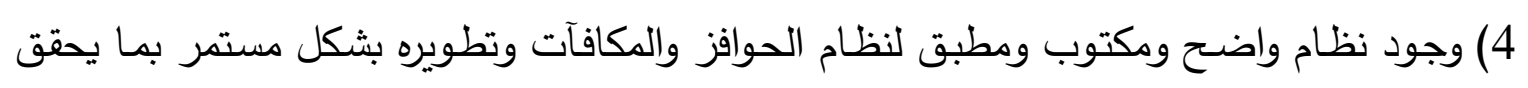
رضا الموظفين وجودة الإنتاج واطلاع الجميع عليه.

5) زيـادة الســاح للعـاملين بالمشـاركة في آرائهم ومقترحـاتهم مـن خـلال إعداد الخطط التشـيلية للقنوات. 6) ضـرورة المقارنـة العلميـة والمهنيـة بين الأعمـال والإجـراءات التي تمـت خـلال إدارة فترة الأزمـة بطريقة منهجية وتلك التي تمت بطريقة عشوائية. 7) وضع نظام إداري وإجراءات واضحة تقلل من شدة الصدمة التي تتتج عن الأزمة والتخفيف من حدة التوترات الناشئة بفعل الأزمات الفنية وتوفير الأدوات والوسائل اللازمة لعملية استعادة النشاط ورجوع الثقة بعد الأزمة الفنية. 8) ضرورة إعلام الموارد البشرية وتوجيهـا بشكل مسبق بالخطط الموضوعة لإدارة الأزمات. 9) إجراء مناورات تجريبية وعمليات محاكاة وسيناريوهات مختلفة لتفادي الأزمات الفنية. 10) العمل على تطـوير وتنميـة مهارات الإبـداع والتطـوير والمعـارف لدى العـاملين في القنـوات الإعلامية، من خلال توفير بيئة عمل محفزة والحصول على كل ما هو جديد في المجال الإعلامي، وتطويره بشكل مستمر ومواكبته. 
11) توفير الدعم الكامل (مادي، معنوي، معلوماتي، مالي) لتمرينات مواجهة الأزمة وكيفية التغلب عليها.

12) ضـرورة زيادة الاهتمـام بالاستعداد والوقاية للأزمات من خـلا إجراءات فنية واضـحة وبطريقة علمية، واستخدام جميع الموارد والإمكانيات المتاحة.

13) عمل نموذج التقارير استشعار الأزمة الفنية والاطلاع عليها، ومتابعتها من خـلال مختصين، وعدم الاكتفاء بتقارير سير العمل. 14) تبني ثقافة نشر المعرفة وتبادل الخبرات بين الجهات الإشرافية بهدف تطوير الأداء ورفع كفاءة الموظفين.

$$
\text { ابن منظور • (1982): معجم لسان العرب، ج1. }
$$

أبو عزيز، سامي (2010): بعنوان: معوقات إدارة الأزمات في وزارة الصحة الفلسطينية في ظل الحصار (دراسة حالة قطاع غزة)، غزة ، فلسطين. ابو فارة، يوسف (2009): إدارة الأزمات: مدخل متكامل، عمان، إثراء للنشر والتوزيع. آل سالم، علي (2008): مدى الجاهزية لإدارة الأزمات والكوارث "دراسة مسحية على ضبأ ضباط الأجهزة الأمنية بمنطقة نجران"، الرياض، السعودية.

بيومي، محمد غازي (2008)، تحسين قدرة المدارس الثانوية العامة والفنية الصناعية على إدارة أزمات الطوارئ،

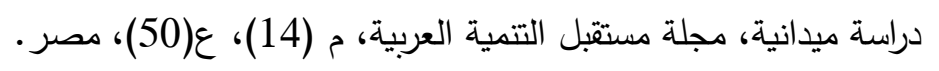

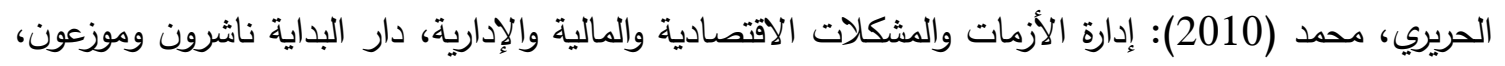
عمان. حريز، سامي (2007): المهارة في إدارة الأزمات وحل المشكلات، دار البداية، ط1، الأردن.

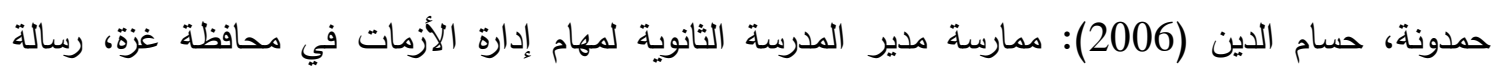

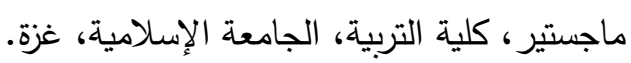

الحملاوي، محمد رشاد (1995): إدارة الأزمات تجارب محلية وعالمية، ط2، القاهرة، دار أبو المجد للطباعة.

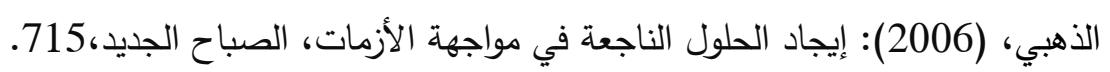
زويلف، إنعام (2015) نجاح نظم المعلومات المحاسبية وأثره في مراحل إدارة الأزمات، عمان، الأردن.

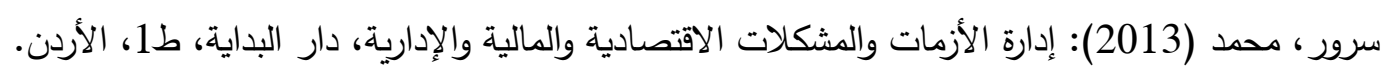

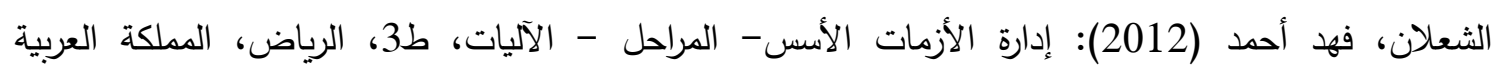
السعودية.

الثهراني، محمد ناصر (2013): دور تخطيط المسار الوظيفي في تحسين أداء العاملين في الأمن الصناعي

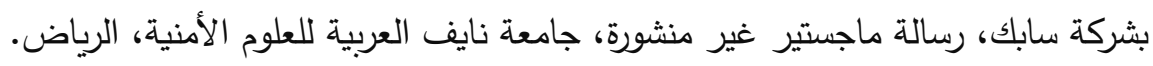

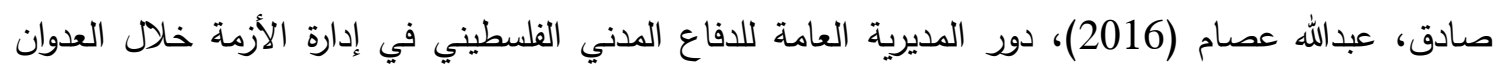
الإسرائيلي على غزة عام 2014، رسالة ماجستير، أكاديمية الإدارة والسياسة، غزة، فلسطين. 


$$
\begin{aligned}
& \text { عبدالعال، محمد (2017)، إدارة الأزمات وأثرها على جودة القرارات الإدارية بوزارتي العمل والتتمية الاجتماعية } \\
& \text { بالمحافظات الجنوبية، غزة ، فلسطين. } \\
& \text { مناع، حاتم (2015): واقع إدارة الأزمات في وزارة النقل والمواصلات في قطاع غزة (من وجهة نظر العاملين)، } \\
& \text { غزة - فلسطين. } \\
& \text { مهنا، محمد. (2004) إدارة الأزمات، الإسكندرية، مؤسسة شباب الجامعة. } \\
& \text { نصر، إياد (2014): واقع إدارة الأزمات وسبل تطويرها في وزارة الداخلية والأمن الوطني بقطاع غزة، رسالة } \\
& \text { ماجستير ، أكاديمية الإدارة والسياسة، غزة، فلسطين. } \\
& \text { نعيم، محمد حسين. (2012): واقع تتمية الموارد البشرية بوزارة التربية والتعليم العالي وعلاقتها بمستوى الأداء } \\
& \text { الإداري، رسالة ماجستير ، الجامعة الإسلامية، غزة. }
\end{aligned}
$$

\section{References}

Abdel-Aal, Muhammad. (2017). Crisis Management and its Impact on the Quality of Administrative Decisions in the Ministries of Labor and Social Development in the Southern Governorates. [Unpublished Master Thesis], Gaza, Palestine. (in Arabic)

Abu Aziz, Sami (2010). Obstacles to Crisis Management in the Palestinian Ministry of Health Under Siege (Gaza Strip Case Study). [Unpublished Master Thesis], Gaza, Palestine. (in Arabic)

Abu Fara, Yusef. (2009). Crisis Management: An Integrated Introduction, Amman, Ithraa for Publishing and Distribution. (in Arabic)

Al Salem, Ali. (2008). The Extent of Readiness to Manage Crises and Disasters, a Survey Study on Officers of the Security Services in Najran Region, Riyadh, Saudi Arabia. (in Arabic)

Alareeni, B. (2018). Does corporate governance influence earnings management in listed companies in Bahrain Bourse?, Journal of Asia Business Studies, 12(4), 551-570. https://doi.org/10.1108/JABS-06-2017-0082

Alareeni, B. (2018). The impact of firm-specific characteristics on earnings management: evidence from GCC countries. International Journal of Managerial and Financial Accounting, 10(2), 85-104. https://doi.org/10.1504/IJMFA.2018.10012808

Alareeni, B., \& Branson, J. (2013). Predicting Listed Companies' Failure in Jordan Using Altman Models: A Case Study. International Journal of Business and Management, 8(1), 113-126. https://doi.org/10.5539/ijbm.v8n1p113

Alareeni, B.A. (2019). The associations between audit firm attributes and audit qualityspecific indicators: A meta-analysis, Managerial Auditing Journal, 34(1), 6-43. https://doi.org/10.1108/MAJ-05-2017-1559

Al-Dhahabi, A. (2006). Finding Effective Solutions in Confronting Crises, The New Morning, 715. (in Arabic)

Al-Hamalawy, Muhammad Rashad. (1995). Crisis Management, Local and International Experiences, 2nd Edition, Cairo, Abu Al-Majd House for Printing. (in Arabic)

Al-Hariri, Muhammad. (2010). Crisis Management, Economic, Financial and Administrative Problems, Dar Al Bedaya Publishers and Distributors, Amman. (in Arabic) 
Al-Shaalan, Fahd Ahmad. (2012). Crisis Management Foundations - Stages Mechanisms, 3rd floor, Riyadh, Kingdom of Saudi Arabia. (in Arabic)

Al-Shahrani, Muhammad Nasser. (2013). The Role of Career Path Planning in Improving the Performance of Employees in Industrial Security at SABIC, [Unpublished Master Thesis], Naif Arab University for Security Sciences, Riyadh. (in Arabic)

Augustine, N. R. (1995). Managing the crisis you tried to prevent. Harvard Business Review, 73(6), 147.

Bayoumi, Mohamed Ghazi. (2008). Improving the capacity of general secondary and technical schools in industrial and management of emergency crises, a field study. Journal of the Future for Arab Development, 14(50). (in Arabic)

Bengtson, A., Ljung, A., \& Hadjikhani, A. (2013). Managing stability and crises in business relationships. European Business Review. https://doi.org/10.1108/EBR01-2013-0007

Brockman, P., Martin, X., \& Unlu, E. (2010). Executive compensation and the maturity structure of corporate debt. The Journal of Finance, 65(3), 1123-1161. https://doi.org/10.1111/j.1540-6261.2010.01563.x

Campo, S., Díaz, A. M., \& Yagüe, M. J. (2014). Hotel innovation and performance in times of crisis. International Journal of Contemporary Hospitality Management. https://doi.org/10.1108/IJCHM-08-2013-0373

DeLoatch, P. (2015). The four negative sides of technology. Retrieved on October, 27, 2015.

Esbensen, L., \& Krisciunas, T. (2008). Crisis Management \& Information Technology.

Examining a crisis communication void: The role of context tomitigate issues.

Hamdouna, Hussam Al-Din. (2006). The Practice of the Secondary School Director in the Tasks of Crisis Management in the Gaza Governorate. [Unpublished Master Thesis], College of Education, Islamic University, Gaza. (in Arabic)

Hariz, Sami. (2007). Skill in Crisis Management and Problem Solving, Dar Al-Bidaya, 1st Edition, Jordan. (in Arabic)

Ibin Manzoor. (1982). The Arab Lisan Dictionary, Part 1. (in Arabic)

Jahjouh, (2015). The Degree of Organizational Loyalty Among Secondary School Principals. (in Arabic)

Manna'a, Hatem (2015). The Reality of Crisis Management in the Ministry of Transport and Communications in Gaza Strip (From the Workers' Point of View). [Unpublished Master Thesis], Gaza - Palestine. (in Arabic)

Michael Anissimov (2017), "What is Technology?" ‘WiseGeek, Retrieved 6-2-2017. Edited)

Moore, D. S., McCabe, G., Duckworth, W. M., \& Sclove, S. L. (2003). Bootstrap methods and permutation tests. The Practice of Business Statistics: Using Data for Decisions, WH Freeman, New York.

Muhanna, Muhammad. (2004). Crisis Management, Alexandria, University Youth Foundation. (in Arabic)

Mwaiwa, F. M., \& Odiyo, W. O. (2015). The Strategic Effect of Crisis Management on Business Continuity Management in Corporate Organizations: A Case of Equitol Bank, Kenya. management, 7(5).

Naeem, Muhammad Hussain. (2012). The Reality of Human Resources Development in the Ministry of Education and Higher Education and its Relation to the Level of Administrative Performance, [Unpublished Master Thesis], Islamic University, Gaza. (in Arabic) 
Nasr, Iyad. (2014). The Reality of Crisis Management and Ways to Develop it in the Ministry of Interior and National Security in the Gaza Strip, [Unpublished Master Thesis], Academy of Administration and Politics, Gaza, Palestine. (in Arabic)

Parmenter, D. (2012). Key performance indicators for government and non profit agencies: Implementing winning KPIs. John Wiley \& Sons. https://doi.org/10.1002/9781119201038

Ramey, K. (2013). What is technology-meaning of technology and its use. Retrieve on, 3(03), 2015.

Sadiq, Abdullah Essam. (2016). The Role of the General Directorate of Palestinian Civil Defense in Crisis Management during the Israeli Aggression on Gaza in 2014, [Unpublished Master Thesis], Academy of Administration and Politics, Gaza, Palestine. (in Arabic)

Sorour, Muhammad. (2013). Crisis Management, Economic, Financial and Administrative Problems, Dar Al-Bidaya, 1st floor, Jordan. (in Arabic)

Taneja, S., Pryor, M. G., Sewell, S., \& Recuero, A. M. (2014). Strategic Crisis Management: A Basis for Renewal and Crisis Prevention. Journal of Management Policy \& Practice, 15(1).

Unlu, A., Kapucu, N., \& Sahin, B. (2010). Disaster and crisis management in Turkey: a need for a unified crisis management system. Disaster Prevention and Management: An International Journal. https://doi.org/10.1108/09653561011037977

Wang, J., Hutchins, H. M., \& Garavan, T. N. (2009). Exploring the strategic role of human resource development in organizational crisis management. Human Resource Development Review, 8(1), 22-53. https://doi.org/10.1177/1534484308330018

Wang, W. T. (2009). Knowledge management adoption in times of crisis. Industrial Management \& Data Systems. https://doi.org/10.1108/02635570910948605

White, C. (2009). Examining a crisis communication void. Journal of communication Management. https://doi.org/10.1108/13632540910951777

Zewailf, Inaam. (2015). The Success of Accounting Information Systems and its Impact on the Stages of Crisis Management, Amman, Jordan. (in Arabic) 